\title{
CONFLICT AND SATISFACTION IN DISTRIBUTION CHANNELS: HOTEL OPERATORS' PERSPECTIVES IN CAMBODIA
}

By

SARIK ENG

A thesis submitted to the Victoria University of Wellington in partial fulfilment of the requirements for the degree of Master of Tourism Management

Victoria University of Wellington

2019 


\begin{abstract}
This study examines hoteliers' perceptions of the level of satisfaction and sources of conflict with both traditional and online intermediaries (TI and OI) in Cambodia. It unveils the overall level of satisfaction of hoteliers with intermediaries in Cambodia, discusses the sources of conflict, and assesses whether there are differences in terms of the levels of satisfaction as well as sources of conflict between TI and OI. This study is focussed on the supply side, which is hoteliers. A mixed methods approach is used for this study and 42 hoteliers in Cambodia were interviewed in three different regions in Cambodia: Siem Reap, Phnom Penh, and Sihanoukville.
\end{abstract}

The study found that the overall level of satisfaction of hoteliers with intermediaries is very positive. The overall level of satisfaction of hoteliers with TI such as travel agencies and tour operators is perceived as satisfactory between "Somewhat good" and "Extremely good". Similarly, the overall level of satisfaction of hoteliers with OI such as Booking.com, Expedia, Agoda, and Ctrip is also perceived as satisfactory ranging from "Somewhat good" to "Extremely good".

The results also reveal that the most common sources of conflict with TI are price level-related conflict, payment-related conflict, and price-quality ratio-related conflict. The least common sources of conflict for TI were booking details-related conflict, commission-related conflict, and overbooking-related conflict. Likewise, the most frequent sources of conflict with OI are price level-related conflict, overbooking-related conflict, and complaint handling-related conflict and commission-related conflict, booking details-related conflict, and fulfillment of contract conditions-related conflict were the least frequent sources of conflict.

Some differences were found for the level of satisfaction and sources of conflict in terms of hotel attributes and respondents' backgrounds. Regarding the level of satisfaction, differences were found in the case of hotel size and hotel age with TI. Concerning the sources of conflict, differences were found in terms of respondents' nationalities, hotel category, hotel size, and hotel age. It is surprising to note that no statistical differences were found in the case of hotel location, ownership, and respondents' job titles. 
Keywords: distribution channel, level of satisfaction, sources of conflict, intermediaries, hoteliers, traditional intermediaries, online intermediaries, Cambodia. 


\section{DEDICATOIN}

To my beloved family, especially to my father who inspired me to pursue my education dream [I wish you could be with us now] 


\section{ACKNOWLEDGEMENTS}

My academic journey would not have been successful without invaluable support from a number of people who have provided support and guidance throughout my time at Victoria University of Wellington.

First and foremost, I would like to express my sincere gratitude to my supervisor Associate Professor Mondher Sahli. I really appreciated your invaluable input, support, guidance, and encouragement to learn new things throughout this journey. I feel very rewarded from what I have learnt and accomplished. I also would like to express my heartfelt thanks to Dr Eerang Park, BTM (Hons) and MTM Director, for her kind support throughout my two years at the university. Special thanks to Dr Lisa Woods, Victoria's Statistical Consultant, for your kind advice and guidance regarding my statistical analysis.

I would also like to thank the NZAID Scholarship programme and New Zealand in general for providing the opportunity to pursue my Master's degree in New Zealand. Special thanks to the scholarship officers at the university for assisting me throughout my whole journey, especially Ryan Stuart and his team. I would like to extend my gratitude to all professors and lecturers within the Tourism Management Group, and staff at the School of Management, Victoria Business School, for their guidance and support.

In addition, I would like to thank to my family for their support and to all my international and Cambodian friends who have come into my life during this period. Your presence has made my time in New Zealand unforgettable. Also, thank you to all my respondents, friends and colleagues, especially to the amazing team at Booking.com Cambodia for their kind support.

To all above people, thank you very much! 


\section{List of Tables}

Table 1.1: Tourism highlights: International arrivals, length of stay, occupancy and receipts ......5

Table 3.1: Response rate of participants............................................ 34

Table 3.2: Respondent categorization based on hotel attributes and backgrounds.................35

Table 4.1: The overall respondents' rating on the level of satisfaction with TI and OI...........48

Table 4.2: Main findings of overall sources of conflict with TI and OI.....................50

Table 4.3: The potential sources of conflict by stage of conflicts.........................54

Table 4.4: The hierarchy of perceived related sources of conflict with TI and OI.................55

Table 4.5: Main findings of common sources of conflict at the contract stage of conflicts........57

Table 4.6: Main findings of common sources of conflict at the pre-stay stage of conflicts........63

Table 4.7: Main findings of common sources of conflict at the stay stage of conflicts..........66

Table 4.8: Main findings of common sources of conflict at the post-stay stage of conflicts.......68

Table 5.1: Hotel attributes \& overall level of satisfaction with the two channels of distributions...73

Table 5.1.a: ANOVA Post Hoc Tukey HSD test result for overall Level of Satisfaction with TI...78

Table 5.1.b: ANOVA Post Hoc Tukey HSD test result for Level of satisfaction with TI of a hotel

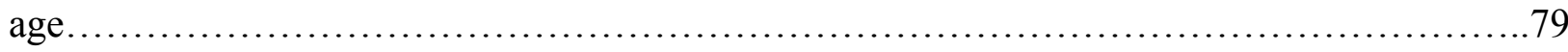

Table 5.2: Hotel attributes and overall frequency of conflict with the two channels of

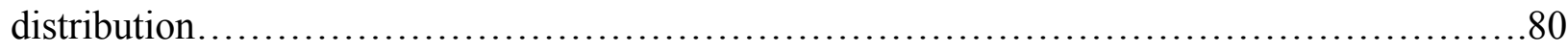

Table 5.3: Contract stage of conflicts: Main findings by hotel attributes and respondents'

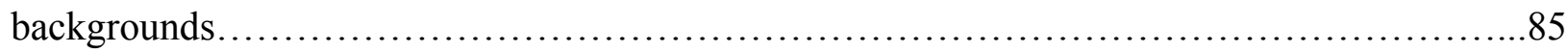

Table 5.3.a: ANOVA Post Hoc Tukey HSD test result for Price-Quality ratio with TA.........88

Table 5.3.b: ANOVA Post Hoc Tukey HSD test result for Commission with OI.................90

Table 5.4: Pre-stay stage of conflicts: Main findings by hotel attributes and respondents'

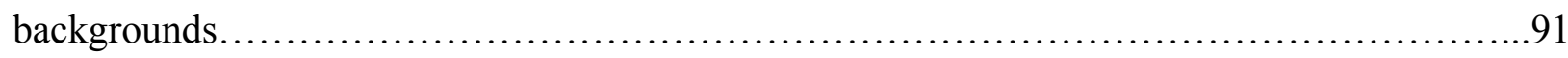

Table 5.4.a: ANOVA Post Hoc Tukey HSD test result for Provision of information for TI......93

Table 5.4.b: ANOVA Post Hoc Tukey HSD test result for booking details with TI.............94

Table 5.4.c: ANOVA Post Hoc Tukey HSD test result for cancellation terms compliance with

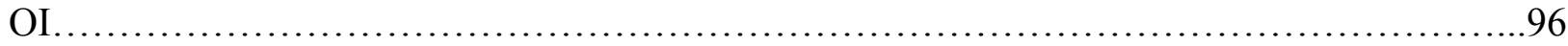


Table 5.5: Stay stage of conflicts: Main findings by hotel attributes and respondents' backgrounds. 97

Table 5.5.a: ANOVA Post Hoc Tukey HSD test result for Overbooking-related conflict with TI. .99

Table 5.6: Post-stay stage of conflicts: Main findings by hotel attributes and respondents' backgrounds. 101 


\section{List of Figures}

Figure 1.1: Tourism Map of Cambodia.............................................. 8

Figure 2.1: Distribution systems in the tourist industry................................. 13

Figure 2.2: Tourism Distribution mechanism....................................... 16

Figure 2.3: Sources of potential conflicts between hotels and travel agencies..................22

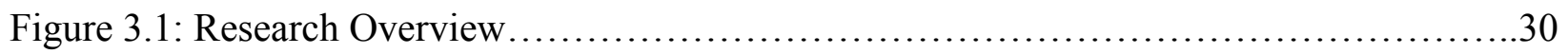

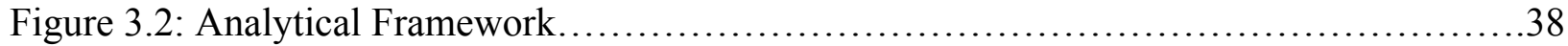

Figure 4.1: Hotel distribution channels in Cambodia.....................................47 


\section{List of Acronyms}

$\begin{array}{ll}\text { ANOVA } & \text { Analysis of Variance } \\ \text { AT } & \text { ANOVA Test } \\ \text { CRS } & \text { Central Reservations System } \\ \text { GDP } & \text { Gross Domestic Product } \\ \text { CI } & \text { Confidence Interval } \\ \text { GDS } & \text { Global Distribution System } \\ \text { GTA } & \text { Gullivers Travel Associates } \\ \text { HRS } & \text { Hotel Reservation System } \\ \text { IT } & \text { Independent Sample t-Test } \\ \text { MOT } & \text { Ministry of Tourism (Cambodia) } \\ \text { NGO } & \text { Non-Governmental Organization } \\ \text { OI } & \text { Online intermediaries } \\ \text { PCT } & \text { Pearson Correlation Test } \\ \text { SD } & \text { Standard Deviation } \\ \text { SPSS } & \text { Statistical Package of Social Science } \\ \text { TI } & \text { Traditional Intermediaries } \\ \text { Tukey's HSD } & \text { Tukey’s Honestly Significant Different } \\ \text { USD } & \text { United States Dollar }\end{array}$




\section{Table of Contents}

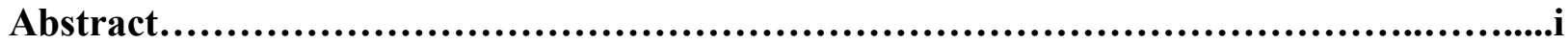

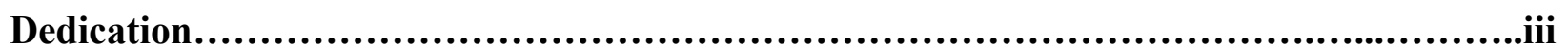

Acknowledgements.................................................................................

List of Tables..........................................................................................

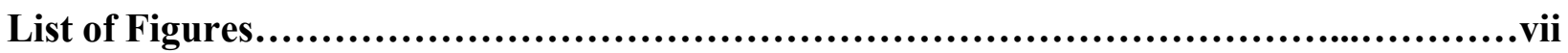

Acronyms.......................................................................................ii

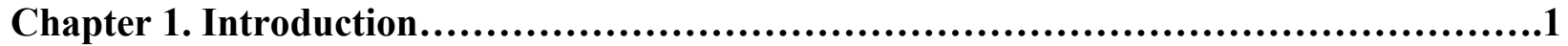

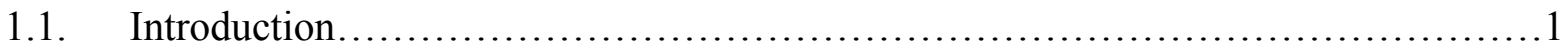

1.2. Cambodia as the research context....................................................

1.3. Brief overview of Cambodia .........................................................

1.4. Cambodia Tourism................................................................

1.4.1. Hotel industry in Cambodia...............................................

1.5. Tourism and main destinations in Cambodia....................................6

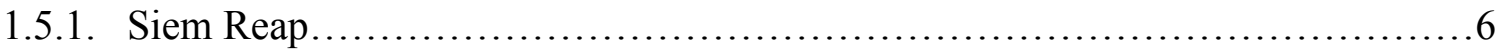

1.5.2. Phnom Penh..................................................................

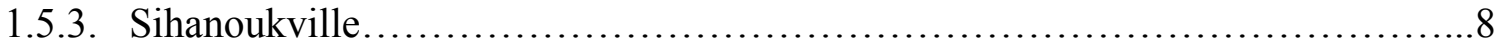

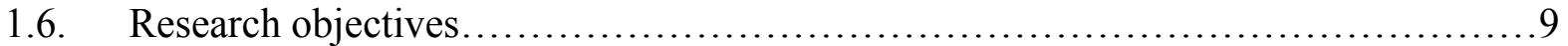

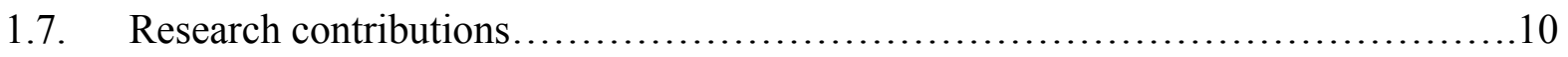

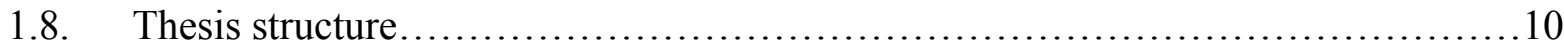

Chapter 2: Literature Review..................................................................11

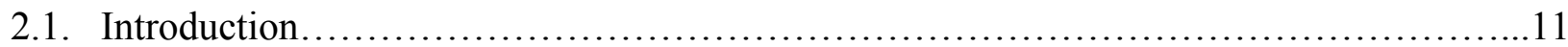

2.2. The concepts of distribution channels...................................................

2.3. Distribution channel members........................................................

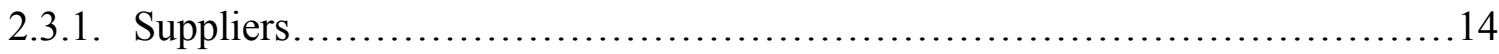

2.3.2. Consumers................................................................

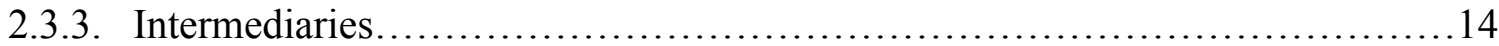

2.4. Hotel's perception and satisfaction of intermediaries.................................. 18

2.5. Hotel's potential sources of conflict with intermediaries................................20

2.5.1. Contract stage related conflicts.........................................21

2.5.2. Pre-stay stage conflict....................................................... 


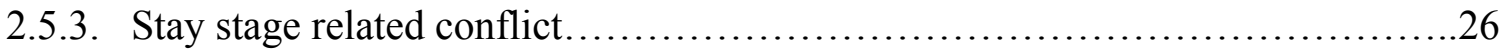

2.5.4. Post-stay stage related conflict.............................................. 27

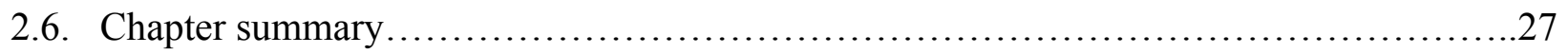

Chapter 3: Research Methodology ......................................................29

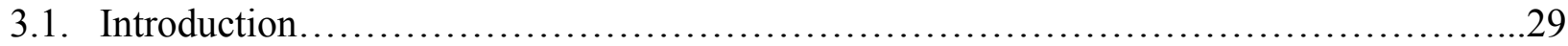

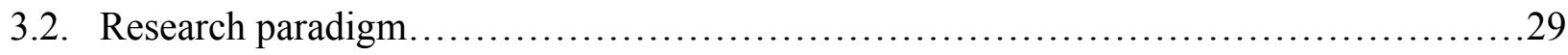

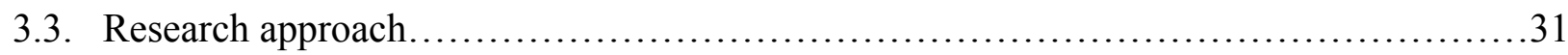

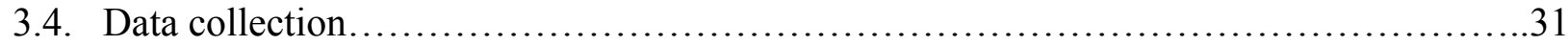

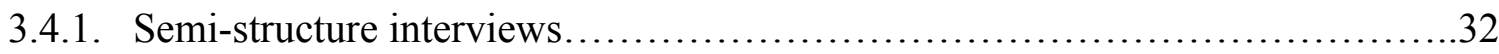

3.4.1.1. Likert scale questions........................................... 32

3.4.2. Document compilation................................................... 33

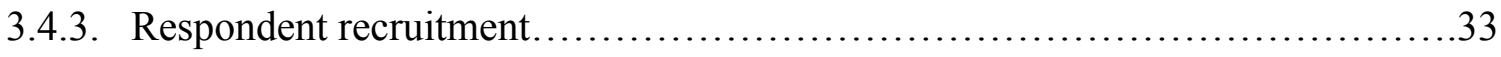

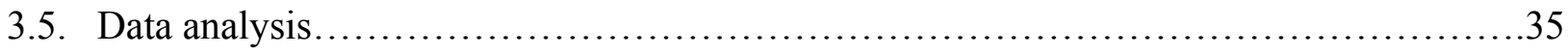

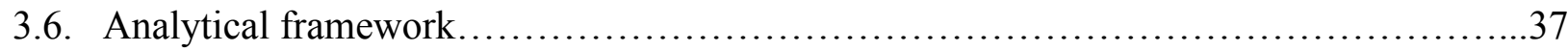

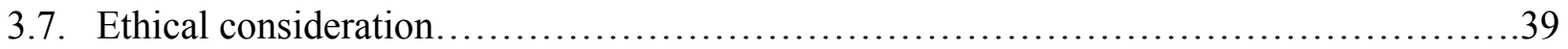

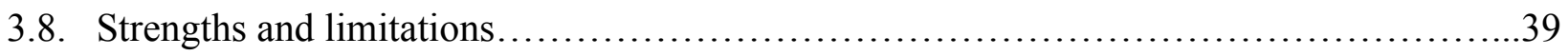

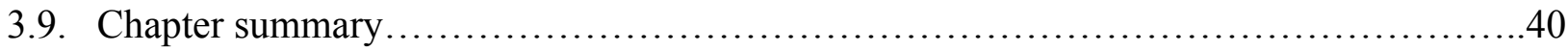

Chapter 4: Level of satisfaction and sources of conflict...................................42

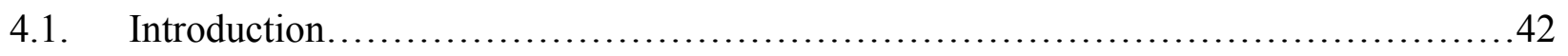

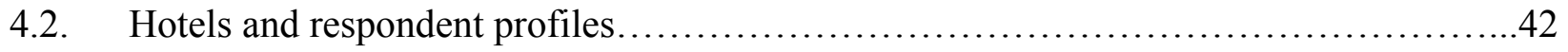

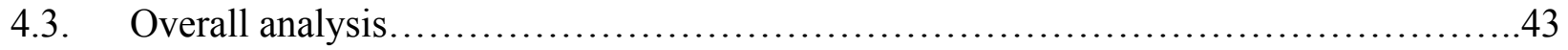

4.3.1. Hoteliers' distribution channels in Cambodia.................................43

4.3.2. A comparison of hoteliers' satisfaction with intermediaries.....................48

4.3.3. Potential frequency of conflicts with intermediaries.........................50

4.3.4. Potential sources of conflict by stage of conflicts.............................53

4.3.4.1. Hierarchy of common potential sources of conflict between hoteliers and

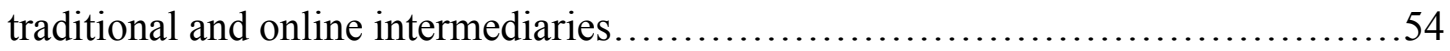

4.3.4.2. Contract stage of conflicts: A comparison of sources of conflict...........56

4.3.4.3. Pre-stay stage of conflicts: A comparison of sources of conflict............62

4.3.4.4. Stay stage of conflicts: A comparison of sources of conflict................66

4.3.4.5. Post-stay stage of conflicts: A comparison of sources of conflict..........68 


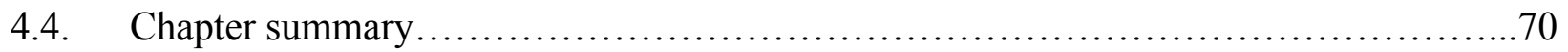

Chapter 5: Cross-case analysis........................................................72

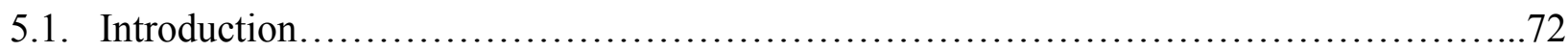

5.2. The overall level of satisfaction with intermediaries................................... 72

5.3. The overall frequency of conflicts with intermediaries................................. 80

5.4. Contract stage of conflicts: Comparative study of potential sources of conflict............84

5.5. Pre-stay stage of conflicts: Comparative study of potential sources of conflict.............91

5.6. Stay stage of conflicts: Comparative study of potential sources of conflict................97

5.7. Post-stay stage of conflicts: Comparative study of potential sources of conflicts..........100

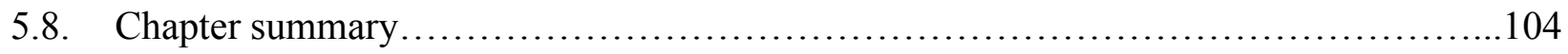

Chapter 6: Discussions, implications, and conclusions................................105

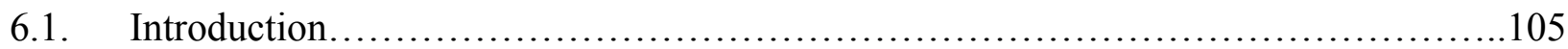

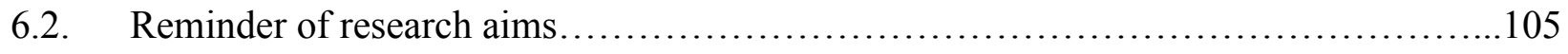

6.3. Discussion aim 1: Overall level of satisfaction of hoteliers with intermediaries in

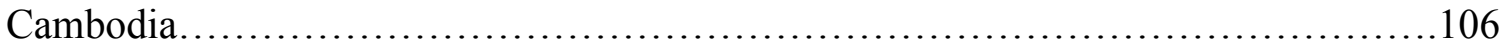

6.4. Discussion aim 2: Potential sources of conflicts with intermediaries in Cambodia......108

6.5. Discussion aim 3: differences of levels of satisfaction and sources of conflicts by hotel attributes and respondents' backgrounds....................................110

6.6. Summary of the research findings......................................... 113

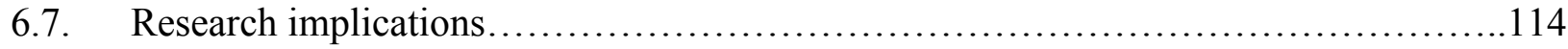

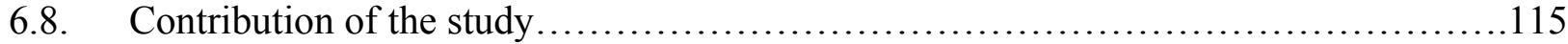

6.9. Research limitations.........................................................

6.10. Avenues for future research............................................... 116

Reference:................................................................................118

Appendix 1: Result of ANOVA and Pearson Correlation tests on source of conflicts by hotel

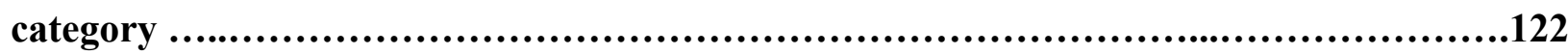

Appendix 2: Result of ANOVA tests on sources of conflict by hotel location ................126

Appendix 3: Result of ANOVA tests on sources of conflict by hotel ownership ...............125 Appendix 4: Result of ANOVA and Pearson Correlation tests on sources of conflict by hotel

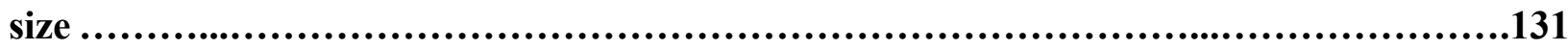


Appendix 5: Result of ANOVA and Pearson Correlation tests on sources of conflict by hotel

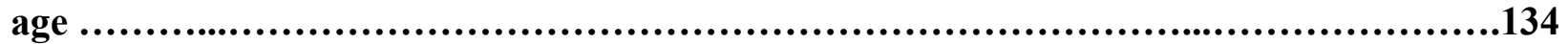
Appendix 6: Result of Independent Sample t-tests on sources of conflict by respondents' job titles .

Appendix 7: Result of Independent Sample t-tests on sources of conflict by respondents'

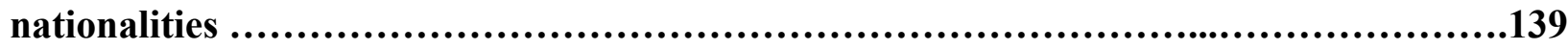

Appendix 8: Information sheet for participants..........................................141

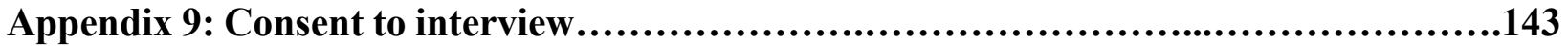

Appendix 10: Interview guide.....................................................145 


\section{Chapter 1. Introduction}

\subsection{Introduction}

Distribution channels are considered to be one of the most significant components of marketing since they are partly responsible for the competitiveness and profitability of a business (Buhalis, 2000a). The growth and expansion of tourism distribution channels has been a significant factor for the development and prosperity of tourism destinations and tourism enterprises such as hotels as they provide information and facilitate tourism transactions (Buhalis, 2000a). McIntosh defines distribution channels as "an operating structure, system or linkages of various combinations of travel organization, through which a producer of travel products describes and confirms travel arrangements to the buyer" (Mill \& Morrison, 1985, p.143). Consumers may buy products and services directly from suppliers such as hotel accommodation, while various distribution and sales intermediaries are also facilitating promotion and distribution (Buhalis, 2000a). Distribution channels did not receive serious academic attention until the 1990s (Douglas \& Christian, 2005).

Tourism distribution channels are frequently involved with traditional travel agents, online travel agencies, Global Distribution Systems (GDSs), and reservation systems (Ivanov, Stoilova, \& Illum, 2014). There have long been intermediaries in the hotel distribution channel and one of the oldest in history is traditional 'brick and mortar' travel agents such as retail agents, wholesalers, and tour operators (Estisgreen \& Lomanno, 2012). Under the traditional distribution model, hotels, for instance, relied heavily on traditional intermediaries such as travel agents and tour operators to distribute their rooms to prospective guests (Rob, Rosanna, Ada, Daniel, \& Lawrence Hoc Nang, 2015). These authors state that some scholars and practitioners are pessimistic that traditional intermediaries will be replaced, while others believe that traditional intermediaries will still be important in the future. However, the irreversible characteristics of traditional intermediaries is the core value that could keep its existence in the future. One of traditional intermediaries' characteristics is the human interaction between customers and traditional intermediaries such as tour operators (Rob et al., 2015). The demand for this interaction is important among particular 
market segments such as organized tour travelers, people on low incomes, people with low education levels, and senior citizens (Rob et al., 2015).

There have been dramatic changes in distribution channels and in particular hotel distribution channels where numerous Internet platforms have emerged to replace traditional methods (Estisgreen \& Lomanno, 2012). These authors state that online travel agencies are one of the main Internet platforms which have changed hotel distribution as it has a great impact on hotel revenue generation, guest interactions, reservations, pricing, payment and inventory control. Myung, Li, and Bai (2009) note that since the introduction of online distribution channels, especially with the entrance of online intermediaries such as Expedia, Hotel.com, Agoda, and booking.com, hotels receive more bookings from these online distributors as they help hotels to push their exposure more in online platforms. The authors further suggest that these online intermediaries have great power to negotiate for lower prices from hotels which benefits consumers but relationships and conflicts are frequently needing to be considered. To respond to this matter, hotels try to convince guests to book directly via their own websites rather than from these third-party online intermediaries (Myung et al., 2009). However, the authors comment that online intermediaries such as Expedia, Booking.com, hotel.com, or Agoda consider themselves to be complementary channels that enhance hotels to fill their vacant rooms, public exposure, and brand building and over time hotels start depending more on them. According to Webb (2002), a conflict of interest is unavoidable with any distribution channel because of the dependency relationship between the channel members. Webb further states that conflicts of interest happen when channel members have opposing perceptions of reality or goals and maybe poor communication. In the age of online distribution, the increased role of online intermediaries brings challenges to hospitality firms such as hotels. However, the presence of traditional intermediaries such as traditional travel agents and tour operators are still playing important roles in developing countries such as Cambodia because technology has not kept pace with other parts of the world.

This research has been developed based on the research gaps in the current literature about the conflicts as perceived by hotels and the main sources of conflict with intermediaries. There is also a gap related to the comparison of hotels' main sources of conflict with traditional and online intermediaries. In this study, Cambodia will be used as the research context and the main focus 
will be on mid-range to upscale hotels in three main destinations in Cambodia. It is time to examine this under-researched topic and the conflicts between hotels and intermediaries. This research attempts to fill the gap in the literature of tourism and hotel conflicts with distribution channels in Cambodia.

\subsection{Cambodia as the research context}

Cambodia's tourism sector is playing a significant role in the country's socioeconomic development and prosperity (Erdener \& Ali, 2012). The country offers various tourist attractions to visitors such as diverse scenery, history, and cultural attractions. This nation has great tourism potential because of its significant cultural heritage and natural resources. The cultural heritage includes aspects such as traditional arts, artistic and architectural features, and historical heritage sites such as the Angkor Wat temple. In terms of natural resources, it is also ranked among the countries possessing the most beautiful natural scenery, flora and wildlife, and unspoiled nature and beaches (Chens, Sok, \& Sok, 2008). Cambodia has experienced a large number of international visitor arrivals in the last few decades. Between 2000-2010, the visitor arrivals have increased from 450,000 to 2.5 million (Erdener \& Ali, 2012) increasing to 5 million in 2016 with the financial returns increasing from \$US 1.5 billion in 2010 to \$US 3.2 billion in 2016 (Cambodia Ministry of Tourism, 2017).

\subsection{Brief overview of Cambodia}

The Kingdom of Cambodia was a colony of France for almost a century and gained its independence in 1953 by King Norodom Sihanouk. Under his guidance, as the builder of the modern Cambodian state, it was once portrayed as the "Pearl of Asia" (Ayres, 2000). After independence, King Norodom Sihanouk formed his own party, Sangkum Reastr Niyum, and ruled for 17 years from 1953 to 1970; under his leadership Cambodia was a prosperous nation (John, 2017). From 1975-1979 as Democratic Kampuchea (Khmer Rouge), Cambodian culture and the economy, which had been developed for centuries, were destroyed (Ayres, 2000). Around 1.7 to 2 million people were killed during the four-year regime and the nation went through gradual recovery from instability and insecurity to a place for investment and leisure. From the late 1990s 
Cambodia's economy grew at an average 8.5 percent per year and tourism had become a significant sector enhancing this prosperity (Erdener \& Ali, 2012).

The country's politics are based on the framework of elective constitutional monarchy where the prime minister is the head of the government and the monarch is the head of state. Cambodian politics have gone through six significant changes: Kingdom of Cambodia (1953-1970); Khmer Republic (1970-1975); Democratic Kampuchea or Khmer Rouge regime (1975-1979); People's Republic of Kampuchea (1979-1989) later renamed the State of Cambodia (1989-1993) and the Kingdom of Cambodia from 1993 until present (Chheang, 2008a). Its economy and infrastructure were almost completely destroyed by decades of civil war, but five permanent members of the United Nations (China, France, Great Britain, Russia, and the USA) helped to find a peaceful solution for the country with the Paris Peace Agreement in 1991.

The economic system has shifted from command or a centrally-planned economy to a free market economy with the reform policy of 1989. Since then, private property rights were recognized; privatization of state-owned enterprises was undertaken; foreign investment was introduced; and

price and exchange rates were allowed to float (Hughes, 2003). Its economy is supported by the agricultural sector and the textile and tourism industries. Cambodia is one of the fastest growing economies in Asia and GDP has grown by 7\% annually since 2011 with garment being the main export sector contributing $70 \%$ to the overall economy (Lim, 2006). This economic progress has helped alleviate the poverty rate from $47.8 \%$ in 2007 to $13.5 \%$ in 2014 , but more than $70 \%$ of Cambodians still live on under $\$ 3$ a day (Asia Development Bank, 2016). In the next section, tourism in Cambodia will be discussed.

\subsection{Cambodian tourism}

Cambodia has geographical advantages for tourism being located in a tropical region which is warm and humid, and therefore favourable to travellers all year round. It has both natural and heritage tourism products, which include seven national parks, diverse ecotourism spots, beaches, and about 1,086 ancient temples in across 14 provinces (Chheang, 2008a). In the 1990s, the country's international tourism arrivals were dominated by North American and European 
travellers, but since the end of the Asian financial crisis in 1997, Asian international tourists took the lead including Japanese, Korean, and Chinese (Dwyer \& Thomas, 2012). Tourism has played and will continue to play an important role in developing the nation's economy, improve local community development and alleviate poverty (Chheang, 2008a). Tourism infrastructure in the country is still limited but tourists have access to the main destinations by land, waterway, railroad, and air routes. There are two international airports in this country located in Phnom Penh and Siem Reap and two regional airports in Sihanoukville and Ratanakiri. The total contribution of travel and tourism to the nation's employment is around $25.5 \%$ or 2.2 million jobs (World Travel \& Tourism Council, 2017). Table 1.2.2 shows that international tourist arrivals in Cambodia increased from 118,183 in 1993 to more than 5 million in 2016. The increase in international tourist arrivals increased steadily from year to year and the last data prior to 2016 showed that it had been increasing between 5-7\% per year (Ministry of Tourism, 2018b).

Table 1.1 Tourism highlights: International arrivals, length of stay, occupancy and receipts

\section{Tourism Highlights}

Int'I Tourist Arrivals, Average Length of Stays, Hotel Occupancy \& Int'I Tourism Receipts 1993 - 2016

\begin{tabular}{|c|c|c|c|c|c|}
\hline \multirow{2}{*}{ Years } & \multicolumn{2}{|c|}{ Int'l Tourist Arrivals } & \multirow{2}{*}{$\begin{array}{l}\text { Average Length } \\
\text { of Stays (Days) }\end{array}$} & \multirow{2}{*}{$\begin{array}{c}\text { Hotel Occupancy } \\
(\%)\end{array}$} & \multirow{2}{*}{$\begin{array}{c}\text { Tourism Receipts } \\
\text { (Million US\$) }\end{array}$} \\
\hline & Number & Change (\%) & & & \\
\hline 1993 & 118,183 & - & N/A & N/A & N/A \\
\hline 1994 & 176,617 & 49.4 & N/A & $\mathrm{N} / \mathrm{A}$ & $N / A$ \\
\hline 1995 & 219,680 & 24.4 & 8.00 & 37.0 & 100 \\
\hline 1996 & 260,489 & 18.6 & 7.50 & 40.0 & 118 \\
\hline 1997 & 218,843 & -16.0 & 6.40 & 30.0 & 103 \\
\hline 1998 & 286,524 & 30.9 & 5.20 & 40.0 & 166 \\
\hline 1999 & 367,743 & 28.3 & 5.50 & 44.0 & 190 \\
\hline 2000 & 466,365 & 26.8 & 5.50 & 45.0 & 228 \\
\hline 2001 & 604,919 & 29.7 & 5.50 & 48.0 & 304 \\
\hline 2002 & 786,524 & 30.0 & 5.80 & 50.0 & 379 \\
\hline 2003 & 701,014 & -10.9 & 5.50 & 50.0 & 347 \\
\hline 2004 & $1,055,202$ & 50.5 & 6.30 & 52.0 & 578 \\
\hline 2005 & $1,421,615$ & 34.7 & 6.30 & 52.0 & 832 \\
\hline 2006 & $1,700,041$ & 19.6 & 6.50 & 54.8 & 1,049 \\
\hline 2007 & $2,015,128$ & 18.5 & 6.50 & 54.8 & 1,400 \\
\hline 2008 & $2,125,465$ & 5.5 & 6.65 & 62.7 & 1,595 \\
\hline 2009 & $2,161,577$ & 1.7 & 6.45 & 63.6 & 1,561 \\
\hline 2010 & $2,508,289$ & 16.0 & 6.45 & 65.7 & 1,786 \\
\hline 2011 & $2,881,862$ & 14.9 & 6.50 & 66.2 & 1,912 \\
\hline 2012 & $3,584,307$ & 24.4 & 6.30 & 68.5 & 2,210 \\
\hline 2013 & $4,210,165$ & 17.5 & 6.75 & 69.5 & 2,547 \\
\hline 2014 & $4,502,775$ & 7.0 & 6.50 & 67.6 & 2,736 \\
\hline 2015 & $4,775,231$ & 6.1 & 6.80 & 70.2 & 3,012 \\
\hline 2016 & $5,011,712$ & 5.0 & 6.30 & 68.9 & 3,212 \\
\hline
\end{tabular}

Source: Cambodia Ministry of Tourism 2016 


\subsubsection{Hotel industry in Cambodia}

Tourism accounted for 28\% of Cambodia's GDP in 2016 and hotels and travel agents are among the leading sectors that provided employment. The hotel industry is still growing and a number of hotels are being built in the three largest tourist cities in Siem Reap, Phnom Penh, and Sihanoukville (World Travel \& Tourism Council, 2017). As shown in Table 1.1 above, the average length of stay in this country is around 6 days for international tourists. The average hotel occupancy rate increased from roughly $37 \%$ in the 1990 s to $69 \%$ in 2016 . Tourism receipts have increased from USD 100 million in 1995 to USD 3,212 million in 2016, which was a gradual positive increase. There were 814 registered hotels in Cambodia in 2018 with 47,585 rooms and 2,269 guesthouses with 33,951 rooms. Furthermore, there were 2,314 restaurants, and 694 travel agencies in which 610 have their Head Office located in Cambodia; 84 are branches of foreign companies (Ministry of Tourism, 2018b). The city of Siem Reap has more 3 star hotels than 4 and 5 star hotels, but in comparison with Phnom Penh and Sihanoukville, Siem Reap has more 4 and 5 star hotels than the other destinations. However, in terms of rooms supplied, 4 star hotels have more than 3 and 5 star hotels in Siem Reap (Bonna Realty, 2016). Bonna Realty notes that there are more rooms supplied by 3 star hotels in Phnom Penh than the 4 and 5 star categories and it is the same for Sihanoukville. There are a number of luxury brands operating in Cambodia namely Fairmont hotel and resorts, Belmond, Accor, Starwood hotels and resorts, Hyatt hotels, and Marriott International; these hotel brands mainly operate in Siem Reap and Phnom Penh (Sarheim \& Vadehra, 2016).

\subsection{Tourism and main destinations in Cambodia}

In this section, a brief overview of tourism destination in Cambodia will be discussed including Siem Reap, Phnom Penh, and Sihanoukville.

\subsubsection{Siem Reap}

Siem Reap is the main gateway and most visited destination in Cambodia as the location of the Angkor Wat temple complex. At least $70 \%$ of international tourists visit Siem Reap province 
(Dwyer \& Thomas, 2012). Located in the northern part of the country, Siem Reap is home to 1,080 ancient temples and Angkor Wat is one of the main highlights of this cultural heritage (Chheang, 2008b). Siem Reap, especially the city centre, is one of the fastest growing cities in the nation as a result of tourists returning to visit the province following years of wars and destruction during the 1970s. When Siem Reap started welcoming international tourists in the 1990s, there were only a few hotels left after the war including the Grand Hotel d'Angkor and the Ta Prohm (Chheang, 2008b). In 2018 Siem Reap had 217 hotels (14,059 rooms), 300 guesthouses (5,003 rooms), and 270 restaurants in 2018 (Ministry of Tourism, 2018b). Siem Reap International airport is the main gateway to Siem Reap which hosted 1,507,039 tourists in 2016 (Ministry of Tourism, 2016). Besides its state of cultural destination with many ancient temples, Siem Reap also offers ecotourism experiences including the Tonle Sap lake and the National park of Kulen mountain (Chheang, 2008a). Siem Reap has 285 traditional and online intermediaries, 233 of which have head offices there and 52 are branches of local or foreign companies (Ministry of Tourism, 2018b).

\subsubsection{Phnom Penh}

Phnom Penh is the capital city with a population of more than 1 million and it has been the predominant urban centre for the country since it became the capital in 1890 (Fallavier, 2005). Phnom Penh is located at the intersection of the Mekong, Tonle Sap and Bassac rivers and these waterways have become one of the main routes for Phnom Penh. The municipality of Phnom Penh has undertaken many projects to rearrange the overall look of the city in order to attract more tourists including developing waterfronts, public spaces, road and public infrastructure (Fallavier, 2005). Phnom Penh was once known as the "Pearl of Asia" and today it is the cultural, commercial, and political centre for the country. Phnom Penh offers a wide variety of cultural and historical attractions to tourists such as the Royal Palace, Khmer Rouge museum, and bustling markets (Ministry of Tourism, 2018a). In 2018 Phnom Penh had 321 hotels (20,372 rooms), 525 guesthouses (10,171 rooms), 554 restaurants, and received 1,164,240 international tourists. Phnom Penh has 370 traditional and online intermediaries, 352 of which have head offices there and 18 are branches of local or foreign companies (Ministry of Tourism, 2018b). 
Figure 1.1 Tourism Map of Cambodia

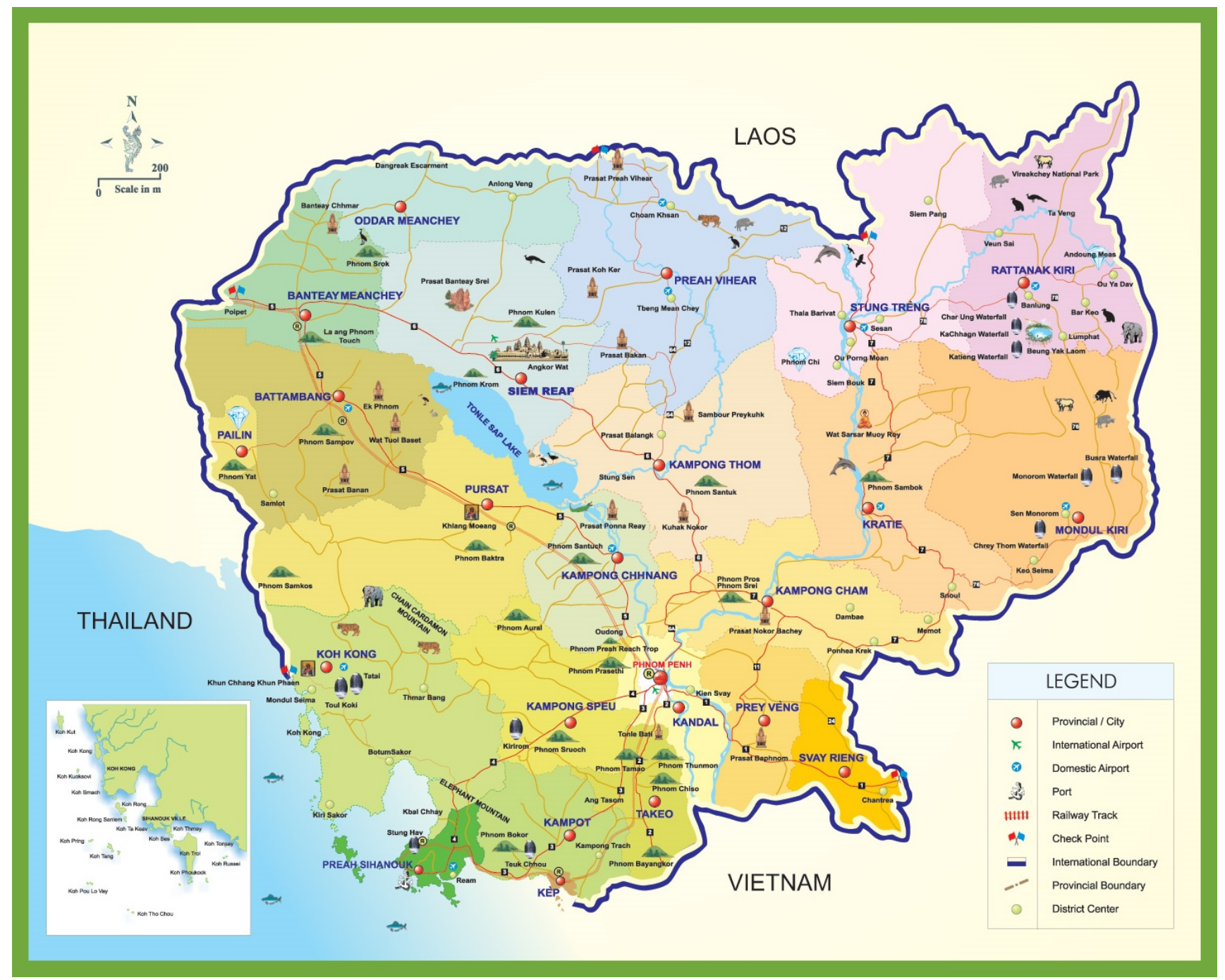

Source: http://ontheworldmap.com/cambodia

\subsubsection{Sihanoukville}

Sihanoukville is a significant economic centre and has potential for tourism development after Siem Reap and Phnom Penh. It is located 230km southwest from Phnom Penh, on the gulf of Thailand, and is connected by a highway, railroad, deep-sea port, and by air (Jackie Ong \& Smith, 2014). Tourism activities and facilities in Sihanoukville are mostly located near the beach areas which are about $1-2 \mathrm{~km}$ from the city centre. Beaches are a top tourist attraction in Sihanoukville and it has many beautiful beaches which are in close proximity to each other, including Otres, 
Ochheuteal, Serendipity, Sokha, Independence and Victory beaches (Jackie Ong \& Smith, 2014). Occheuteal beach was voted one of the "Top Ten Beaches in Asia" in 2009 by Australian Travel Magazine. Apart from beaches, Sihanoukville also has other seaport activities such as scuba diving, snorkeling, and fishing off the coastal islands. Sihanoukville also has Ream National Park which covers 210 square $\mathrm{km}$ and around 30\% of marine park (Ministry of Tourism, 2011). In 2018, Sihanoukville had 68 hotels (3,735 rooms), 251 guesthouses (3,792 rooms), and the numbers were set to increase. Sihanoukville has 15 traditional and online intermediaries, 10 of which have head offices there and 5 are branches of local or foreign companies (Ministry of Tourism, 2018b).

\subsection{Research objectives}

This thesis seeks to examine the nature of the relationship between mid-range and upscale hotels in Cambodia and their intermediaries (traditional and online). It concentrates on the different forms of conflicts experienced by hoteliers in three regions of Cambodia (Siem Reap, Phnom Penh, and Sihanoukville). To further elaborate on this topic, we looked at the perceived differences by region, each hotel's attributes and the hotel operator's background.

The three main research questions are:

1. How do hoteliers in Cambodia perceive their level of satisfaction with traditional and online intermediaries?

2. What are the main sources of conflict that arise between hoteliers in Cambodia and their intermediaries?

3. Do the perceived sources of conflict differ by region, hotel attributes or hotel operator's background?

The last question will allow us to critically examine the sources of conflict according to the three criteria mentioned above. 


\subsection{Research contributions}

This research aims to make a contribution to the literature on tourism distribution channels in the context of a developing country. To our knowledge, this is the first comparative study that looks at similarities and differences in terms of perceived sources of conflict between hotels and different channels of distribution (traditional and online intermediaries). Furthermore, it is also the first exploratory study that deals with tourism distribution channels in the context of Cambodia. Therefore, this study will contribute to the body of knowledge regarding tourism in Cambodia since Cambodia's tourism research is at an early stage of development.

\subsection{Thesis structure}

This thesis consists of six chapters. The first chapter provides introductory information about the research by explaining the background, objectives and research questions. Chapter two discusses literature review of the level of satisfaction and sources of conflict of hoteliers and both traditional and online intermediaries. Chapter three addresses the research paradigm, research approach, data collection, data analysis, analytical framework, ethical consideration, and strengths $\&$ limitations. Chapters four and five present the findings about the nature of the relationships between mid-range and upscale hotels in Cambodia and their intermediaries (traditional and online) and the different forms of conflicts experienced by hoteliers in three regions of Cambodia. Chapter six addresses

the discussions, recommendations and conclusions of the research. It will conclude the key research findings, present research implications, suggest recommendations and indicate directions for future research. 


\section{Chapter 2: Literature Review}

\subsection{Introduction}

The preceding chapter has provided valuable information about the research context of Cambodia, and also the research scope and questions. This chapter discusses the current academic literature on distribution channels. The first part illustrates an overview of the concept of distribution channel including the definition and structure of distribution. The second part examines the members of distribution channels but mainly focuses on intermediaries (Traditional and Online) since they are the main attention of this study. The third part explores the literature on the level of satisfaction of hoteliers with intermediaries as well as the sources of conflicts they encounter in their day-to-day business with tourism distribution channels.

\subsection{The concepts of distribution channels}

According to Pearce, Tan, and Schott (2004), some articles illustrate the essential characteristics of distribution channels while empirically evidence-based research has a tendency to focus on pairs of distribution channel partners including suppliers and wholesalers, or hotel and travel agencies.

Distribution is considered as one of the most significant managerial decisions which could affect the profitability and competitiveness of companies (Buhalis \& Laws, 2001). Tourism Distribution channels establish the connection between tourism service producers. Buhalis \& Laws (2001) added that distribution channels also have influences on other elements of marketing mix such as price, product, and promotion. According to Buhalis (2000b), their purpose is to distribute information to prospective travelers and intermediaries as well as creating the mechanism that enables customers to plan, confirm and finalize for reservations. For their products to go to the market, tourism service providers are making use of travel intermediaries to make retail of their tourism products as well (Cooper \& Lewis, 2001). The authors further state that the connection among suppliers, intermediaries, and consumers create the distribution channels in which information transfer, payment, and sale are taking place. 
"The principal role of intermediaries is to bring buyers and sellers together, either to create markets where they previously did not exist or to make existing markets work more efficiently and thereby to expand market size"' (Fletcher, Fyall, Gilbert, \& Wanhill, 2013, p.12). According to Garcia-Falcon and Medina-Muñoz (1999), sales transaction between suppliers and customers in tourism industry takes place in four methods based on the distribution system in the tourist industry including direct system, a system with one channel, a system with two channels, and system with three channels. As illustrated in figure 2.1, all the latter three systems excluding direct system involved with different types of intermediaries before they reach consumers. The authors explain that with a direct distribution system, the suppliers communicate directly with consumers and provide all information in order to sell their tourism products or services. Similarly, the authors mention that a system with one channel is an indirect distribution channel which involves one intermediary and in this system, retailers (retail travel agency or specialty retail distributor) connect suppliers and tourists. Also, the system with two channels involves two intermediaries including wholesalers, and it follows the pattern of the system with one channel, but in this case, wholesalers sell to retail travel agencies or specialty retail distributors. Garcia-Falcon and MedinaMuñoz (1999) state that indirect system with three channels involves with three intermediaries and it follows the previous systems while in this case wholesaler sell tourism products to travel agencies and travel agencies sell products to specialty distributor intermediaries. 
Figure 2.1: Distribution systems in the tourist industry

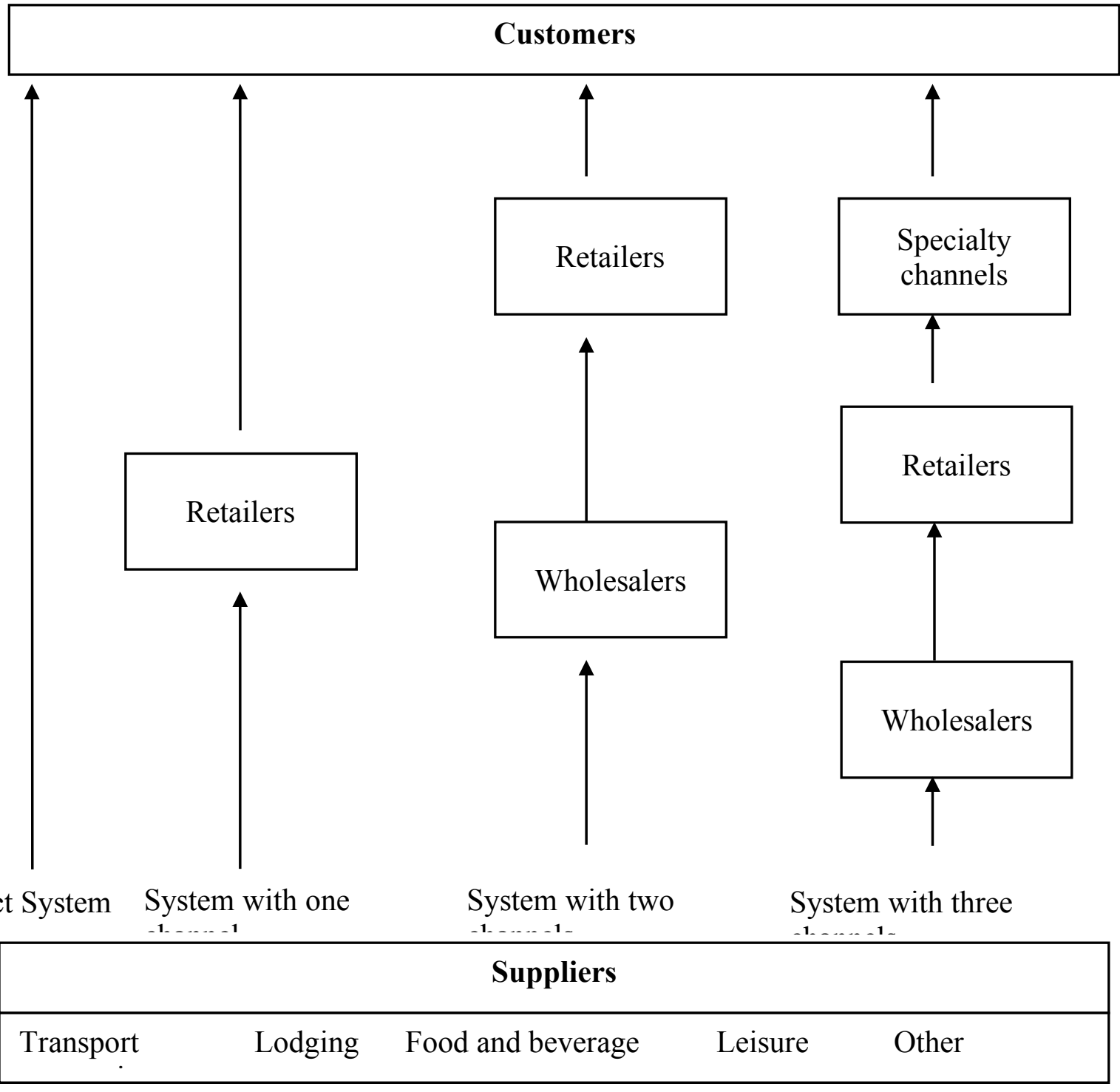

Sources: Adapted from Garcia-Falcon and Medina-Muñoz (1999, p.108)

\subsection{Distribution Channel Members}

The creation of distribution channels is driven by the pursuit of sales to generate revenues and aiming for profits (Knowles \& Grabowski, 1999). Buhalis and Laws (2001) comment that tourism distribution has its distinctive features from that of manufacturing where in tourism distribution, 
each component of transport, accommodation, and tourism activities are put together as the packages for tourist consumption.

\subsubsection{Suppliers}

According to Knowles and Grabowski (1999), principals or suppliers are the most significant members in distribution channels as they provide tourism services including core travel products of transportation, accommodation, and other facilities. The authors state that if there are no suppliers, there would not be any members down the distribution channel. The article reports that intermediaries are relying on suppliers to produce their tour packages and sell it to their customers and the significant of suppliers could not be overlooked in tourism industry.

\subsubsection{Consumers}

According to Cooper and Lewis (2001), consumers are connected to suppliers via intermediaries such as travel agents and tour operators, but it could vary depending on the market, destination, industry sector, and the product type. The authors further state that as consumer preferences and tastes changes continuously as a result of technology advancement, intermediaries may have to stay up-to-date with these changes in order to meet the consumers' needs. The authors also note that the shifting patterns of consumer behavior are influencing the structure of distribution significantly.

\subsubsection{Intermediaries}

According to Thakran and Verma (2013), before the internet era (1995-2000) accommodation suppliers including hotels depend significantly on traditional intermediaries such as travel agencies and paid relatively high transaction fees for each reservation.

Travel agencies are divided into different types which include outgoing/outbound travel agencies (retailers), tour operators (wholesalers), and incoming travel agencies to handle tour services at destinations (Buhalis \& Laws, 2001). As illustrated in Figure 2.2 of tourism distribution channels, 
consumers may buy different services and products directly from producers while many distributions and sales intermediaries are used to promote tourism products (Buhalis \& Laws, 2001). Outgoing travel agencies are different from other retailers because they cannot stock travel products, but instead, they store travel information in the form of brochures, leaflets, data and professional travel consultants (Holloway, 1989). The author further states that this is the main reason why outbound travel agencies have less burden on financial risks because they never buy tourism products in advance, but instead they only purchase or issue travel documents only when customers order. According to Buhalis and Laws (2001), outgoing travel agencies are profitmaking organizations which intend to maximize their profits by generating more customer volumes and large profit margins and generally they receive about 8-12 percent of commission from selling tourism products through incoming travel agencies internationally. In addition, override or incentive commissions are extra bonus that principals (suppliers) or wholesalers pay to outgoing travel agencies to attract more bookings and increase the loyalty of outgoing travel agencies with them and frequently it is up to $17-18$ percent of commissions.

Tour operators offer a wide range of tourism products and services so that they could negotiate with suppliers and sell their tour packages to travelers (Buhalis \& Laws, 2001). Buhalis and Laws (2001) state that tour operators are usually regarded as wholesalers because they book various tourism products and services before distributing them to outgoing travel agencies. The authors note that tour operators usually pre-reserve and frequently pre-purchase tourism products and services including airline seats, accommodations, and transportation services at destinations and offer as package tours. Wanhill (1993) comments that tour operators need to conduct marketing research before preparing their inclusive package tour and they analyze the overall market size, demand trends and the attractiveness of their services at destinations. The author further comments that tour operators also evaluate their profit margins in each destination and the overall profits for every service they arrange for their customers. Tour operators make negotiation with tourism principals (suppliers) and incoming travel agencies for a number of tourism products, services and accommodations for their customers and two types of contracts are used by tour operators when making negotiations for accommodations (Buhalis \& Laws, 2001). 
Figure 2.2: Tourism Distribution mechanism (Buhalis \& Laws, 2001, p.11)

Outbound

Travel

Agencies
Tour

Operators
Inbound

Travel

Agencies

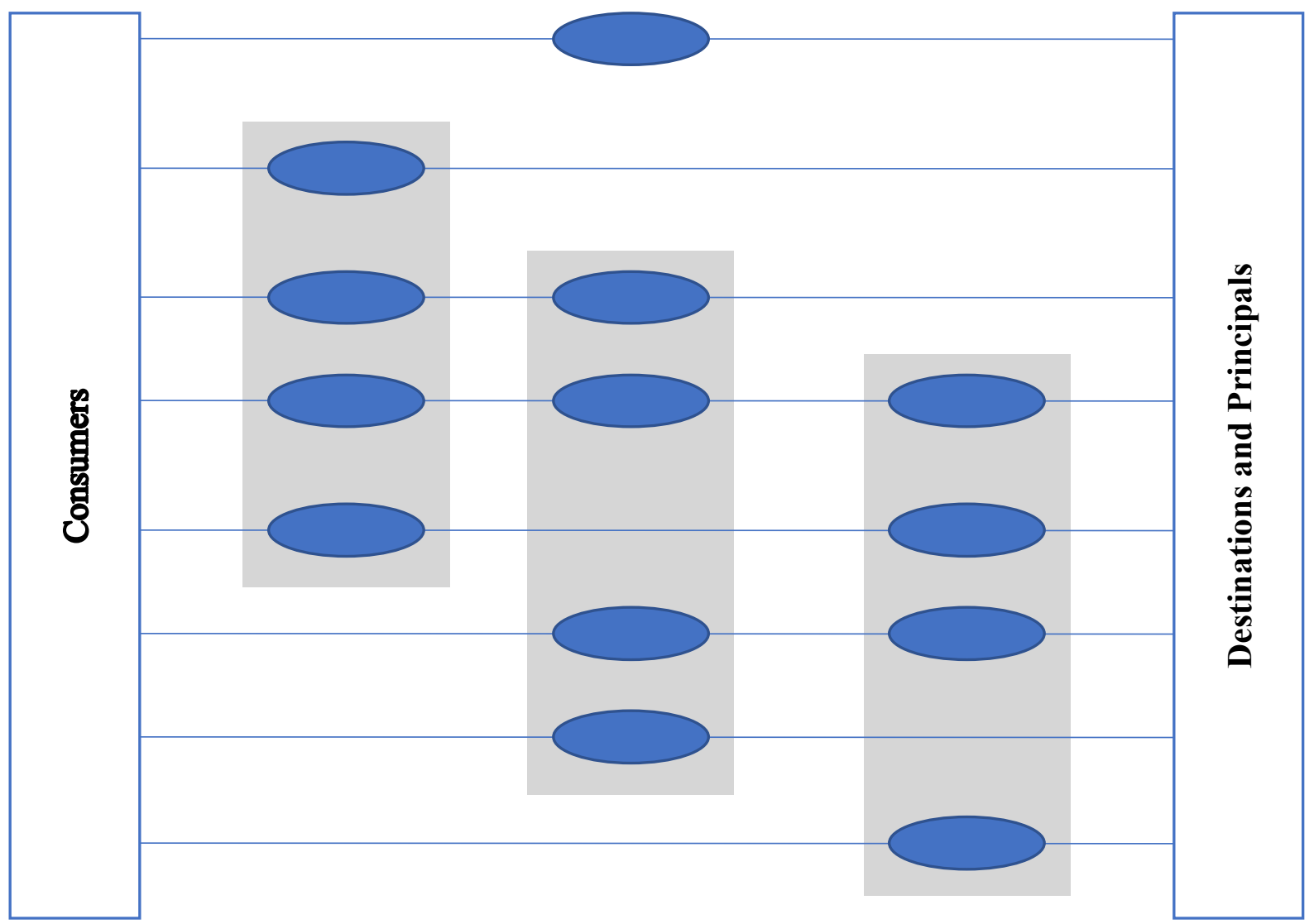

Inbound/incoming travel agencies or often referred to as incoming tour operators or ground operators are not so well-known in distribution channel members and their roles involving in planning and execution of tour packages at destinations (Buhalis \& Laws, 2001). According to Gee, Markens, and Choy (1989), inbound travel agencies act as intermediaries between tour operators and principals (suppliers) and they are the representative for both tour operators and local authorities. Gee et al. (1989) comment that the needs of inbound travel agencies occur when tour operators do not have enough knowledge of destinations and do not have adequate present there. 
The authors suggest that inbound travel agencies handle hotel transfers, overnight accommodation, sightseeing, unique arrangements, and manage the service execution provided by local suppliers.

The advancement of internet technology has strengthened the role of online intermediaries and enhance their positions to become more significant for suppliers' strategies and potentially threatening the traditional distributors (Buhalis \& Laws, 2001; Thakran \& Verma, 2013). Internet advancement has enhanced the role of online intermediaries and become as one of the prominent strategic tools for tourism suppliers and potential as a threat to traditional distributors (Buhalis \& Laws, 2001). Myung et al. (2009) state that the introduction of online distribution channels has changed and challenged hotel distribution systems, especially with the arrival of online intermediaries such as Expedia (www.expedia.com), and hotels.com (www.hotels.com). Customers could have a "one-stop-shop" travel experience with online intermediaries because online intermediaries sell services from various suppliers where they combine services and reduce cost simultaneously (Stangl, Inversini, \& Schegg, 2016). Stangl et al. (2016) note that online intermediaries have the ability to create customer value and offer convenience to customers through information search and booking. The rate of using online intermediaries is different from one country to another as well as intermediary companies. For instance, the top online intermediaries in Germany are HRS, Hotel.de, Booking.com, and Expedia.com, while in Austria and Switzerland, the strongest is Booking.com (Stangl et al., 2016). Online intermediaries are not only involving facilitating distribution but also affecting other marketing mix such as determine the cost by accessing real-time available supply and demand (Thakran \& Verma, 2013). These authors further assert that accommodation suppliers such as hotels started to invest more in online intermediaries such as online booking engines including Expedia, Travelocity, booking.com, and Agoda.

Furthermore, accommodation suppliers began to lose control over the pricing of rooms and the potential shifting of pricing authority to those online intermediaries as consumers prefer the lowest rates in targeted markets and the increase of price transparency on the internet (Thakran \& Verma, 2013). Traditionally, customers have two options to book for hotel rooms by directly contacting the service providers (hotels) or travel agents (Swati \& Kamal, 2007). Online distribution of room information, prices, and availability have revolutionized the way tourist book hotel's room (Bill \& Judy, 2003). The authors state that those firms that compete in hotel distribution channels are 
online intermediaries (Expedia, Agoda, Booking.com, etc.), Global Distribution Systems (GDSs), Traditional travel agencies, and hotel websites.

\subsection{Hotels' perception and satisfaction of intermediaries}

Hoteliers should review their relationship regularly with their channels of distribution to make sure that they not only gain advantages in market exposures but also maximize their share of value for being parts of the network (Stangl et al., 2016). With the increase of dependency on a particular channel of distribution, for example online intermediaries, hoteliers would have considerable consequences in losing control of their products and brands (Stangl et al., 2016). The authors suggest that to balance the dependency, hoteliers need to diversify their distribution channels such as own hotel websites, traditional intermediaries, and online intermediaries. Hotels and online intermediaries have cooperation and competition with each other simultaneously (Chang, Hsu, \& Lan, 2019). For example, online intermediaries help to find new customers to hotels, but hotels have the consequences of deep discounts and large commission from online intermediaries (Chang et al., 2019). The authors comment that hotels and online intermediaries could also be seen as competitors because they sell rooms on their own websites and compete to attract customers. Hotels believe that they gain a large number of benefits from online intermediaries in terms of filling room occupancy and revenue gains (Myung et al., 2009). The authors also assert that other benefits include a global distribution of products, the visibility of the hotels, and the ability to push the inventory via their strong marketing campaign such as pop-up ads. While online intermediaries help hotels to increase their sales and exposure, hotels need to sacrifice their profits and share those profits with online intermediaries as part of their commission (Myung et al., 2009). Online intermediaries affect hotels' profits in many ways. Rich (2002) comment that since online intermediaries promise to their customers for the lowest rates, hotels have to provide the same or better rates for their guests in order to compete with online intermediaries. They sometimes offer an alternative option such as credit to frequent-stayer points (Rich, 2002). Hotels cost about 25$30 \%$ of their retail rates when dealing with online intermediaries (Myung et al., 2009). Hotels view

online intermediaries as their competitors rather than complimentary distribution channels because online intermediaries may have control on their pricing decisions and take some of their businesses (Rich, 2002). 
Hotels also rely heavily on traditional intermediaries such as travel agencies and tour operators which are unquestionably among the leaders in distribution channels (Ujma, 2001). The authors assert that some of these traditional intermediaries are gigantic and they have power over hotels, and some of those aspects include dependency, coercion, and conflict. For example, these influential members of traditional intermediaries could take advantages of the unfavorable hotels by putting pressure on them during contract negotiations (Ujma, 2001). There is a broad agreement in tourism and hospitality management literature about the dominant role of traditional intermediaries, especially large tour operators, on their relationship with hotels for various reasons (Buhalis, 2000b; Karamustafa, 2000). For example, intense competition among traditional intermediaries forces them to reduce their cost and lead to low pay to their suppliers (hotels) as well. Similarly, some traditional intermediaries are large, and they merge or expand into even larger business groups comprise of accommodation companies, airlines, and retail travel agencies (Karamustafa, 2000; Medina-Muñoz, Medina-Muñoz, \& García-Falcón, 2003). Despite the fact that the roles and business ethics of traditional intermediaries, especially large tour operators and travel agencies, are the main source of controversy within distribution channels, it should be acknowledged that traditional intermediaries contribute considerably into tourism value system (Bastakis, Buhalis, \& Butler, 2004). The authors note that small and medium-sized accommodation enterprises in Eastern Mediterranean perceive that, on average, they are satisfied with traditional intermediaries (Tour Operators) in terms of financial consistency, and operational efficiency. Medina-Muñoz et al. (2003) assert that the control of German and British traditional intermediaries (tour operators) on accommodation companies (hotels) is "medium" and can be explained as "neither low or considerable." However, there is a vast extent of variation for the degree of control as well, while some tour operators barely have any control, others possess a high degree of control (Medina-Muñoz et al., 2003). To our knowledge there was limited literature which deals with the hotel's level of satisfaction for both traditional and online intermediaries in one study. The previous studies either examine on traditional intermediaries or online intermediaries. For instance, the study of Myung et al. (2009) explores the relationship of hotel operators with online intermediaries (E-wholesalers), Stangl et al. (2016) discuss the hotel dependency on online intermediaries, Laurette and Leo (2000) investigate hotel marketing through intermediaries. Similarly, some other previous studies focus only with level of satisfaction or 
relationship with traditional intermediaries. For example, Bastakis et al. (2004) assess the perception of small and medium hotels with traditional intermediaries (tour operators), Ivanov et al. (2014) examine the hotels' relationships and conflicts with traditional intermediaries, Buhalis (2000b) discusses hotel's relationship with tour operators, Medina-Muñoz et al. (2003) explore the relationship and control of tour operators from Germany and the United Kingdom on hotels. To sum up, there were gaps in literature which discuss hotels' level of satisfaction with both traditional and online intermediaries from the perspective of hoteliers.

\subsection{Hotels' potential sources of conflicts with intermediaries}

According to Ford, Wang, and Vestal (2012), in tourism distribution network relationship, the imbalance power between any two organizations usually occur in which the dependent organization tends to be disadvantaged by this asymmetry power. Consequently, the disadvantaged organization is usually seeking strategies in order to have more power in this relationship so that it represents their share of values in the exchange. The authors emphasize that, because there is imbalance power within the tourism distribution network, the advantage organization with stronger power can force the disadvantaged organization (partner) to accept the low value of a product or service by threatening from the relationship and change to different suppliers. Intermediaries, for example, that have a significant contribution to the sales of hotel rooms may use its power to negotiate and threaten to terminate sales contract with the aim to achieve specific proposed conditions from the hoteliers (Ford et al., 2012). The authors comment that the reverse situation is also valid even though hoteliers are considered as disadvantaged organization in this relationship which tends to have weaker power. The article states that some conflicts happen in the form of healthy competition while others may damage the relationship by ruining the trust between the partners. According to Ivanov et al. (2014), hoteliers accuse travel agencies of aggressive, demanding and huge hotel rate decrease request which causes tension between them. Factors which contribute to the conflict between hoteliers and intermediaries and, in particular, travel agencies include factors during contracts stage, customer service stage such as pre-stay, stay and post-stay conflicts (Ivanov et al., 2014). The authors further suggest that in practice every point of contact between hoteliers and intermediaries may be considered as the sources of conflicts and it could be in the form of late payment and provision of booking details, or conflicts between the 
employees. Figure 2.3 illustrate the potential sources of conflicts between hoteliers and intermediaries which could be divided into the following four stages: contract stage, pre-stay stage, stay stage, and post-stay stage. The nature of conflicts varies in real practice from one stage to another as it is shown in the figure below.

\subsubsection{Contract stage of conflict}

Contract stage is likely to be the main source of potential conflicts between hoteliers and intermediaries since all the steps of price negotiation take place during this stage : price level, commission, price/quality ratio, release periods, general contract terms (cancellation and payment terms), contract obligation commitment and timing of contract negotiations (Ivanov et al., 2014). According to Bastakis et al. (2004), travel agencies tend to have more bargaining power with hoteliers at destinations, and they use their powers to negotiate their contracts with hoteliers. The authors state that the intermediaries have more power if they keep sending more bookings/tourists to hoteliers and they would have the power to negotiate for lower accommodation rates. The article notes that hoteliers accuse intermediaries of fierce negotiation, in particular, large travel agencies, in order to receive a lower rate in their contract terms. For example, travel agencies may negotiate for lower rate during/immediately after low sales period, and they may confront hoteliers against each other as their strategies. However, one could argue whether this is aggressive negotiation or general business strategies that intermediaries need to utilize for their benefits (Buhalis, 2000b).

According to Andriotisy (2003), hoteliers at destinations depend heavily on travel agencies to distribute their products and services as travel agencies have high bargaining power. Product distributors have high bargaining power when they buy massive amount of volumes compared to seller sales, full market information, and can influence customer's buying decisions (Ivanov et al., 2014). Coff (1999) emphasizes that the strongest bargaining power happens when parties are working together in a collaborative manner (i.e., the merger or acquisition of travel agencies to form a bigger group to reduce competition), access to crucial information of supply and demand, have high replacement cost to the firm (e.g., when replacing one agency with another has high cost for hoteliers), and has low cost if switching to other firms (travel agencies change their preferences of hotel options). Ivanov et al. (2014) state that the strong bargaining power of intermediaries 
originates from different sources such as their access to customers and facilitation of hotels' product distributions, their ability to convince customers to change to other hotelier options, and the knowledge of their customers and markets. The authors state that contract terms are the sources of legitimate power of intermediaries with hoteliers while the desire of hoteliers to cooperate with intermediaries' brands present weak power to their partners.

Figure 2.3: Sources of potential conflicts between hotels and travel agencies
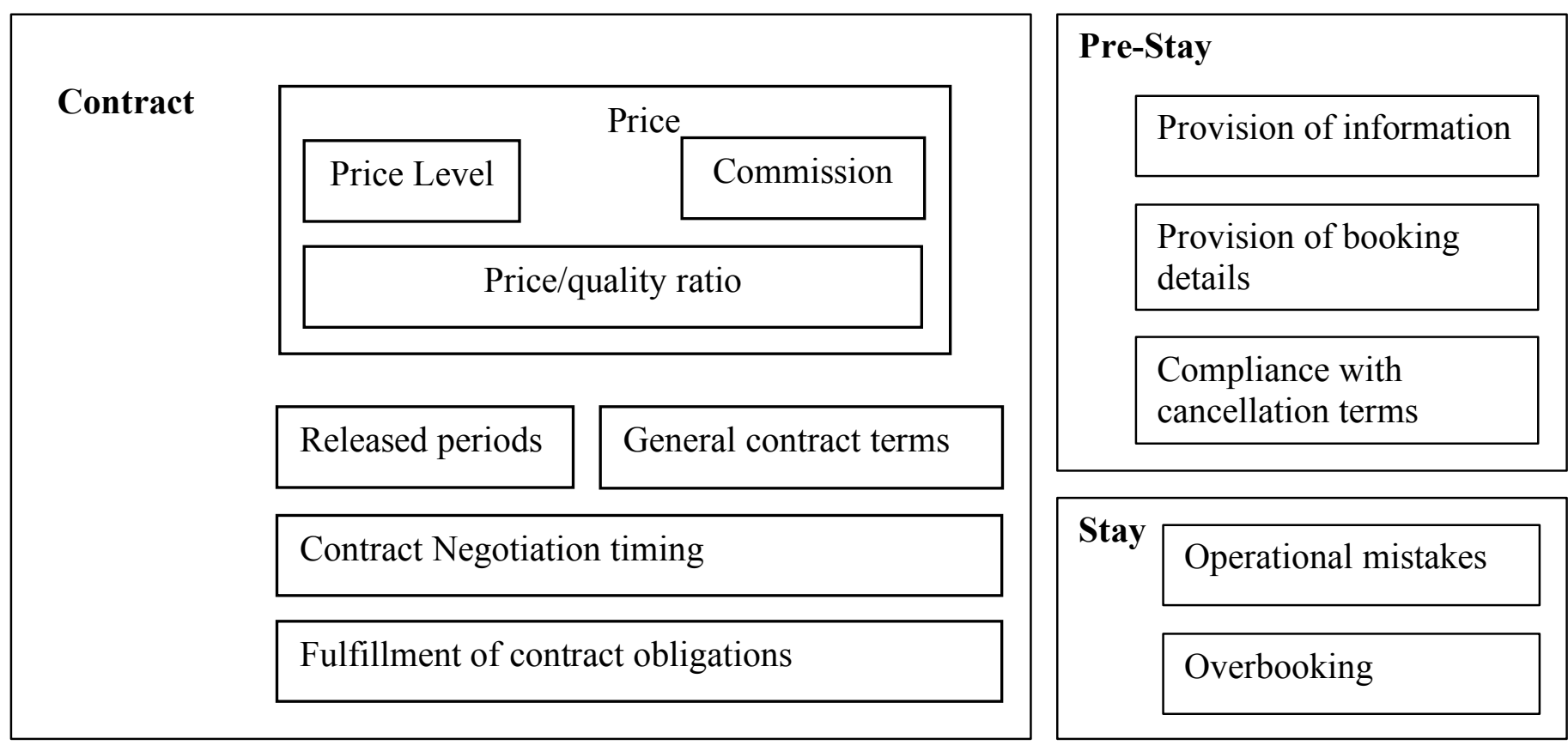

\begin{tabular}{|l|l|}
\hline Post-Stay & $\begin{array}{l}\text { Customer satisfaction surveys and } \\
\text { complaint handlings }\end{array}$ \\
\hline
\end{tabular}

Source: Ivanov, Stoilova, Illum (2014)

Price level and commission are among the main factors which trigger tension between hoteliers and intermediaries as their relationship in this context follows a game theory perspective of zerosum pattern in which the gain for one party means the loss for the another party (Buhalis, 2000b). The author emphasizes that with this perception in mind, both parties of hoteliers and 
intermediaries are sensitive toward the negotiations of price level and commissions because they are both willing to maximize their profits. From a short-term perspective, to achieve this goal each party needs to maximize the benefits from every deal/contract which means that hoteliers and intermediaries negotiate their contracts with a high chance of conflicts. From a long-term perspective, the goals for both parties seem to align with each other which aim to attract more tourists and generate more revenue for both sides, and in this context, they could change from "zero-sum" game to "cooperative" game instead (Buhalis, 2000b). Guo and He (2012) state that if any side of both parties shows opportunistic behavior to maximize benefits, it is likely to damage their trust in each other and the willingness to renew the contract would be low. The authors further comment that to achieve a long-term goal of maximizing the benefits of both parties, it does not necessarily mean extracting the maximum benefits in the short run, but to cooperate well including the pricing level. The article also notes that the uncertainty of contract renewal of hoteliers and intermediaries also depends on the monthly and quarterly profits which stimulates them to seek for short-term rather than long-term benefits in their contract negotiations and as a result leads to a more potential conflict.

According to Bastakis et al. (2004), price/quality ratio may be another potential root of conflicts between intermediaries and hoteliers. For instance, intermediaries may demand highest accommodation quality that hoteliers could offer in the contract rates. In contrary, hoteliers accuse intermediaries of willing to pay much less than their operating expenses in maintaining the quality of their accommodation services. The authors further emphasize that intermediaries' products are more competitive when they could offer high quality of service at a low price and could lead them to generate more revenues for themselves and also hoteliers. The authors also note that a higher quality of accommodation service costs more and hoteliers are expected to cover more expenses to deliver the expected level of services. Thus, when intermediaries use their strong bargaining power to lower hoteliers' rates, the reaction by hoteliers is to reduce the quality of service to match the lower prices offered by intermediaries (for instance by using basic quality bathroom products, fewer options and poor quality food and beverage in all-inclusive hoteliers' services). Bastakis et al. (2004) further comment that this reaction from hoteliers could lead to counter-reaction from intermediaries by cancelling the contract and opting for lower accommodation quality which has lower cost and this trend could trigger potential conflicts. The authors comment that the only 
solution for hoteliers to avoid this potential conflict is to diversify their distribution channels. Calveras and Vera-Hernández (2005) state that if intermediaries focus more on quality rather than price as a source of their competitive advantage, hoteliers would offer better quality of services and level of cooperation with such intermediaries.

Release periods is the time when intermediaries should release the unsold rooms from their allotment, and the preference of intermediaries and hoteliers are opposite regarding this aspect (Ivanov et al., 2014). The authors elaborate that hoteliers favor longer release periods which enable them to sell unsold rooms from intermediaries' allotments while intermediaries are willing to have shorter release periods so that they could maximize their sales. With the increase of competition among hoteliers and strong bargaining power of intermediaries, the release periods are shortened, and hoteliers are bearing the costs of unsold rooms. For example, the release periods in certain urban areas is at 6 p.m. on the expected guest arrival day and this is nearly impossible chance for hoteliers to sell their rooms afterwards (Ivanov et al., 2014). Also, the coverage of the allotment by intermediaries is source of tension between both parties as day-to-day practices show that intermediaries usually over-contract by block larger amount of rooms than they could actually sell in order to secure the room availability, but eventually could not meet the expected sales and release much of it (Andriotisy, 2003). The author comments that by expecting such behavior from intermediaries, hoteliers respond by signing allotment contracts with a larger amount of rooms available at their actual properties and if not managed effectively, it may lead to overbooking, and sources of conflicts may arise. According to Buhalis (2000b), contract negotiation timing is also another source of conflict as intermediaries may put more pressure on their rates during slow business periods, weak sales and low occupancy of hotels. Confronting with all the expenses which they need to pay during their weak sales periods, hoteliers may be more complaint and sensitive with intermediaries' requests for lower prices, later payment, shorter release periods and they may consider this as opportunistic act from intermediaries during their low seasons, and this could trigger tension between the two parties (Buhalis, 2000b). 


\subsubsection{Pre-stay stage of conflict}

Pre-stay conflicts are those issues that happen before the arrival of guests at accommodation properties, and it may involve with information correctness, timeline and completeness that hoteliers and intermediaries provide to each other and customers regarding booking details, quick confirmation/rejection by hoteliers and compliance with cancellation terms and conditions specified in the contracts (Ivanov et al., 2014). The authors state that "Provision of information" is another source of conflicts between the two parties and if hoteliers could provide complete and accurate information to intermediaries, hoteliers usually receive more benefits of increasing more bookings from intermediaries. However, some potential conflicts arise when hoteliers fail to report about the repairs in or around accommodation properties, malfunctioning of their facilities, and non-updated website that lead to complaints from customers. Clerides, Nearchou, and Pashardes (2008) comment that intermediaries are also responsible for these types of conflicts because they may intentionally or not provide wrong information to customers even though hoteliers provide them accurate information. For instance, some intermediaries, mostly large ones, have their rating system for hoteliers and their rating may be different from the official rating that hoteliers provided. The authors further emphasize that when intermediaries downgrade the rating of hoteliers on their websites or brochures that is when the conflicts may arise. Intermediaries may portrait different image of destinations or accommodation properties and this misleading information is intended to divert customers' preferences to other accommodation properties (Klemm \& Parkinson, 2001). The authors state that when customers receive misleading information and they finally found their gaps for their expectation before and after their stay, customers may file the complaints to either hoteliers or intermediaries and that may be the conflicts may trigger.

According to Buhalis (2000b), booking detail provision is another source of potential conflicts that intermediaries may delay sending their already confirmed bookings to hoteliers and demanding promotional lower rate due to slow sales. The author states that after receiving lower rates from hoteliers, intermediaries may send those previously confirmed bookings to hoteliers and intermediaries are the ones who benefit from the difference between the original contracted rate and the new promotion rate while customers do not benefit from this discount. On the operational 
level, hoteliers may control such opportunistic behavior by tracking intermediaries' website, but on the other hand, hoteliers may need to seek diversified partners rather than relying on one particular intermediary (Buhalis, 2000b). The article notes that hoteliers may cause the conflicts relating to booking details and intermediaries may lose customers because hoteliers provide slow feedback for booking status (confirmed/rejected/amended) and unavoidably leading to losing customers to quick competitors due to slow response to customers. "Compliance with cancellation terms" is another source of conflict in which hoteliers and intermediaries are sometimes not willing to comply with (Ivanov et al., 2014). For instance, hoteliers may confirm different cancellation terms for some bookings than the terms in previously specified in the contracts, and if these new terms are beneficial to intermediaries and customers, then it would not be an issue. If not, they may cause conflicts and tensions between the two parties. On the other hand, intermediaries may cancel bookings after the deadline of cancellation and hoteliers may lose revenues in case the bookings are not guaranteed (e.g., intermediaries do not take customer credit card details beforehand or pay on arrival).

\subsubsection{Stay stage of conflict}

Operational errors and overbookings are the two categories of stay-of conflict (Ivanov \& Hristov, 2006). The authors state that overbooking is defined as confirming more rooms than the available capacity of the accommodation properties and frequently happens when hoteliers shield protection for themselves when there are unused rooms because of no-shows, late cancellations, and termination of stay by already accommodated guests. Hoteliers may aim to maximize their profits from these situations where they could sell their rooms to new guests. If managed properly, they would generate more revenues for their business, but if the information provided from intermediaries is incorrect, overbooking may happen and trigger the conflicts (Ivanov \& Hristov, 2006). Operational errors occur when wrong room types is offered to customers on their arrivals, but if customers have been compensated appropriately, it would not be a major issue. 


\subsubsection{Post-stay stage of conflict}

Post-stay issues are related to payments, customer satisfaction, and handling of customers' complaints (Buhalis, 2000b). The author states that delayed payments by intermediaries are one of the major sources of conflicts because hoteliers may need the payments to cover the expenses to suppliers. In the worst case, default payments from intermediaries could be a major problem for hoteliers in which conflicts are inevitable. The same author states that intermediaries are willing to pay as late as possible, while hoteliers are in favor of early payment as soon as possible. The terms of payment are usually specified clearly in the original contracts, but it could be a major cause of conflict when intermediaries could not comply with the agreements (Buhalis, 2000b). The same author further comment that intermediaries may use customer satisfaction survey manipulation in order to request for lower prices when negotiating for contract renewal. Since hoteliers do not have access to primary data from customers like intermediaries do, intermediaries may take the advantages of this by reporting the customer satisfaction survey in any way they prefer to receive better price rates. "Handling complaints" may be another source of conflicts if both intermediaries and hoteliers do not act together to solve the problems for customers with timely manners. Intermediaries usually compensate their customers for the accommodation complaints and deduct the amount paid for compensation with the amount due to hoteliers and this lead to conflict. To sum up, similar to the level of satisfaction discussed above, there were limited studies in the previous literature which deal with sources of conflicts with both online and traditional intermediaries from the hotel's perspectives.

\subsection{Chapter summary}

Conflicts and level of satisfaction of hoteliers with traditional and intermediaries have been limited discussed in the previous literature. Some of the previous research either discuss the relationship or conflicts with traditional intermediaries or with online intermediaries. Based on the lack of this study, research gaps have been identified. This study is partly the expansion of the previous study by Ivanov et al. (2014) who discussed only the sources of conflicts with traditional intermediaries (travel agencies). Some sources of conflict are discussed in four different stages of conflict including contract stage, pre-stay stage, stay stage, and post-stay stage. Some of the potential 
sources of conflict include price level, commission, price-quality ratio, release period, fulfillment of contract conditions, provision of information, bookings details, overbooking, operation errors, payment, and complaint handling.

The next chapter discusses the research paradigm, research approach, respondent recruitment, data collection, and data analysis. 


\section{Chapter 3: Research Methodology}

\subsection{Introduction}

This chapter covers the research development process and justification of the methodological design including the research paradigm, research approach, data collection, data analysis, analytical framework, ethical consideration, and strength and limitation. The three largest urban cities in Cambodia were selected for data collection including Siem Reap, Phnom Penh, and Sihanoukville. The participants for this research were senior people working in mid-range to upscale hotels such as Sales Directors, Managers, or General Managers. These participants were believed to be able to provide information regarding the research questions. The data collections were in-depth, semi-structured interviews (open-ended and closed questions) and document compilation.

\subsection{Research paradigm}

For this study, pragmatism was chosen as the research paradigm from a researcher's position. According to Morgan (2014, p.1045), "although the possibility of pursuing pragmatism as a paradigm for social research is not entirely new, its frequent linkage with mixed-methods research has heightened the awareness of pragmatism." Creswell (2014) suggests that this worldview focuses significantly on research problems rather than methodologies. Pragmatism as a worldview

arises out of actions, situations, and consequences (Creswell, 2014). The author suggests that pragmatists do not view the world as having an absolute unity and they believe that a pragmatic worldview does not attach to any one system of philosophy and reality. Therefore, mixed methods could be a good option for collecting and analyzing data rather than sticking to only one approach (Creswell, 2014). Patton (2002) also suggests that researchers could understand the worldview of respondents through a pragmatist approach. Hence, pragmatism is an appropriate paradigm for this research since it seeks to understand the perceived level of satisfaction and sources of conflict among hoteliers and pragmatism supports both the worldview of qualitative and quantitative approach. Figure 3.1 illustrates the research overview, which consists of a research paradigm, research objectives, research questions, research mixed-methods, and research participants. 
Figure 3.1: Research Overview

Pragmatism

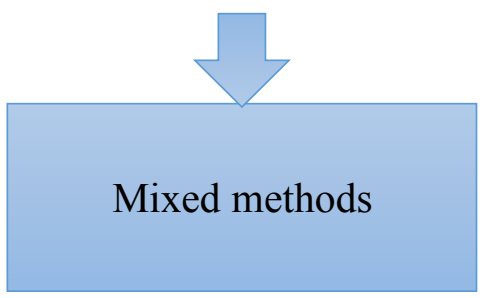

Research Objective

To examine the levels of satisfaction of hoteliers with intermediaries and discuss the sources of conflict that arise between hotels and intermediaries in Cambodia.
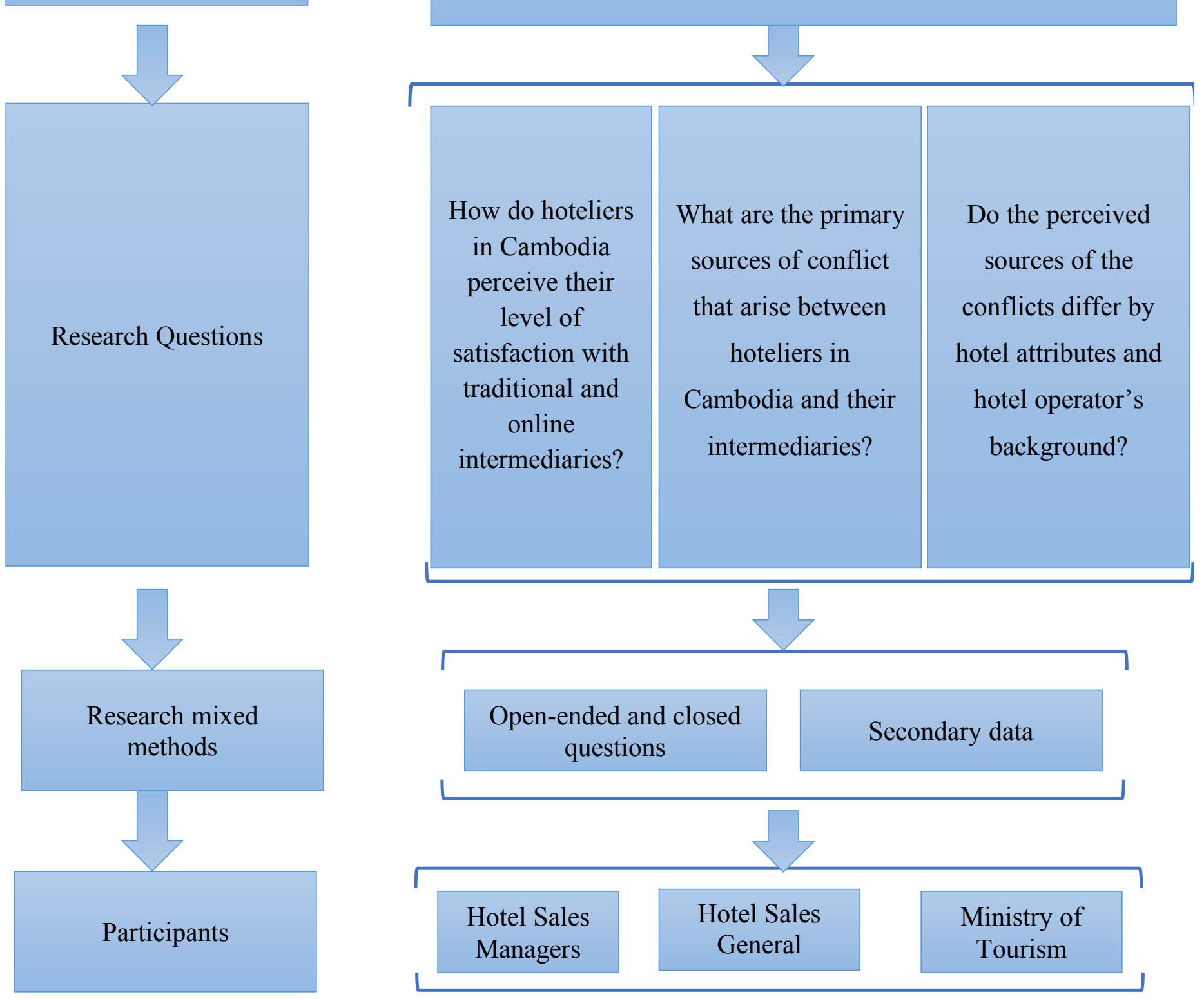


\subsection{Research approach}

There are three approaches to conducting research in social sciences: qualitative, quantitative, and a mixed methods approach (Creswell, 2014). The same author states that the differences between qualitative and quantitative research could be identified by using words (qualitative) rather than using numbers (quantitative) or by adopting open-ended questions (qualitative) rather than closedended questions (quantitative). Qualitative approach is used widely in tourism research as more information can be gathered from fewer cases (Jennings, 2005). Qualitative research is an approach to seek understanding and meaning of groups or individuals, which occur in human or social problems (Matthews \& Ross, 2010). Quantitative, in contrast, is an approach to examine the

problems, which seek to find a connection between variables by using statistical procedures (Creswell, 2007). Mixed methods research is the combination of both qualitative and quantitative since it incorporates the aspects of both methods together (Creswell, 2014). Creswell (2014) notes that the primary assumption of mixed methods approach would provide a more complete understanding of the research issue rather than adopting either qualitative or quantitative approach.

This thesis adopts a mixed methods approach. According to Cross (2013), open-ended questions are a common characteristic of the qualitative approach and are frequently in the form of a semistructured interview. The same author comments that the semi-structured interview is a sufficient tool to address a particular topic, which involves the phenomenon of the study area and also provides space for interviewees to generate new meaning of the research focus. Creswell (2014) notes that closed-ended questions in a quantitative approach are more common in a Likert scale, which involves numeric values. Since this study adopts mixed methods, both semi-structured interviews and Likert scale were used.

\subsection{Data collection}

The data collection process for this study took place between 1-30 September 2018. In-depth semistructured interviews (open-ended questions and Likert scale questions) were adopted for the data collection process in combination with document compilation. 


\subsubsection{Semi-structured interviews}

According to Blaikie (2010), semi-structured interviews are frequently used in social science research, and there are pre-determined questions and specific objectives from the interviewer, there is still freedom for the interviewer to adjust those questions and objectives so that the interviewees could have a chance to co-lead the discussion. Blaikie (2010) further states that the semi-structured interview is considered one of the most effective tools for research in the qualitative approach and the use of discussion of the interview as a research method has been long valued in social science research. Semi-structured interviews can be seen as a more casual discussion rather than an interview, and even though the interviewer knows the scope of the topic, the discussion could go beyond that as the interviewees are given the freedom to broaden the discussion when appropriate (Fylan, 2005). Similarly, McIntosh and Morse (2015) state that semi-structured interviews have a unique structure that fits qualitative research, which is aimed to ascertain the participants' opinions and perspectives about particular topics. The same author further comments that attention to lived experience is one of the main benefits of the semi-structured interview while it also has potential to deal with the complexity of the research topic. Semi-structure interviews are useful for this study since it helped researcher to understand the participants' viewpoints with regards to the research aims. With consideration of the research aim and research questions, in-depth semi-structured interviews were adopted for this study.

\subsubsection{Likert Scale questions}

Likert scale questions are frequently used as a type of instrument to measure the affective variables such as motivation, self-confidence, and satisfaction since they allow researchers to collect a large amount of data with ease (Nemoto \& Beglar, 2014). These authors define the Likert scale as "a psychometric scale that has multiple categories from which respondents choose to indicate their opinions, attitudes, or feelings about a particular issue" (Nemoto \& Beglar, 2014; p.2). The positive points of Likert scale questions are that data could be collected from large pool of respondents without being time consuming, and the data collected could be used to compare, contrast, and be combined with qualitative data such as interviews to make a data-rich result (Bertram, 2007). Boone and Boone (2012) state that Likert scale data is analyzed using an interval measurement 
scale and descriptive statistics are recommended. This authors further comment that some of the analysis could be used including a mean for central tendency, the standard deviation for variability, Pearson's correlation, t-test, ANOVA, and regression. In this study, five-point Likert scale questions were used to examine the level of satisfaction and the sources of conflict. This kind of question is useful for this study because it is easy for participants to rate their perceptions on the level of satisfaction and sources of conflict with intermediaries.

\subsubsection{Document compilation}

Researcher gains lots of benefits from document analysis approach as it could provide significant information about the topic being studied and the literature (Punch, 2014). Punch (2014) suggests that document analysis does not only refer to written documents, but also audio and visual proof including film, TV programmes, and websites. This author states that prior to taking those documentary products to use in their research, the researcher needs to think of the credibility of the authors and how the articles are constructed.

In this study, secondary data or document compilation have been collected from various sources including from the government institutions and NGOs, and online material. Both published and unpublished data have been collected from the local newspapers, tourism reports from various stakeholders, and the Cambodian Ministry of Tourism. Some staff from this ministry were contacted to help to facilitate this process. Some other documents were collected from hotel websites and newspapers as well. These documents were helpful in understanding more about the research context of Cambodia hoteliers. It provides an overview of the current situation and the trend of the topic being studied.

\subsubsection{Respondent recruitment}

A stratified sampling approach was used in this study to collect data from interviewees. Participants were divided into smaller non-overlapping sub-groups (strata), and a simple random sample was used from each group. The strata for this research were 3, 4, and 5-star hotels in three different destinations in Siem Reap, Phnom Penh, and Sihanoukville in Cambodia. To reduce 
sampling error, the sampling fraction from each sub-group was collected proportionately to each category of hotels in each of the above three regions. Because Cambodia does not have an official star ranking for hotels, the researcher used star ranking on Booking.com and Agoda websites as the medium through which to select hotels which are categorized into those rankings. So, hotels with the matching characteristics were contacted, and potential participants from these hotels who responded to the researcher were selected for interviews.

Before conducting the fieldwork, the researcher sent an interview invitation email to 70 selected hotels from mid-range to upscale categories in Siem Reap, Phnom Penh, and Sihanoukville. The numbers of selected hotels were chosen proportionately between each destination to make the balance as well as the numbers of hotels in each category. The interview invitation email came with the description and purpose of the research, as well as a consent form to participate. The targeted participants from those hotels were Sales Managers, Directors, or General Managers who could describe the level of satisfaction and potential sources of conflict of their hotels with traditional and online intermediaries. The researcher asked permission from the participants to record the interview and use it for citing the reference in the research project. The interviewees were assured that the privacy of the information was guaranteed. All the digitally recorded interview files were saved on the author's personal computer by setting up a locked folder to make sure confidentiality was protected. The interviews were conducted both in English and Khmer (Cambodian). English was used when interviewing foreign participants, and Khmer was used when interviewing Cambodian participants. Out of the 70 contacted individuals, 42 were recruited for the interview with a response rate of $60 \%$ (see Table 3.4). The rejection rate was $40 \%$ of those invited to participate. The respondents were categorized based on hotel attributes and the respondents' backgrounds (see Table 3.2).

Table 3.1 Response rate of participants

\begin{tabular}{|l|l|l|}
\hline Recruitment & Number & Percentage (\%) \\
\hline Invited & 70 & $100 \%$ \\
\hline Accepted & 42 & $60 \%$ \\
\hline Declined & 28 & $40 \%$ \\
\hline
\end{tabular}


Table 3.2 Respondent categorization based on hotel attributes and backgrounds

\begin{tabular}{|c|c|c|c|}
\hline \multicolumn{2}{|c|}{ Hotel Attributes } & \multirow{2}{*}{$\begin{array}{r}\text { Number } \\
7\end{array}$} & Total \\
\hline \multirow{3}{*}{ Category of hotels } & 3-star hotel & & \multirow{15}{*}{42} \\
\hline & 4-star hotel & 17 & \\
\hline & 5-star hotel & 18 & \\
\hline \multirow{3}{*}{ Location } & Siem Reap & 21 & \\
\hline & Phnom Penh & 15 & \\
\hline & Sihanoukville & 6 & \\
\hline \multirow{3}{*}{ Ownership } & $\begin{array}{l}\text { Cambodian } \\
\text { ownership }\end{array}$ & 27 & \\
\hline & $\begin{array}{l}\text { Partnership of } \\
\text { Cambodian and } \\
\text { foreigner }\end{array}$ & 8 & \\
\hline & $\begin{array}{l}\text { Foreign } \\
\text { ownership }\end{array}$ & 7 & \\
\hline \multirow{3}{*}{ Hotel Size } & Small (1-50 rooms) & 19 & \\
\hline & Medium (51-120 rooms) & 11 & \\
\hline & Large (above 120 rooms) & 12 & \\
\hline \multirow{3}{*}{ Hotel Age } & New $(1-3$ years $)$ & 13 & \\
\hline & Average (4-10 years) & 17 & \\
\hline & Old (above 10 years) & 12 & \\
\hline \multicolumn{2}{|c|}{ Respondents' background } & Number & Total \\
\hline \multirow{2}{*}{$\begin{array}{l}\text { Respondents' job } \\
\text { title }\end{array}$} & General Manager & 20 & \multirow{4}{*}{42} \\
\hline & Sales Manager & 22 & \\
\hline \multirow{2}{*}{ Nationalities } & Cambodian & 33 & \\
\hline & Foreigner & 9 & \\
\hline
\end{tabular}

\subsection{Data analysis}

In this study, mixed methods were used to analyze the data in which qualitative and quantitative data are used to cross check each other. 
Some questions in the interview are in the form of a Likert scale, and they were used for quantitative analysis. It provides a comprehensive understanding of a distribution channel study, especially related to the level of satisfaction and perception on the sources of conflict. Statistical Package of Social Science (SPSS) is typically selected for data analysis. The questions are divided into two parts: open-ended and close-ended questions. There are many steps in doing quantitative analysis, but some of the main steps involve providing a descriptive analysis of data independent of, and dependent on, the study. The analysis illustrates the means, standard deviations, and range of scores for the variables (Creswell, 2014). Descriptive analysis may not be enough for some research and going beyond that by identifying appropriate statistical analysis (i.e., factor analysis) is recommended.

In this study, descriptive analysis is conducted for the early part of the findings and further statistical analysis was chosen as well. The findings were illustrated in table form and are useful to support the study. Triangulation is vital to verify the responses from the interviews.

One-way Analysis of Variance (ANOVA) is used in this analysis to compare differences between the means of more than two groups. In this study, one-way ANOVA is used to compare different means of variance among various groups such as by category of hotels, location, ownership, and hotel size to identify if there is any statistical significance among these groups. The Tukey's HSD post hoc test is used to analyze further differences identified through ANOVA. Also, the Independent and Paired sample t-test were adopted to compare the differences between the two variances. The confidence level for both tests is set to be $95 \%$, which means that it is statistically significant when the p-value is less than 0.05 . Furthermore, Pearson's correlation is used to assess connection between two variables and explain whether there is a linear relationship between them.

Apart from quantitative analysis, this study also adopts qualitative analysis. Qualitative data analysis aims to make sense of the scripts and image data collected, and it is involved with dividing and taking apart the data. Since the text and image data are so dense and rich, not all the information can be used in quantitative research (Creswell, 2014). The author used thematic techniques to aggregate data into a small number of themes, which have common or similar ideas. Thematic analysis is more relevant to this research project because based on the research questions, the data 
needs to be reviewed repeatedly in order to find trends which convey the participants' interviews. The interview is the main data collection technique. For this thesis, all interviews were conducted in Khmer and English. All digitally recorded interviews were transcribed and translated by the researcher.

\subsection{Analytical framework}

An analytical framework is crucial for data analysis since it simplifies the data analysis structure and helps readers to understand the findings clearly (Pearce, 2012). Pearce comments that analyzing data could be more ambiguous and problematic without a clear analytical framework and could mean that the findings are lengthier than they should be. For this study, figure 3.6 illustrates the analytical framework for the study and the data analysis is divided into two phases: overall case and cross-case analyses.

Firstly, the analytical framework is helpful for the author to see the sequential steps for data analysis which consists of two phases and three steps. Second, this process eventually aims to answer the three main research objectives of the study. 
Figure 3.2: Analytical Framework

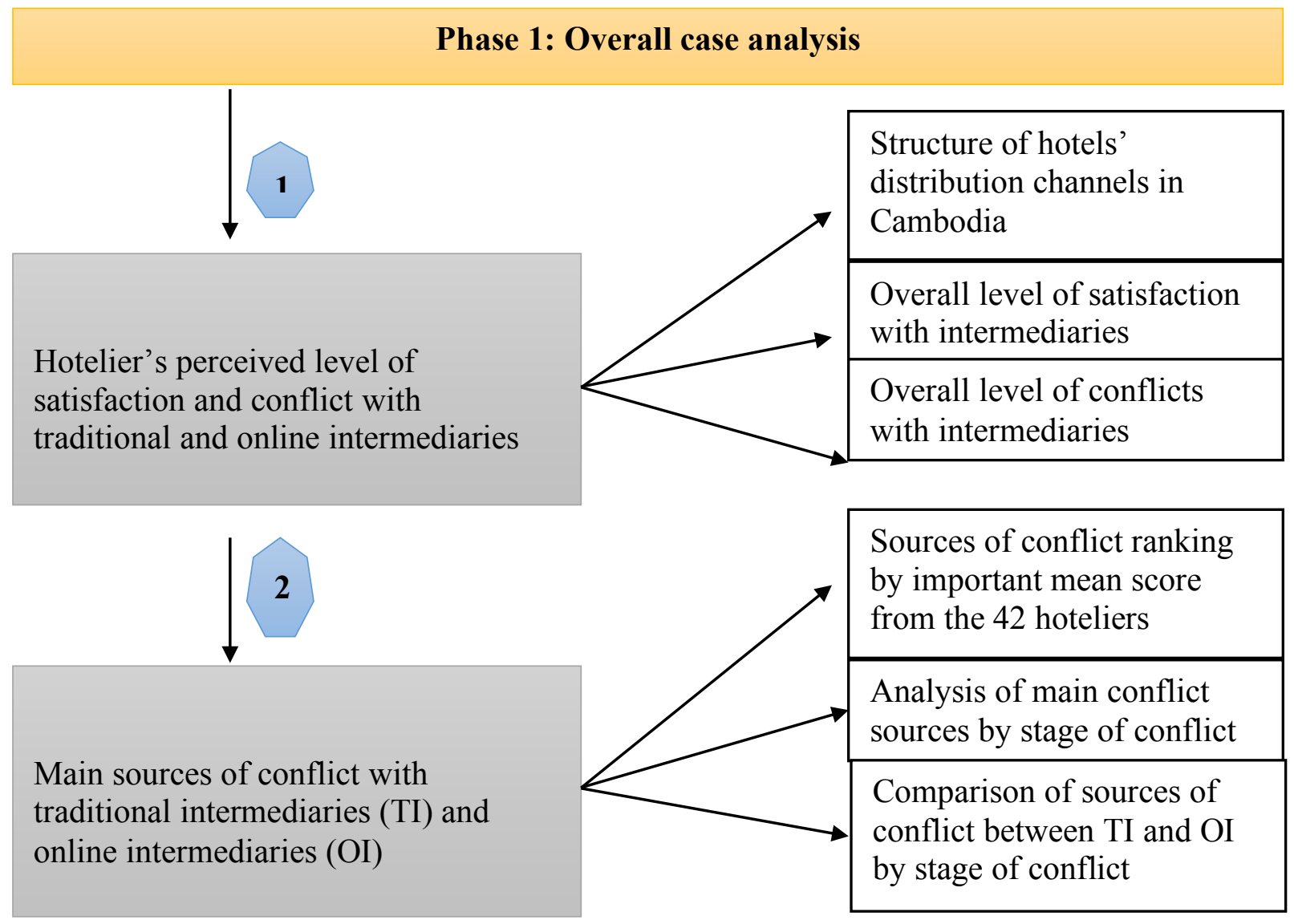

\section{Phase 2: Cross-case analysis}

\begin{tabular}{l}
$\begin{array}{l}\text { Comparison of hotelier's } \\
\text { perceived sources of } \\
\text { conflict by hotel } \\
\text { attributes and hotel } \\
\text { operators' backgrounds }\end{array}$ \\
$\begin{array}{l}\text { Hotel } \\
\text { attributes }\end{array}$ \\
$\begin{array}{l}\text { Hotel } \\
\text { operators' } \\
\text { backgrounds }\end{array}$ \\
ownership \\
\hline $\begin{array}{l}\text { Comparison by hotel's size } \\
\text { category }\end{array}$ \\
\hline $\begin{array}{l}\text { Comparison by hotel's age } \\
\text { location }\end{array}$ \\
\hline $\begin{array}{l}\text { Comparison by respondents' } \\
\text { job titles }\end{array}$ \\
\hline $\begin{array}{l}\text { Comparison by respondents' } \\
\text { nationalities }\end{array}$ \\
\hline
\end{tabular}




\subsection{Ethical consideration}

Ethics approval from Victoria University of Wellington was required for this research before the data collection could start. Some interview questions could lead to a certain degree of risk for participants and interviewer. To some extent, the process of exploring hotelier distribution channels and their level of satisfaction with intermediaries could involve sensitive information, which may affect the participants or their organizations. To protect both parties, the researcher had to go through the Ethics approval process before conducting the fieldwork. The author of the current study applied for Ethics approval from the Pipitea Human Ethics Committee at Victoria University of Wellington in August 2018 and his application was approved later on that month after making some suggested amendments from the committee.

Confidentiality and informed consent are usually discussed in qualitative research. The researcher provides assurance to the participants that the information collected will be protected and not be revealed to any third-party (Punch, 2014). For the current study, participants were referred to by their roles within each organization rather than their real names in order to protect their identities.

The participants were provided with a consent form and information sheet prior to their interview. They were asked to read the information carefully before participation. Before the interview began, the author reconfirmed verbally with all the necessary information they needed to understand and the agreement within the consent form. The author also requested permission to audio record the interview and for the participant to sign the consent form, which allowed the author to use the information collected in the report.

\subsection{Strengths and limitations}

Mixed methods were used for this study, and it was one of the strengths which helped to investigate the research objective of the perceived level of satisfaction and sources of conflict of hoteliers in Cambodia with intermediaries. The study employed in-depth semi-structured interviews with embedded questions from the Likert scale to gain in-depth insight from the participants on the research topic. This approach was deemed appropriate to investigate the issues of this study. 
Another strength of this research design was the inclusion of the three main tourist destinations in Cambodia in which most hotels are located. Siem Reap, Phnom Penh, and Sihanoukville are the main tourist destinations each with their own characteristics: leisure, business, and coastal tourism respectively. Most of the hotels in Cambodia are located in these three destinations, and this inclusion is helpful for data collection to represent Cambodia as the research context. The three regions attract different types of tourists. Many hotels were recruited in each location from midrange to upscale ranking, and each of them represented a different ranking group. To obtain richdetailed information, participants in managerial positions were invited for interviews including Sales Managers, Directors or General Managers of hotels.

However, some limitations should be acknowledged for this study. First, the research involved a small sample data collection due to time and financial constraints. Only 42 hotels were recruited for this study so it could not represent the overall population of more than 700 hotels in these three cities. Guest houses are counted separately from these 700 hotels. This study focuses only on 3-5 star hotels and from these 700 hotels there might be some budget hotels counted in as well. Another issue with an in-depth semi-structured interview should be noted as well. Due to the confidentiality of the information, some managers refused to answer some sensitive questions in order to protect their businesses. So, some participants could not provide full and detailed answers to the questions. Similarly, there were fewer participants in Sihanoukville by comparison to the other two destinations due to time constraint and the lack of willingness to participate from new hoteliers who are mainly Chinese investors. Sihanoukville received an influx of Chinese investors in the last two years who invested in casinos and hotels.

\subsection{Chapter summary}

This chapter discusses the research methodology that is adopted to conduct this study. The research used pragmatism paradigm and the research approach is mixed methods. In-depth semi-structured interview is adopted with embedded Likert scale questions for respondents to rate their perceptions. Secondary data was also collected for document analysis for this study. Forty-two respondents were interviewed in three different regions in Cambodia including Siem Reap, Phnom Penh, and Sihanoukville. Regarding data analysis, some of statistical tests were used including 
ANOVA test, Pearson correlation test, Independent sample t-test, and Paired sample t-test. Analytical framework has been proposed as a guide for data analysis.

Chapter 4 covers the first part of the findings for this research. It examines hotels' distribution channels in Cambodia, and the level of satisfaction and sources of conflicts. 


\section{Chapter 4: Level of satisfaction and sources of conflict}

\subsection{Introduction}

This chapter describes the findings of the questionnaire that dealt with various aspects of tourism distribution channels in three tourist destinations of Cambodia including the perceived level of satisfaction of hoteliers with their intermediaries as well as the perceived sources of conflict that they confront in the day-to-day operations with traditional intermediaries (TI) and online intermediaries (OI).

First, the overall structure of hotel distribution channels in Cambodia is presented. This latter is based on participants' feedback from three hotel categories (3, 4, and 5-star hotels) in three regions (Siem Reap, Phnom Penh, and Sihanoukville).

This chapter also assesses the overall perceived level of satisfaction of hoteliers as well as the sources of conflict that they have experienced on a daily basis with traditional and online intermediaries. Comparisons are also conducted by using Paired sample t-test.

As discussed in the literature review, the sources of conflict include price level, commission, price-quality ratio, release period, fulfillment of contract conditions, provision of information, booking details, cancellation terms, operation errors, overbooking, payment, and complaint handlings.

\subsection{Hotels and respondent profiles}

Forty-two hoteliers agreed to participate in this study. Their hotels are located in Siem Reap, Phnom Penh, and Sihanoukville and range from three to five stars. The invitations were sent to about 70 hotels belonging to the three categories in these three cities and the response rate was around $60 \%$ of the targeted hotels. 
All the interviews were transcribed and coded using Nvivo software and part of the surveys were imported to SPSS software for analysis. From the data analysis, the data were categorized into different groups such as the location of hotels, category, ownership, hotel size, hotel age, respondents' job titles, and respondents' nationalities. A comparison of the perceived level of satisfaction of hoteliers with their intermediaries and the potential sources of conflict have been performed among these identified groups and quotations from respondents have been provided throughout the chapter in order to support our findings. For the purpose of confidentiality, respondents are coded by number: from 1 to 42, for example, Respondent\#1, Respondent\#2, and up to Respondent $\# 42$.

\subsection{Overall analysis}

In this section, we present the overall findings from our 42 respondents without taking into account hotel attributes and respondents' job titles and nationalities. The first part explores the nature of hotel distribution channels used by hotels in Cambodia. In the second part, an assessment of the overall perceived level of satisfaction of hoteliers with intermediaries. Finally, we investigate the potential sources of conflict with intermediaries.

\subsubsection{Hoteliers' distribution channels in Cambodia}

According to the interviewed participants, each hotel tends to have its own chosen distribution channels. Moreover, the location of hotels could affect the way how hoteliers choose their intermediaries and sell their rooms and services to the targeted guests. For hotels in Siem Reap, their main distribution channels are both traditional and online intermediaries such as foreign tour operators, local travel agencies, wholesalers, inbound operators, Agoda, Booking.com, Expedia, Hotels.com, and Ctrip.

For instance, respondent \#3 from Siem Reap commented on his choice of distribution:

"We work with both traditional and online intermediaries for our room distribution. For traditional intermediaries, we closely work with inbound operators, local travel agencies, 
foreign tour operators. Apart from that we also have international Event Organizers which is not under any kind of travel agency or tour operator, and MICE (Meetings, Incentives, Conference, and Events). For online intermediaries, we have Booking.com, Expedia, Hotels.com, and Agoda. Besides this, we see that Ctrip is rising very fast recently, and they became the main competitor on the market. Hotelbeds, Gullivers Travel Associates (GTA) are also major players."

Respondent\#3 from Siem Reap region showed that his hotel's distribution channels depend on traditional and online intermediaries, but he differentiates his preferences according to the markets that he targets. He mentioned that while some hotels still prefer working with traditional intermediaries, some new small hotels were more keen in collaborating with online intermediaries because it is easier to manage their room allotment and there are also more choices with online intermediaries. Some of the new online intermediaries that were widely used by hotels in Siem Reap were Ctrip, Booking.com, Agoda, Expedia, Gullivers Travel Associates (GTA), and Hotelbeds.

The respondents from Phnom Penh also expressed a similar structure of distribution channels, although they mention different features as well. On top of traditional and online intermediaries, hey also rely heavily on corporate segments which are mainly businesses, government, and nongovernment organizations.

Respondent \#22 expressed his view on how he sells his hotel's rooms:

"We are cooperating closely with traditional intermediaries such as wholesalers, inbound operators, local travel agencies, and foreign tour operators. Also, we work with corporate accounts which include NGOs, embassies, companies, and Governments. For online intermediaries, we have Agoda, Booking.com, Expedia, Hotels.com, Ctrip, and GTA (Gullivers Travel Associates).”

This statement shows that this hotelier relies on traditional intermediaries including travel agencies, foreign tour operators, and wholesalers. While at the same time, he also works closely 
with several online intermediaries including Ctrip, Rakuten which specializes in Chinese and Japanese tourists respectively. Interestingly, he said that several hoteliers in Phnom Penh also deal directly with the corporate segment entitled "Corporate Accounts" besides traditional and online intermediaries. This corporate segment includes business companies, Non-Governmental Organizations, Embassies, and Ministries.

Similar to Siem Reap, Sihanoukville hotels also relied on traditional and online intermediaries. Some hotels work smoothly with, for example, Ctrip while others may work better with Expedia. However, most hotels choose to work with as many intermediaries as possible to maximize their room distribution.

For example, respondent\#37 from Sihanoukville described his sales strategy as follows:

"We worked with both traditional and online intermediaries. So, we work with foreign tour companies, local travel agencies, wholesalers, inbound operators as well. For online intermediaries, we work with Agoda, Booking.com, Hotels.com, Rakuten (Japanese markets), Orbitz (American), Wetu (South African), TripAdvisor, and Facebook but not too much. We also work with Expedia, and Expedia itself has expanded into China under the affiliate Ctrip and Trip.com [...] We also worked with HRH which is a hotel reservation system. We also worked with, obviously Booking Button, which is our booking system, Hotel Exchange, and also the one in Singapore called Travel Liko. So that is a new Singapore company that does not charge commission."

This respondent explained how he sells his hotels' rooms via different channels which work best for him. This hotelier seems to diversify his distribution channels so that he could sell the maximum number of available rooms. He commented that while some hotels are heavily dependant on online intermediaries, some are balancing between traditional and online intermediaries. 
Figure 4.3 illustrates the different types of hotel distribution channels used by hotels in Cambodia which rely on traditional and online intermediaries as well as the corporate segment. These three channels are the main sources of distribution channels for hoteliers in Cambodia. 
Figure 4.1: Hotel distribution

channels in Cambodia
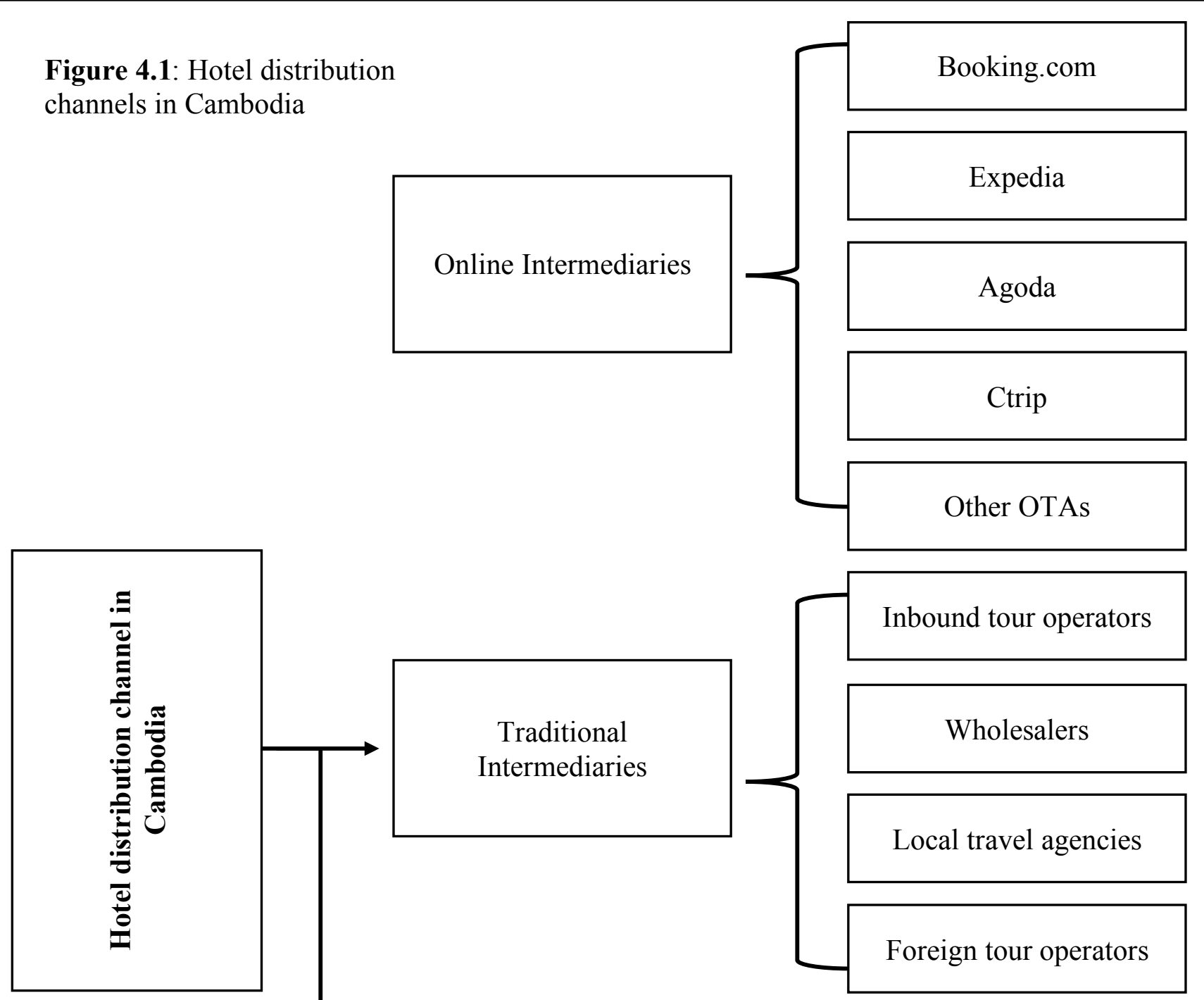

Foreign tour operators
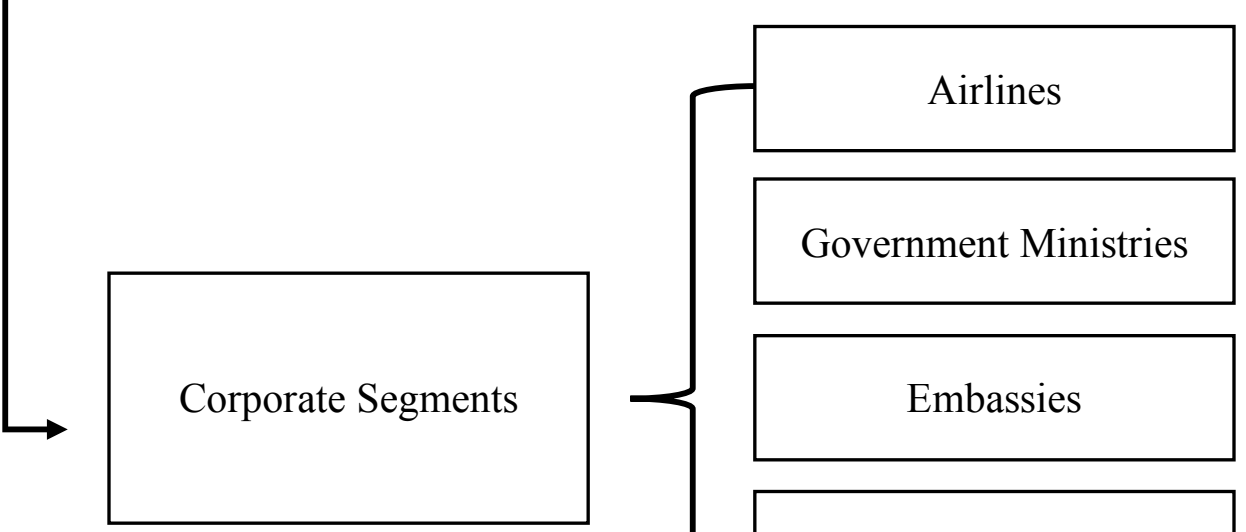

Government Ministries

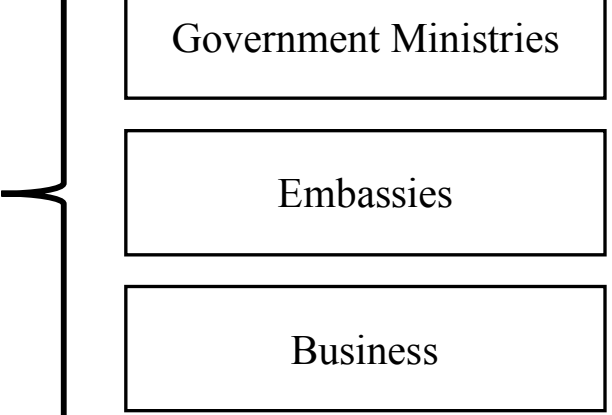

NGOs 


\subsubsection{A comparison of hoteliers' satisfaction with intermediaries}

This section assesses the hoteliers' satisfaction with their relationships with traditional intermediaries (TI) and online intermediaries (OI) by examining the mean scores, standard deviation, and the Paired sample t-test. We first asked the respondent to provide an overview of their relationship with intermediaries by using a five-point Likert scale ranged from extremely bad (1) to extremely good (5).

Table 4.1 The overall respondents' rating on the level of satisfaction with TI and OI

\begin{tabular}{lcccccc}
\hline & \multicolumn{5}{c}{ Total } & \\
\cline { 2 - 5 } & $\mathrm{N}$ & Min. & Max. & Mean & Std. & Paired sample t-test \\
\hline $\begin{array}{l}\text { Level of satisfaction } \\
\text { with TI }\end{array}$ & 40 & 3 & 5 & 4.13 & .723 & \\
\hline $\begin{array}{l}\text { Level of satisfaction } \\
\text { with OI }\end{array}$ & 42 & 2 & 5 & 4.00 & .765 & \\
& & & & & & \\
\end{tabular}

Note: A five-point Likert Scale of the perceived level of satisfaction from 1: Extremely bad, 2: Somewhat bad, 3: Neither good nor bad, 4: Somewhat good, 5: Extremely good

The information presented in Table 4.1 shows the mean scores, minimum, maximum, and standard deviation of the total respondents' ratings on the relationships with traditional and online intermediaries. Mean scores of the total respondents' ratings on these two types of levels of satisfaction ranged from 4.0 to 4.13 , and the scores are rated from a minimum of 2 to a maximum of 5 .

The mean score of the overall level of satisfaction with TI is 4.13, which is above the mid-point of the scale $(3=$ Neither good nor bad). Therefore, hoteliers in Cambodia seem to have good relationships with TI since the overall score is considered "somewhat good" which illustrates a healthy level of satisfaction. 
For example, respondents \#7 of 4-star hotel from Siem Reap explained his positive level of satisfaction with traditional intermediaries.:

"We have an extremely good relationship with traditional intermediaries. The factors that help our good relationship with them is the real relationship which I refer to as a business relationship. Because a business relationship makes you stay ahead of the competitors. However, first, you need to stick to your good service, and we do the promotion with real loyalty, and we gain this as the advantages in the relationship. So, when traditional intermediaries have prospective guests, they always prioritize us, and it helps us always to get a high chance of receiving the business."

Likewise, the mean score of their level of satisfaction with online intermediaries is 4.0 which is also above the mid-point of the scale $(3=$ Neither good nor bad). The rating ranged from a minimum score of 2 to a maximum score of 5. Hence, the overall level of satisfaction of hoteliers with online intermediaries is assumed to be "Somewhat Good." It is evident that some of the most important factors which contribute to this level of satisfaction are the speed of actions from online intermediaries, good reviews, service consistency, and knowledge of the products.

For instance, respondent\#22 from Phnom Penh seems to have a very positive attitude toward her collaboration with online intermediaries:

"For us, it is number 5: extremely good. One of the factors of the good relationship with online intermediaries is property promotion, and the second is business support, and the third is understanding the markets and strategy. So, this is the same as I have mentioned before that normally we come up with some suggestions with online intermediaries, and they always come back to us if we can do it or not. So, if we can do, we will proceed with that path."

Table 4.1 above also presented a Paired sample t-test, which was conducted to compare the level of satisfaction that hoteliers have with traditional versus online intermediaries. Our result presented showed that there is no significant difference in the responses to the level of satisfaction of hoteliers 
with traditional intermediaries $(\mathrm{M}=4.13, \mathrm{SD}=0.723)$ and online intermediaries $(\mathrm{M}=4.00, \mathrm{SD}=$ $0.765) ; t(39)=0.947, p=0.349$. These results suggest that the scale of satisfaction level that hoteliers have with traditional and online intermediaries are quite similar, which is in between "somewhat good" and "extremely good."

The next section examines the potential frequency of conflicts, which hoteliers experienced with traditional and online intermediaries.

\subsubsection{Potential frequency of conflicts with intermediaries}

Forty-two respondents were asked to rate the potential frequency of conflicts with traditional intermediaries (TI) and online intermediaries (OI) by using a five-point Likert scale ranging from never (1) to always (5). This section describes the overall potential frequency of conflicts of hoteliers with traditional and online intermediaries by examining the mean scores, standard deviation, and the Paired sample t-test.

Table 4.2 Main findings of overall sources of conflict with TI and OI

\begin{tabular}{lcccccc}
\hline & \multicolumn{5}{c}{ Total } \\
& $\mathrm{N}$ & Min. & Max. & Mean & Std. & Paired sample t-test \\
\cline { 2 - 6 } & 40 & 1 & 5 & 2.38 & .807 & \\
\hline $\begin{array}{l}\text { Conflict with } \\
\text { traditional } \\
\text { intermediaries }\end{array}$ & & & & & & \\
Conflict with & & & & & & \\
online & 42 & 1 & 5 & 2.40 & .964 & \\
intermediaries & & & & & & \\
\hline
\end{tabular}

Note: A five-point Likert Scale of perceived conflict from 1: never, 2: sometimes, 3: about half of the time, 4: most of the time, 5: always. 
Table 4.2 illustrates the mean scores, minimum, maximum, and standard deviation of the total respondents on the potential frequency of conflicts with TI and OI. The obtained mean scores varied between 2.38 and 2.40 respectively. The mean score rating of the respondents for the potential frequency of conflicts with TI is 2.38 which is just about below the mid-point of the scale $(3=$ About half of the time). The total valid number of respondents for TI was 40 because two hoteliers do not conduct business with TI. The minimum score rating was 1 , and the maximum score rating was 5. Thus, the frequency of potential conflicts of hoteliers with TI is in between "Sometimes" and "About half of the time." Among the perceived factors that have caused some conflicts with TI are late payment, rate parity between traditional and online intermediaries, miscommunication, overbooking, and cancellation.

For example, in the following quotation, respondent $\# 37$ raised some potential of conflicts that his hotel faced with TI:

"We experience conflicts with traditional intermediaries all the time. Most of it has to do with rate parity. So, travel agencies employed somebody to sit there and see the rate online cheaper and what you have offered them. So, other complaints from travel agencies are the miscommunication, for instance, room category. They expect the sea-view room in their booking, but they do not get the sea-view room when they are here, and they start complaining. Another problem is with payment. Most of the big companies usually get credit, and they are the worst for payment usually.

Regarding the potential frequency of conflicts with online intermediaries (OI), table 4.2 shows that a mean score of 2.40 which is just below the mid-point of the scale ( $3=$ About half of the time). The total valid number of respondents was 42 which illustrates that all our respondents use OI as a main channel of distribution of their hotels' rooms. The minimum score rating for potential frequency of conflicts with online intermediaries was 1 , and the maximum was 5 . The mean score of 2.40 illustrates the fact that the frequency of conflicts between hoteliers and OI is in between "Sometimes" and "About half of the time."

For instance, the response from respondent \#26 supported these findings: 
"We had conflicts with online intermediaries several times. One of the highest disputes with hoteliers and online intermediaries is rate parity. Rate parity means that we sign the agreement that we are supposed to sell the same price with all online travel agencies (online intermediaries). From our side as a hotel, we have our devices and software to regulate this and there should not be any problems with the rates-the rate selling to ourselves and the rate selling to online intermediaries is the same. However, in the online intermediary worlds [...] some online intermediaries manipulate this. Moreover, we spend most of our time fixing this because when other online intermediaries see these differences, they will complain to us."

Most of the interviewees suggested that potential conflicts with OI were around rate parity, wrong channel promotion, dishonest marketing strategy, allotment provision, personal relationship, and lack of quick support from online intermediaries' teams. Dishonest marketing strategy such as manipulation on conversion rate, undercut their own commission on some markets or regions are typically the cause that triggers the conflicts. Among all factors, rate parity is the most dominant one who has been raised by most hoteliers. Rate parity signifies that hoteliers need to sell their rooms at the same rate in all online platforms. Hoteliers claimed that they usually sell their rooms at the same price to all online intermediaries but sometimes problems occur when some online intermediaries manipulate the price, and their competitors report that to hotels.

A Paired Sample T-test was conducted to compare the overall frequency of conflicts that hoteliers have with TI and OI. Table 4.2 shows that there is no significant difference in the responses to the conflicts of hoteliers with traditional intermediaries $(\mathrm{M}=2.38, \mathrm{SD}=0.807)$ and online intermediaries $(\mathrm{M}=2.40, \mathrm{SD}=0.964) ; \mathrm{t}(39)=0.00, \mathrm{p}=1.00$. This result indicates that the frequency of hoteliers having conflicts with TI and OI is roughly the same which is in between "sometimes" and "about half of the time."

The following quotation from respondent\#2 expresses this point of view regarding the potential frequency of conflicts between a hotelier and its intermediaries: 
"Of course, we have problems with traditional intermediaries about half of the time. We have two kinds of conflict. First, the problem involves with guests, for example, the guest was promised a different experience than he/she gets, so this can come from different responsibility. The second one, of course, the conflict with payment. Most of the time it happens with liquidations in the travel industry. For online intermediaries, about half of the time we have conflicts with them. It is usually about the promotion. For example, we have five online intermediaries, and we do the same promotions with them, but one or two online intermediaries that sell a few dollars difference because of their tax calculation in their systems."

The respondent above has described the frequency of his hotel having conflicts with traditional and online intermediaries, which occurred about half of the time. While the overall frequency of conflicts that they have are quite similar, the nature of the conflicts seems different; for example, traditional intermediaries may experience more conflict with payment while online intermediaries may face price parity.

As discussed in chapter 2, sources of conflict have been introduced. In the following section, we assess the potential sources of conflict by investigating four stages of conflicts including contract stage, pre-stay stage, stay stage, and post-stay stage.

\subsubsection{Potential sources of conflict by stage of conflicts}

This part analyzes the potential sources of conflict that hoteliers have faced with intermediaries over different stages of their collaboration with intermediaries. In order to compare the nature and the frequency of conflicts that hoteliers come across with traditional and online intermediaries, we classify the sources of conflict by mode of distribution channels. These conflicts are also discussed by stage of conflicts such as contract stage, pre-stay stage, stay stage, and post-stay stage. As presented in Table 4.3, there are 12 potential sources of conflict over the four stages of conflicts that have been discussed by (Ivanov et al., 2014). 
Table 4.3 The potential sources of conflict by stage of conflicts

\begin{tabular}{|c|c|}
\hline $\begin{array}{l}\text { Stage of } \\
\text { conflict }\end{array}$ & $\begin{array}{l}\text { Sources of } \\
\text { potential conflicts }\end{array}$ \\
\hline \multirow{5}{*}{$\begin{array}{l}\text { Contract } \\
\text { Stage }\end{array}$} & Price Level \\
\hline & Commission \\
\hline & Price-Quality Ratio \\
\hline & Release Period \\
\hline & $\begin{array}{l}\text { Fulfillment of } \\
\text { contract Conditions }\end{array}$ \\
\hline \multirow{3}{*}{$\begin{array}{l}\text { Pre-stay } \\
\text { Stage }\end{array}$} & $\begin{array}{l}\text { Information } \\
\text { provision }\end{array}$ \\
\hline & Booking details \\
\hline & $\begin{array}{l}\text { Cancellation } \\
\text { Terms Compliance }\end{array}$ \\
\hline \multirow[b]{2}{*}{$\begin{array}{l}\text { Stay } \\
\text { Stage }\end{array}$} & Operation Errors \\
\hline & Overbooking \\
\hline \multirow[b]{2}{*}{$\begin{array}{l}\text { Post-stay } \\
\text { Stage }\end{array}$} & Payment \\
\hline & Complaint handling \\
\hline
\end{tabular}

The section below assesses the hierarchy of common potential sources of conflict by mode of distribution channel from the most to least common sources of conflict over the different stages of the business cycle between hoteliers and their intermediaries.

\subsubsection{Hierarchy of common potential sources of conflict between hoteliers and traditional and online intermediaries}


Table 4.4 below illustrates the ranking of potential conflict factors experienced by hoteliers in Cambodia. Our findings show that price level, payment, and price-quality ratio are among the most common sources of conflict that hoteliers in Cambodia have faced with TI. On the contrary, the least common sources of conflict with TI are issues around booking details, commission, and overbooking. With regards to OI, the most common sources of conflict is the same as traditional intermediaries - price level is the most common one. However, overbooking and complaint handling were second and third respectively while overbooking was in the least problematic with TI. Fulfillment of contract conditions, booking details, and the commission were among the least problematic factors with OI.

Table 4.4 The hierarchy of perceived related sources of conflict with TI and OI

\begin{tabular}{|c|c|c|c|c|c|c|c|c|}
\hline \multicolumn{5}{|c|}{ Potential conflict factor ranking (TI) } & \multicolumn{4}{|c|}{$\begin{array}{l}\text { Potential conflict factor } \\
\text { ranking }(\mathrm{OI})\end{array}$} \\
\hline Factors & $\mathbf{N}$ & Mean & SD & Ranking & $\mathbf{N}$ & Mean & SD & Ranking \\
\hline Price Level & 40 & 2.53 & 1.261 & 1 & 42 & 2.6 & 1.27 & 1 \\
\hline Payment & 40 & 2.2 & 1.043 & 2 & 42 & 1.71 & 0.97 & 7 \\
\hline Price-Quality Ratio & 40 & 2.08 & 1.185 & 3 & 42 & 1.81 & 1.018 & 6 \\
\hline Complaint Handling & 40 & 1.9 & 0.709 & 4 & 42 & 2.19 & 0.833 & 3 \\
\hline $\begin{array}{l}\text { Cancellation Terms } \\
\text { Compliance }\end{array}$ & 40 & 1.87 & 1.067 & 5 & 42 & 1.71 & 1.066 & 8 \\
\hline Release Period & 40 & 1.8 & 1.091 & 6 & 42 & 1.83 & 0.986 & 5 \\
\hline $\begin{array}{l}\text { Fulfillment of contract } \\
\text { Conditions }\end{array}$ & 40 & 1.75 & 0.981 & 7 & 42 & 1.5 & 0.994 & 12 \\
\hline Operation Errors & 40 & 1.65 & 0.58 & 8 & 42 & 1.93 & 0.867 & 4 \\
\hline Information Provision & 40 & 1.53 & 0.679 & 9 & 42 & 1.69 & 0.924 & 9 \\
\hline Booking Details & 40 & 1.47 & 0.716 & 10 & 42 & 1.55 & 0.861 & 11 \\
\hline Commission & 40 & 1.45 & 1.037 & 11 & 42 & 1.57 & 0.859 & 10 \\
\hline Overbooking & 40 & 1.45 & 0.552 & 12 & 42 & 2.26 & 1.17 & 2 \\
\hline
\end{tabular}


Note: A five-point Likert Scale of perceived conflict factors: Extremely Unlikely (1), Somewhat Unlikely (2), Neither Likely nor Unlikely (3), Somewhat Likely (4), Extremely Likely (5).

The following section addresses the sources of conflict by stage of conflicts as well as the differences between traditional and online intermediaries.

\subsubsection{Contract stage of conflicts: A comparison of sources of conflict}

As discussed in the literature review, the contract stage is likely to be the primary source of potential conflict between hoteliers and intermediaries (Ivanov et al., 2014). This stage deals mainly with price issues (price level, commission, price/quality ratio), release periods, and general terms conditions (fulfillment of contract conditions). As shown in Table 4.5, the analysis focuses on the sources of conflict during the contract stage and assesses the mean scores, standard deviations, hierarchy within each stage of conflicts and Paired sample t-test.

Table 4.5 shows the hierarchy of sources of conflict at the contract stage between hoteliers and their two distribution channels (TI and OT). These include price level, commission, price-quality ratio, and fulfillment of contract conditions. Paired sample t-test were conducted to compare the significance of each sources of conflict between TI and OI. The hierarchy presented in Table 4.5 is based on the internal ranking among the five sources of conflict at this contract stage. It ranged from 1 to 5 depending on the mean scores.

Pair 1 (Price level between TI and OI): The mean scores of both intermediaries are quite similar. Price level was ranked the top with the highest mean score among the five sources of conflict for both TI and OI. This shows that price level tends to cause hoteliers more conflicts with TI and OI than any other factor such as commission, price-quality ratio, release period, and fulfillment of contract conditions. The mean score is $2.53(\mathrm{M}=2.53, \mathrm{SD}=1.261)$ regarding the frequency of price level conflict with TI while its value is $2.60(\mathrm{M}=2.60, \mathrm{SD}=1.270)$ regarding OI. This latter was the highest one among the above five sources of conflict. Most respondents mentioned "somewhat unlikely" or "Neither likely nor unlikely" that this sources of conflict causes conflicts with TI and OI. 
Table 4.5 Main findings of common sources of conflict at the contract stage of conflicts

\begin{tabular}{|c|c|c|c|c|c|}
\hline Conflict & $\begin{array}{l}\mathrm{TI}^{*} \\
\text { or } \\
\mathrm{OI}^{* *}\end{array}$ & $\begin{array}{l}\text { Mean } \\
\text { (Std.) }\end{array}$ & Ranking & $\begin{array}{c}\text { Mean } \\
\text { difference } \\
{[95 \% \mathrm{CI}]}\end{array}$ & Paired t-test results \\
\hline \multirow[b]{2}{*}{ Price Level } & TI & $2.53(1.261)$ & 1 & -0.05 & \multirow[b]{2}{*}{$t(39)=-0.213, p=0.832$} \\
\hline & OI & $2.60(1.270)$ & 1 & {$[-0.525,0.425]$} & \\
\hline \multirow{2}{*}{ Commission } & TI & $1.45(1.037)$ & 5 & -.125 & \multirow{2}{*}{$t(39)=-0.682, p=0.499$} \\
\hline & $\mathrm{OI}$ & $1.57(0.859)$ & 4 & {$[-0.496,0.246]$} & \\
\hline \multirow{2}{*}{$\begin{array}{l}\text { Price } \\
\text { Quality ratio }\end{array}$} & TI & $2.08(1.185)$ & 2 & 0.250 & \multirow[b]{2}{*}{$t(39)=1.464, p=0.151$} \\
\hline & OI & $1.81(1.018)$ & 3 & {$[-0.095,0.595]$} & \\
\hline \multirow{2}{*}{$\begin{array}{l}\text { Release } \\
\text { period }\end{array}$} & TI & $1.8(1.091)$ & 3 & -0.025 & \multirow[b]{2}{*}{$t(39)=-0.129, p=0.898$} \\
\hline & $\mathrm{OI}$ & $1.83(0.986)$ & 2 & {$[-0.418,0.368]$} & \\
\hline \multirow[t]{2}{*}{$\begin{array}{l}\text { Fulfillment } \\
\text { of contract } \\
\text { conditions }\end{array}$} & TI & $1.75(0.981)$ & 4 & $\begin{array}{c}0.225 \\
{[-0.236} \\
0.686]\end{array}$ & \multirow[t]{2}{*}{$t(39)=0.988, p=0.329$} \\
\hline & $\mathrm{OI}$ & $1.50(0.994)$ & 5 & & \\
\hline
\end{tabular}

Note: A five-point Likert Scale of potential conflict factors from 1: Extremely Unlikely, 2: Somewhat Unlikely, 3: Neither likely nor Unlikely, 4: Somewhat Likely, 5: Extremely Likely $\mathrm{TI}^{*}: \mathrm{N}=40 ; \mathrm{OI}^{* *}=42$.

Finally, the paired sample t-test shows that there was no significant difference between TI and OI regarding the frequency of the price level conflict since the P-value was higher than 5\% $p=$ 0.832). This result suggests that the frequency of hoteliers in Cambodia having price level conflict with traditional intermediaries is the same as with OI, which is in between "Somewhat unlikely" and "Neither likely nor unlikely."

For instance, respondents \#32 expressed this view regarding the similarity of frequency of pricelevel conflict between the two intermediaries:

"I can say that is number 3: Neither likely nor unlikely for traditional intermediaries because they do not usually look into the contract. They always look for the price in the contract if they sell a package for one or two years ahead or something like that. However, if they quote for, let's say, an arrival in the next three-six months, they always call and 
make the request for a quotation. For online intermediaries, I think it is number 3: Neither likely nor unlikely. Most of the percentages for conflict caused by the price level with online intermediaries have resulted from price manipulations from their competitors of online intermediaries. When their systems detected small differences in price, they always complain to us, and in the same way, when we notice, they play around with us for the price reduction in their channel, we also complain back to them. It is going back and forth, and it is one of our headaches as well."

As stated by respondent \#32 above, with regards to TI, most of the problems that have been found for price level happened during the new contract signing process where the price negotiation was tough. Because the signing process for price level comes with a period of 1-2 years, they always want it to be as low as possible. Regarding online intermediaries, price Level is also a sensitive issue that causes conflicts with hoteliers. The problems occurred mostly with price parity when discussing price level issues. The online intermediaries themselves that usually manipulate the prices among their competitors and undercut their commissions to receive more sales. When one of them is doing this tricky strategy, their competitors usually complain to hoteliers that they are not giving the same price for each online channel. It is one of the standard practices that hoteliers frequently need to deal with. However, the frequency of conflicts that hoteliers have with traditional and online intermediaries was almost identical ranking from "Somewhat Unlikely" to "Neither Likely nor Unlikely." Overall, this factor seems to have caused more conflicts than other factors.

Pair 2 (Commission between TI and OI): As shown in Table 4.5 above, commission mean score is $1.45(\mathrm{M}=1.45, \mathrm{SD}=1.037)$ for $\mathrm{TI}$ and it received the mean score of $1.57(\mathrm{M}=1.57, \mathrm{SD}=0.859)$ for OI. It is ranked fifth and fourth respectively. This result signifies that most hoteliers in Cambodia haven't often encountered this type of conflict with both TI and OI. Table 4.5 also shows that there was no significant difference of the frequency of this type of conflict between TI and OI since $p>0.05(p=0.499)$. Consequently, we could state that hoteliers in Cambodia face similar level of commission-related conflict with both channels of distribution.

Hotelier \#12 mentioned his opinion on the commission: 
“...with traditional intermediaries, we do not have conflicts at all for the commission because we do not provide a commission to them. Some big hotel chains probably do, but we do not offer that kind of thing. We provide them with a good rate so that they could have a flexible markup space for their profits. So, I would rate it number 1-Extremely Unlikely. Talking about online intermediaries, we provide commission to them as this is the nature of their business. Because each online intermediary has a different commission and policy, we follow their policy, and it is not a problem for us as well. So, I would rate it number 1Extremely Unlikely as well."

The result showed that hoteliers had the same frequency of conflicts when they deal with commission related conflict. The frequency of conflict with traditional and online intermediaries mostly range from "Extremely Unlikely" to "Somewhat Unlikely." Among the five factors, the commission tends to be the lowest in ranking that causes conflicts with traditional intermediaries. The reason that hoteliers do not have many conflicts with TI is that they do not provide commission to them. They only provide net rates to them and leave some markup space for TI to benefit. However, with OI such as Agoda, Booking.com, Expedia or Ctrip, the commission is the nature of their businesses, and they usually have a fixed commission policy when signing the contract, for example, $20 \%$ or $18 \%$. So, hoteliers do not have any conflicts with them either.

Pair 3 (Price quality ratio between TI and OI): Another sources of conflict illustrated in table 4.5 is related to the price-quality ratio. It has a mean score of $2.08(\mathrm{M}=2.08, \mathrm{SD}=1.185)$ for $\mathrm{TI}$ and is ranked second in terms of frequency after the price level related sources of conflict. For OI, pricequality ratio was ranked third and received a mean score of $1.81(\mathrm{M}=1.81, \mathrm{SD}=1.018)$. From the table above, there was no significant difference in terms of frequency of the price quality conflict between TI and OI $(p=0.151)$. Consequently, hoteliers in Cambodia have almost identical perception of the frequency of this conflict which was between "Extremely unlikely" and "Somewhat unlikely" demonstrating a low frequency of this sources of conflict.

To support this finding, respondent\#13 provided the following answer regarding the price-quality ratio: 
"Price-quality ratio is an important aspect for us. We make sure that the price is reasonable with our service quality. With traditional intermediaries, we always talk when guests pass their feedback to them, they always pass it on to us, and we try to note and make sure it is better the next time. We do not have many conflicts with traditional intermediaries. With online intermediaries, the price-quality ratio is not a big deal for us because we usually compare our property to our competitors, and we set the price based on our service quality. It occasionally happens that guests complain that our room is not like the pictures and it is not worth the money. However, that is rare. So, I would rate it as "Somewhat Unlikely."

Apart from this quotation, several hoteliers seem to be aware of their competitors' pricing in order to adapt their pricing policy to the quality of service they can offer. They mentioned that the majority of their price setting is in line with the market demands and they do not receive many complaints about the price-quality ratio. Even though there were no statistical difference in the result, hoteliers seem to have a bit more chance of having more conflicts with TI than OI because the mean score is slightly higher (2.08 versus 1.81$)$.

Pair 4 (Release Period between TI and OI): release period had a total mean score of 1.8 (M=1.8, $\mathrm{SD}=1.091)$ for $\mathrm{TI}$ and $1.83(\mathrm{M}=1.83, \mathrm{SD}=0.986)$ for $\mathrm{OI}$. Release period was ranked second sources of conflict for OI and third for TI. Similarly to previous sources of conflict within the contract stage, Paired t-test result shows there was no significant difference between TI and OI $(p=0.898)$. This indicates that the perceived frequency of release period related conflict is quite similar for both distribution channels. Hoteliers' responses ranged from "extremely unlikely" to "Somewhat unlikely."

Respondent\#30 mentioned how his hotel perceived the release period related conflict:

“...with clear contract agreements, we do not have any issues with traditional intermediaries related to the Release Period. This is because from their side, they also note when they need to release our room if they book way in advance, and from our side, we also have someone to look after that and follow up with them when the cut-off date is near. 
So, we manage that well, and I would rate it number 1-Extremely Unlikely. With online intermediaries, they tend to work differently because of their nature of the business, which books in a short time before their arrival. However, they also have their cut-off date, which allows the release period to be long enough for us to re-sell the room. If the guests break that rule, they will be charged. So, we do not have many conflicts with them as well. I would give them Somewhat Unlikely."

According to this hotelier, this release period related conflict with TI usually occur long time before the arrival date of the guests. For example, travel agencies may book many months in advance before their guest arrivals, and they have to release the room before the cutoff date set by hoteliers. On the contrary, when it comes to online intermediaries, it often happens in a short period of time as guests usually book their rooms only a few days (or hours) before their arrivals, and if they cannot release according to hoteliers' conditions, they will be charged.

Pair 5 (Fulfillment of contract conditions between TI and OI): Likewise, concerning the fulfillment of contract conditions for $\mathrm{TI}$, the total mean score was $1.75(\mathrm{M}=1.75, \mathrm{SD}=0.981)$ and ranked fourth among the five sources of conflict. For OI, interestingly, fulfillment of contract conditions received the lowest ranking among the listed sources of conflict within the contract stage with a mean score of $1.50(\mathrm{M}=1.50, \mathrm{SD}=0.994)$. The result shown in table 4.5 indicated that there was no significant difference of the frequency of these sources of conflict between TI and OI $(p=0.329)$ ranging from "extremely unlikely" to "Somewhat unlikely."

Hotelier \#41 described her perception of the fulfillment of contract conditions as follows:

"Most of the traditional intermediaries have fulfilled contract conditions well overall because we often talk and visit them and we understand each other. Because they are often our long-term partner and their businesses to help us fill our room occupancy is more stable than Agoda, Expedia, etc., we communicate more with them to strengthen our business relationships. Even some times we have problems with them, but in the overall picture, they are still good for us. So, I rate them number 2--Somewhat Unlikely. Online intermediaries are also very good if talking about the fulfillment of contract conditions. 
They are fierce in business, and since most of them are big international companies, they have clear policies and usually hold to them well. So, we do not have any headaches with them. I give them number 1-Extremely Unlikely."

As seen from the response above, fulfillment of contract conditions is not a big issue for most hoteliers regarding their conflicts with traditional intermediaries since it causes fewer conflicts for

them than any other factors. Similarly, because most online intermediaries are big companies, they tend to fulfill contract conditions well. They were rated low for these two factors; however, the overall picture of conflict frequency for the fulfillment of contract conditions is in between "Extremely Unlikely" to "Somewhat Unlikely."

\subsubsection{Pre-stay stage of conflicts: A comparison of sources of conflict}

The pre-stay stage is dealing with issues that happen before the arrival of guests at accommodation properties, and it may involve with information correctness, timeline, and completeness (Ivanov et al., 2014). These aspects of cooperation between hoteliers and intermediaries are very important since they provide each other and their customers useful information regarding booking details and compliance with cancellation terms.

In this part, we focus on three sources of conflict that could occur at the pre-stay stage between hoteliers and intermediaries. A similar analysis is conducted here by looking at the hierarchy between the three sources of conflict within this pre-pay stage and Paired sample t-test.

Table 4.6 presents the main findings with regards to the three pre-stay sources of conflict : information provision, booking details and cancellation terms compliance. 
Table 4.6 Main findings of common sources of conflict at the pre-stay stage of conflicts

\begin{tabular}{lccccc}
\hline \multicolumn{1}{c}{ Conflict } & $\begin{array}{c}\text { TI* } \\
\text { or } \\
\text { OI** }\end{array}$ & Mean (Std.) & Ranking & $\begin{array}{c}\text { Mean difference } \\
{[95 \% \mathrm{CI}]}\end{array}$ & Paired t-test results \\
\hline $\begin{array}{l}\text { Information } \\
\text { provision }\end{array}$ & TI & $1.53(0.679)$ & 2 & -0.200 & \\
\hline $\begin{array}{l}\text { Booking } \\
\text { details }\end{array}$ & OI & $1.69(0.924)$ & 2 & {$[-0.564,0.164]$} & $t(39)=-1.113, p=0.273$ \\
\hline $\begin{array}{l}\text { Cancellation } \\
\text { terms }\end{array}$ & OI & $1.47(0.716)$ & 3 & -0.100 & $t(39)=-0.726, p=0.472$ \\
compliance & OI & $1.87(0.861)$ & 3 & {$[-0.379,0.179]$} & \\
\hline
\end{tabular}

Note: A five-point Likert Scale of potential conflict factors from 1: Extremely Unlikely, 2: Somewhat Unlikely, 3: Neither Likely nor Unlikely, 4: Somewhat Likely, 5: Extremely Likely $\mathrm{TI}^{*}: \mathrm{N}=40 ; \mathrm{OI}^{* *}=42$.

Pair 1 (Information provision between TI and OI): Table 4.6 shows a mean score of $1.53(\mathrm{M}=1.53$, $\mathrm{SD}=0.679)$ for $\mathrm{TI}$ and $1.69(\mathrm{M}=1.69, \mathrm{SD}=0.924)$ for $\mathrm{OI}$. The ranking of the provision of information was second for both TI and OI. This means that hoteliers in Cambodia perceived the frequency of this sources of conflict very much the same between TI and OI from "extremely unlikely" to "Somewhat unlikely." Table 4.6 also shows there was no significant difference for the perceived frequency of this conflict between TI and OI since $p>0.05(p=0.273)$.

As respondent $\# 9$ explained her viewpoint on this issue:

"Most of the traditional intermediaries such as travel agencies are very professional in terms of their management regarding the provision of information, and we do not experience any problems with this. They manage from their side very well, and we also try to do the same. So, it is not a big deal for this. I think it is somewhat unlikely for this factor. For the conflict with online intermediaries, we also do not have any problems with the provision of information because we update most information on online intermediaries such as Agoda, Expedia, or Booking.com. We manage that by ourselves and we control all 
the information that we want to provide to our guests by ourselves, so it is not much of an issue here. I would say the conflict rate for this factor is 1 - Extremely Unlikely."

This type of conflict with traditional intermediaries that resulted from the provision of information seems rare as the respondent above mentioned that she had fewer conflicts from this source of contest. The reason is that her hotel handled well the provision of information to avoid conflicts with intermediaries because she always distributes all updated information to every channel that she has. When all updated information was distributed, the misunderstanding could be reduced and the conflicts also reduced. Provision of information was also less likely to cause conflicts with online intermediaries. Provision of information is not a problem because online intermediaries have space and features to update all information about the hotel and rooms and guests could be well-informed before they book the room. Even though the methods used to provide information differ from TI to OI, the hotelier still perceived these sources of conflict as minor because everything is handled correctly from both sides.

Pair 2 (Booking details between TI and OI): the total mean score of booking details for TI was $1.47(\mathrm{M}=1.47, \mathrm{SD}=0.716)$ while it was $1.55(\mathrm{M}=1.55, \mathrm{SD}=0.861)$ in the context of OI. Hoteliers in Cambodia ranked it third which is the lowest among the three sources of conflict. Table 4.6 also shows that there was no significant difference in the frequency of conflict with TI and OI resulted from booking details as $p>0.05(p=0.472)$. From this finding, it could be inferred that there is a similarity of the frequency of this conflict among hoteliers. The range of frequency is the same as that of the provision of information.

Respondent \#33 explained his thoughts on booking details that his hotel found quite similar:

"For booking details regarding conflicts with traditional intermediaries, we have some problems as well but not many. For example, when local travel agencies got all the booking details from their guests, they sometimes forgot to update us as a hotel such as foods that guests are allergic to, and when the guests arrive, we know nothing about it. In the case of online intermediaries, booking details are not much of a problem because guests are the ones who provide us with their details and usually it is clear and precise as to what they 
need and their requests. As long as we follow what they said, we do not have any problems for this. So, I would say it is Somewhat Unlikely in this case."

From the response above, booking details did not cause a lot of conflicts between hoteliers in Cambodia and TI. This is because most of TI and hoteliers double check the booking details. More importantly, because most of large intermediaries use IT systems to record all types of information. Booking details also cause fewer conflicts for OI because in an online platform, most guests book rooms by themselves and this creates fewer errors in the booking details.

Pair 3 (Cancellation terms compliance between TI and OI): regarding the cancellation terms compliance, the mean score was $1.87(\mathrm{M}=1.87, \mathrm{SD}=1.067)$ for $\mathrm{TI}$ and $1.71(\mathrm{M}=1.71, \mathrm{SD}=1.066)$ for OI. The ranking of compliance of cancellation terms was first for both TI and OI which signify that they are more problematic among the three sources of conflict in this pre-stay stage. Our finding also shows that there was no significant difference in terms of frequency of this conflict between TI and OI with a P-value higher than 5\% $(p=0.361)$. From this result, we can state that the frequency of this conflict is between "extremely unlikely" and "Somewhat unlikely" for both channels of distribution.

For example, respondent \#14 from Siem Reap commented on this sources of conflict:

"Compliance of cancellation terms with traditional intermediaries are not frequently a hot topic because they only occur from time to time. However, it is not causing much of the conflict as we negotiate and understand each other. For online intermediaries, compliance of cancellation terms is not a problem because we set the cancellation policy through our channel and online intermediaries facilitate this. If they pass the cancellation period, it is charged at full price and usually no exception. I give it number 2 Somewhat Unlikely."

Finally, the frequency of conflicts between hoteliers and traditional intermediaries resulting from cancellation terms compliance was also relatively low. Even though the mean-scores of this sources of conflict are the highest among the three types of conflicts presented in table 4.6, most hoteliers reported that they are non-significant by comparison with other sources of conflict that 
could occur at different other stages. With online intermediaries, compliance of cancellation terms is less likely to cause conflicts. The majority of hoteliers do not face conflicts since the cancellation policy with online intermediaries are clear and mostly non-negotiable. If guests cancel after the cut-off date, they will be charged. Apart from the respondent above, most of hoteliers in Cambodia mentioned that conflicts of this nature happened but they managed to negotiate with their intermediaries in order to keep solid business relationships with their partners.

\subsubsection{Stay stage of conflicts: A comparison of sources of conflict}

As discussed in chapter 2, stay-stage deals with issues during the stay of their guests. This could lead to two potential sources of conflict : operational errors and overbooking (Ivanov et al., 2014). In this section, our analysis focuses on these two sources of conflict by conducting a similar statistical approach to the ones presented earlier.

Table 4.7 Main findings of common sources of conflict at the stay stage of conflicts

\begin{tabular}{llcccc}
\hline \multicolumn{1}{c}{ Conflict } & $\begin{array}{c}\text { TI* } \\
\text { or } \\
\text { OI** }\end{array}$ & Mean (SD) & $\begin{array}{c}\text { Ranking } \\
\text { Mean difference } \\
{[95 \% \mathrm{CI}]}\end{array}$ & Paired t-test results \\
\hline $\begin{array}{l}\text { Operation } \\
\text { Errors }\end{array}$ & TI & $1.65(0.580)$ & 1 & -0.275 & \\
& OI & $1.93(0.867)$ & 2 & {$[-0.574,0.024]$} & $t(39)=-1.863, p=0.070$ \\
\multirow{2}{*}{ Overbooking } & TI & $1.45(0.552)$ & 2 & -0.875 & \multirow{2}{*}{$t(39)=-4.376, p=0.000$} \\
& OI & $2.26(1.170)$ & 1 & {$[-1.279,-0.471]$} & \\
\hline
\end{tabular}

Note: A five-point Likert Scale of potential conflict factors from 1: Extremely Unlikely, 2: Somewhat Unlikely, 3: Neither Likely nor Unlikely, 4: Somewhat Likely, 5: Extremely Likely $\mathrm{TI}^{*}: \mathrm{N}=40 ; \mathrm{OI}^{* *}=42$.

Table 4.7 presents the total respondents for conflicts with traditional and online intermediaries for the Stay-stage, which includes two sources of conflict such as operation errors, and overbooking.

Pair 1 (Operation errors between TI and OI): As shown in table 4.7, operation errors relatedconflict had mean scores of $1.65(\mathrm{M}=1.65, \mathrm{SD}=0.580)$ for $\mathrm{TI}$ and $1.93(\mathrm{M}=1.93, \mathrm{SD}=0.867)$ for 
OI. This conflict is ranked first for TI and second for OI. Paired t-test result also shows that there was no significant difference in terms of perceived frequency of this type conflict between TI and OI since P-Value was $(p=0.070)$. However, this result is showing that it is trending toward significant difference. Thus, we could state that the frequency of operation errors related conflict is somehow different between TI and OI. Hoteliers in Cambodia seem to face more conflictual situation with OI than TI when it comes to operation errors related conflict.

Respondent \#34 expressed his thoughts that his hotel experienced with operation errors as well:

"With traditional intermediaries, we do not have any problems with operational errors. Because we usually receive bookings way in advance before the guest's arrival, we are able to avoid mistakes. So, I think it is number 2-Somewhat Unlikely. For online intermediaries, we experience some problems, which are more than that of traditional intermediaries. The problems that we experienced with operational errors include assigning wrong room types to guests from our staff, missed pickups for guests from the airport, which we included as a free service, and confirming the wrong date occasionally. However, these problems do not happen very often, and we do not have many conflicts. So, it is Somewhat Unlikely."

Form the response above, the hotelier noted that they usually receive booking from TI well in advance which is a bit different from OTA who often send last minutes bookings. As a result, this explain why this hotelier has less of this problem with TI by comparison with OI because he has enough time to prepare for guest services.

Pair 2 (Overbooking between TI and OI): regarding this conflict, overbooking had mean scores of $1.45(\mathrm{M}=1.45, \mathrm{SD}=0.552)$ with $\mathrm{TO}$ and $2.26(\mathrm{M}=2.26, \mathrm{SD}=1.170)$ for OI. Overbooking is ranked second for TI while it is first for OI. Table 4.7 also shows that there was a significant difference of the frequency of this conflict between TI and OI with a P-value $(p=0.000)$. This result suggests that that hoteliers in Cambodia have different levels of conflicts resulting from overbooking. Such conflict is more often reported by hoteliers dealing with OI. This result also shows that the 
overbooking related-conflict is less likely to happen between hoteliers in Cambodia and TI. The mean score of overbooking was 1.45 for TI while it was 2.26 with OI.

For instance, respondent \#4 described his experiences when it comes to dealing with overbooking:

"It is extremely unlikely that we are overbooked through traditional intermediaries because they always send their bookings to us way in advance and we could manage that properly. So, the conflicts that resulted from this are rarely an issue for us. However, in the case of online intermediaries, it is different because it is likely that we have conflicts with online intermediaries. Usually, it happens during the peak period such as Christmas or New Year where we got many bookings at the same time and sometimes the system has an error and generates bookings with the same date and room types. When this happens, we are the ones responsible for all the expenses to find alternative accommodation for the overbooked guests. Sometimes, we cannot find suitable rooms for them, and that is when we have problems with online intermediaries."

\subsubsection{Post-stay stage of conflicts: A comparison of sources of conflict}

Ivanov et al. (2014) assert that the post-stay stage deals with issues that may cause conflicts related to payments, customer satisfaction, and handling of customers' complaints. It is the stage where services are completed after guests returning to their home.

Table 4.8 Main findings of common sources of conflict at the post-stay stage of conflicts

\begin{tabular}{llcccc}
\hline Conflicts & $\begin{array}{l}\text { TI* } \\
\text { or } \\
\text { OI** }\end{array}$ & Mean (Std.) & $\begin{array}{c}\text { Ranki } \\
\text { ng }\end{array}$ & $\begin{array}{c}\text { Mean difference } \\
{[95 \% \text { CI }]}\end{array}$ & Paired t-test results \\
\hline \multirow{2}{*}{ Payment } & TI & $2.20(1.043)$ & 1 & 0.450 & \\
& OI & $1.71(0.970)$ & 2 & {$[0.004,0.896]$} & $t(39)=2.040, p=0.048$ \\
\hline $\begin{array}{l}\text { Complaint } \\
\text { handling }\end{array}$ & TI & $1.90(0.709)$ & 2 & -0.325 & $t(39)=-2.117, p=0.041$ \\
\hline
\end{tabular}

Note: A five-point Likert Scale of potential conflict factors from 1: Extremely Unlikely, 2:

Somewhat Unlikely, 3: Neither Likely nor Unlikely, 4: Somewhat Likely, 5: Extremely Likely 
$\mathrm{TI}^{*}: \mathrm{N}=40 ; \mathrm{OI}^{* *}=42$.

Pair 1 (Payment between TI and OI): Table 4.8 shows mean scores of $2.20(\mathrm{M}=2.20, \mathrm{SD}=1.043)$ for $\mathrm{TI}$ and $1.71(\mathrm{M}=1.71, \mathrm{SD}=0.970)$ for OI. Payment-related conflict is ranked first for TI and second for OI. The finding also shows that there was a significant difference in terms of the frequency of this type of conflict between TI and OI with P-value less than $5 \%(p=0.048)$. Such sources of conflict is more frequent with TI than OI.

For example, respondent \#27 admitted that he has problems with payment for TI but not for OI:

"For conflict with traditional intermediaries, I would give it number 4--Somewhat Likely that we have conflicts with them. Usually, traditional intermediaries collect payment from their guests before arrival, but they delay payment to us as long as they can. They ask for credit terms for payment such as one month, or two months and sometimes three months depending on how big they are. The bigger they are, the longer they ask for credit terms. Sometimes they ask for six months, and it is too long for us. However, for payment with online intermediaries, they are very fast and never fail to pay us on time. That is one of the reasons I like working with them. So, I think it is number 1-Extremely Unlikely."

This hotelier explained the difference in terms of frequency of this conflict between TI and OI by the fact that it is more common for him to involve credit term arrangements for payments from TI while this type of arrangement is less common with OI.

Pair 2 (Complaint handling between TI and OI): Complaint handling had mean scores of 1.90 $(\mathrm{M}=1.90, \mathrm{SD}=0.709)$ for $\mathrm{TI}$ and $2.19(\mathrm{M}=2.19, \mathrm{SD}=0.833)$ for OI. Complaint handling is ranked second for TI and first for OI. The result from Table 4.8 shows that there was also a significant difference in terms of frequency of this conflict between TI and OI $(p=0.041)$. Hoteliers in Cambodia noticed that this type of conflict is relatively more numerous with online intermediaries than traditional intermediaries. The frequencies of this conflict are in between "Somewhat unlikely" to "Neither likely nor unlikely." 
Respondent \#16 from Siem Reap provided her views on the differences that she found between TI and OI with regards to complaint handling:

"For the complaint handling with traditional intermediaries, yes, sometimes the guest did not mention their complaint to the reception for us to act immediately and kept it and when they go back, they write the complaint to the travel agent. It is not very often though. So, I think it is Somewhat Unlikely. With online intermediaries, it is Somewhat Likely. Most of our guests come with goodwill and wish to pay for the stay without any issues related to that. However, you always have a minor percentage that is looking for extra freebies. So, this is where you need to be careful and train your team to understand. They may come back and write bad reviews about us in order to get some compensation. Some reviews are genuine, but some are a bit too much, and we need to reply and show the public that we are not that bad. So, yes, it is Somewhat Likely that we have conflicts with online intermediaries."

To sum up, the complaint handling related conflict is less likely to happen with traditional intermediaries than online intermediaries. The main reason is that most of the complaints are around compensation or refund by guests who made online booking. If they are not satisfied with the service offered, they often use online platforms to complain and request compensation.

\subsection{Chapter summary}

This chapter explores hotels' distribution channels in Cambodia, the level of satisfaction, and sources of conflict with both traditional and online intermediaries. The main distribution channels in Cambodia includes traditional intermediaries, online intermediaries, and corporate segments. Phnom Penh predominantly relies on corporate segments than other two regions. The level of satisfaction of hoteliers with both intermediaries suggests that most of them are satisfied with traditional and online intermediaries. The most common sources of conflict with traditional intermediaries are price level, payment and price-quality ratio, while the most common sources of conflict with online intermediaries are price level, overbooking, and complaint handling. 
Chapter 5 discusses the perception of respondents on the level of satisfaction and sources of conflicts based on hotel attributes and respondents' backgrounds. 


\section{Chapter 5. Cross-Case analysis}

\subsection{Introduction}

The preceding chapter discussed the overall level of satisfaction and sources of potential conflicts between hoteliers in Cambodia and their two intermediaries. In this chapter, we examine to what extent this level of satisfaction and sources of potential conflicts have been influenced by hotel attributes (hotel category, location, ownership, hotel size, and hotel age), and respondents' backgrounds (respondents' job titles and nationalities).

To assess these independent variables, statistical tools have been performed to investigate whether hotel attributes and respondents' backgrounds have influenced the respondent's rating of sources of conflicts. Some of the statistical tools used include descriptive statistics (means, and standard deviation), Analysis of Variance (ANOVA) test, Pearson Correlation test, and Independent Sample t-test.

This chapter is structured into three parts. The second part discusses the perceived level of satisfaction based on hotel attributes (5.2). The third part examines the frequency of conflicts in terms of hotel attributes (5.3). The fourth part investigates how hotel attributes and respondents' backgrounds have impacted on the sources of conflicts over the four different stage described in the previous chapter (5.4-5.7). All significant results in this section are highlighted in yellow (pvalue $<0.05)$ and light pink when it trends towards significant difference $(0.05<\mathrm{p}$-value $<0.10)$.

\subsection{The overall level of satisfaction with intermediaries}

As mentioned in chapter 4, our 42 respondents were asked to rate on the overall level of satisfaction with traditional intermediaries (TI) and online intermediaries (OI) by using a five-point Likert scale ranged from (1) Extremely bad, (2) Somewhat bad, (3) Neither good nor bad, (4) Somewhat good, (5) Extremely good 
In this section, the mean responses for the overall level of satisfaction by mode of distribution channel and hotel attributes are presented in table 5.1. This is followed by an ANOVA analysis and a post hoc $\mathrm{F}$ test to determine whether differences among hotel attributes lay. When appropriate, Pearson correlation test is then calculated to obtain an overall impression of the linear relationship between hotel attributes and their overall level of satisfaction with their two distinct channels of distributions. This statistical test was conducted for the following hotel attributes: category, hotel size, and hotel age.

Table 5.1 Hotel attributes \& overall level of satisfaction with the two channels of distributions

\begin{tabular}{|c|c|c|c|c|c|c|}
\hline $\begin{array}{c}\text { Hotel } \\
\text { Attributes }\end{array}$ & & Category & Mean & Std. & ANOVA test results & $\begin{array}{c}\text { Pearson Correlation } \\
\text { test result }\end{array}$ \\
\hline \multirow{6}{*}{$\begin{array}{l}\text { Category } \\
\text { of hotels }\end{array}$} & \multirow{3}{*}{$\begin{array}{l}\text { Level of } \\
\text { Satisfaction } \\
\text { with TI }\end{array}$} & & 3.86 & 0.69 & \multirow{3}{*}{$F(2,37)=1.489, p=0.239$} & \multirow{3}{*}[r=0.266,p=0.097]{} \\
\hline & & $4^{*}$ & 4 & 0.655 & & \\
\hline & & $5^{*}$ & 4.33 & 0.767 & & \\
\hline & \multirow{3}{*}{$\begin{array}{l}\text { Level of } \\
\text { Satisfaction } \\
\text { with OI }\end{array}$} & $3 *$ & 4.14 & 0.9 & \multirow{3}{*}{$F(2,39)=0.755, p=0.477$} & \multirow{3}{*}[r=0.043,p=0.785]{} \\
\hline & & $4^{*}$ & 3.82 & 0.809 & & \\
\hline & & $5^{*}$ & 4.11 & 0.676 & & \\
\hline \multirow{6}{*}{ Location } & \multirow{3}{*}{$\begin{array}{l}\text { Level of } \\
\text { Satisfaction } \\
\text { with TI }\end{array}$} & Siem Reap & 4.14 & 0.727 & \multirow{3}{*}{$F(2,37)=0.622, p=0.542$} & \\
\hline & & Phnom Penh & 4.23 & 0.725 & & \\
\hline & & Sihanoukville & 3.83 & 0.753 & & \\
\hline & \multirow{3}{*}{$\begin{array}{l}\text { Level of } \\
\text { Satisfaction } \\
\text { with OI }\end{array}$} & Siem Reap & 4 & 0.707 & \multirow{3}{*}{$F(2,39)=0.789, p=0.461$} & \\
\hline & & Phnom Penh & 4.13 & 0.743 & & \\
\hline & & Sihanoukville & 3.67 & 1.033 & & \\
\hline \multirow{6}{*}{$\begin{array}{l}\text { Types of } \\
\text { Ownership }\end{array}$} & \multirow{3}{*}{$\begin{array}{l}\text { Level of } \\
\text { Satisfaction } \\
\text { with TI }\end{array}$} & Local owner & 4 & 0.784 & \multirow{3}{*}{$F(2,37)=1.289, p=0.288$} & \\
\hline & & $\begin{array}{l}\text { Partnership } \\
\text { between local } \\
\text { and foreigner }\end{array}$ & 4.43 & 0.535 & & \\
\hline & & Foreign owner & 4.33 & 0.516 & & \\
\hline & \multirow{3}{*}{$\begin{array}{l}\text { Level of } \\
\text { Satisfaction } \\
\text { with OI }\end{array}$} & Local owner & 3.96 & 0.744 & \multirow{3}{*}{$F(2,39)=0.131, p=0.877$} & \\
\hline & & $\begin{array}{l}\text { Partnership } \\
\text { between local } \\
\text { and foreigner }\end{array}$ & 4.13 & 0.991 & & \\
\hline & & Foreign owner & 4 & 0.632 & & \\
\hline \multirow{2}{*}{ Hotel Size } & \multirow{2}{*}{$\begin{array}{l}\text { Level of } \\
\text { Satisfaction } \\
\text { with TI }\end{array}$} & $\begin{array}{l}\text { Small }(1-50 \\
\text { rooms })\end{array}$ & 3.94 & 0.725 & \multirow{2}{*}{$F(2,37)=3.989, p=0.027$} & \multirow{2}{*}[r=0.359,p=0.023]{} \\
\hline & & $\begin{array}{l}\text { Medium (50- } \\
120 \text { rooms) }\end{array}$ & 3.9 & 0.738 & & \\
\hline
\end{tabular}




\begin{tabular}{|c|c|c|c|c|c|c|}
\hline & & $\begin{array}{c}\text { Large (above } \\
120 \text { rooms) }\end{array}$ & 4.58 & 0.515 & & \\
\hline & \multirow{3}{*}{$\begin{array}{l}\text { Level of } \\
\text { Satisfaction } \\
\text { with OI }\end{array}$} & $\begin{array}{l}\text { Small }(1-50 \\
\text { rooms })\end{array}$ & 4 & 0.882 & \multirow{3}{*}{$F(2,39)=0.583, p=0.563$} & \multirow{3}{*}[r=0.075,p=0.638]{} \\
\hline & & $\begin{array}{l}\text { Medium (50- } \\
120 \text { rooms) }\end{array}$ & 3.82 & 0.874 & & \\
\hline & & $\begin{array}{c}\text { Large (above } \\
120 \text { rooms) }\end{array}$ & 4.17 & 0.389 & & \\
\hline \multirow{6}{*}{ Hotel Age } & \multirow{3}{*}{$\begin{array}{l}\text { Level of } \\
\text { Satisfaction } \\
\text { with TI }\end{array}$} & New (1-3 years) & 4 & 0.816 & \multirow{3}{*}{$F(2,37)=4.139, p=0.024$} & \multirow{3}{*}[r=0.316,p=0.047]{} \\
\hline & & $\begin{array}{c}\text { Average (4-10 } \\
\text { years) }\end{array}$ & 3.87 & 0.64 & & \\
\hline & & $\begin{array}{c}\text { Old (Above } 10 \\
\text { years) }\end{array}$ & 4.58 & 0.515 & & \\
\hline & \multirow{3}{*}{$\begin{array}{c}\text { R Level of } \\
\text { Satisfaction } \\
\text { with OI }\end{array}$} & New (1-3 years) & 4.23 & 0.725 & \multirow{3}{*}{$F(2,39)=0.858, p=0.432$} & \multirow{3}{*}[r=-0.163,p=0.301]{} \\
\hline & & $\begin{array}{l}\text { Average (4-10 } \\
\text { years) }\end{array}$ & 3.88 & 0.993 & & \\
\hline & & $\begin{array}{c}\text { Old (Above } 10 \\
\text { years) }\end{array}$ & 3.92 & 0.289 & & \\
\hline
\end{tabular}

Note: A five-point Likert Scale of perceived Level of Satisfaction from 1: Extremely bad, 2: Somewhat bad, 3: Neither good nor bad, 4: Somewhat good, 5: Extremely good.

Of the five hotel attributes exhibiting differences in terms of category of hotels, location, ownership, hotel size, and hotel age (see Table 5.1), three were attributes in which respondents could not be distinguished (category, location, and ownership) for both distribution channels (TI, OI). In the case of hotel categories $\left(3^{*}, 4^{*}\right.$, and $5^{*}$ hotel), Table 5.1 showed that the ratings measured by means of the responses ranged from 3.86 to 4.33 for the perceived level of satisfaction with TI and from 3.82 to 4.14 for the perceived level of satisfaction with OI. Additionally, ANOVA tests show that there was no significant difference in terms of mean-scores between the three hotel categories. Likewise, we found similar results when it comes to the perceived level of satisfaction with OI of hoteliers belonging to the three categories of hotels $\left(3^{*}, 4^{*}\right.$ and $\left.5^{*}\right)$. Thus, we could conclude that there was consistency among the three categories of hotels in terms of rating their overall level of satisfaction with both intermediaries above the neutral (3) mid-point of Likert-type scale (Neither good nor bad).

For instance, respondent \#37 from a three-star hotel raised his view with regard to his level of satisfaction with traditional intermediaries (TI): 
"I give them four on the rating with traditional intermediaries because our relationship with them is very good. Some of the factors which contribute to our good relationship including a personal conversation where you build up a personal relationship with travel agents. The personal side of dealing with the travel agent is much better than online intermediaries to certain extent."

Similarly, respondent \#12 from a five-star hotel also expressed a favorable opinion of TI:

"Our relationship with traditional intermediaries is very good so far. We communicate to provide a smooth operation from both sides. For example, when we have a new promotion, we update them on time, and they need to do the same if they have cancellations, etc. So, my experience with them is very positive.

Finally, the Pearson correlation test result shows that there was no statistically significant correlation between hotel star rating and the level of satisfaction of respondents with TI [ $r=0.266$, $p=0.097]$ as well as with OI [ $r=0.043, p=0.785]$. This finding suggests that the star rating of hotels in Cambodia does not influence the level of satisfaction of the relationship between hoteliers and TI and OI.

Similarly, in the case of location, ANOVA tests illustrate that there was no significant difference in terms of mean-scores between the three hotel locations (Siem Reap, Phnom Penh, Sihanoukville). Table 5.1 indicates that the mean score of the level of satisfaction with OI ranged from 3.67 to 4.13 which is between "Neither good nor bad" and "Extremely good" on the Likert scale. Therefore, we could conclude that there is a broad-agreement between hoteliers in Cambodia in terms of rating the overall level of satisfaction with OI in the three locations where this research has been undertaken.

"Our hotel is based in Siem Reap because it is the most popular in tourism destination in Cambodia. Our cooperation with online intermediaries is "somewhat good" from my experience. They help us a lot during the last minute of filling room occupancy, and we often communicate to strengthen this good relationship." 
Another respondent \#24 from Phnom Penh expressed similar experiences on the level of satisfaction with OI:

"We work with many online intermediaries and our relationship with them could be considered very good. We are based in the capital of Phnom Penh, and we receive lots of business travelers through online platforms, and we try our best to keep this relationship."

Likewise, ANOVA tests regarding the level of satisfaction with TI show that there was also no significant difference in terms of mean-scores between the three categories of hotel ownership (local owner, partnership between local and foreigner and foreign owner). These mean scores fluctuated from 4.0 to 4.43 which is above "Somewhat good" on Likert scale. Hence, the overall level of satisfaction of hotels with TI is relatively similar among the three ownership types.

Respondent \#7 from a local owner of a hotel in Cambodia raised his view regarding the level of satisfaction with TI:

"[...] our owner is Cambodian, and he owns the property 100\%. We have a very good relationship with traditional intermediaries because we target them as one of our main channels of distribution. Their good point is that they have consistency in providing guests to us."

Respondent \#31 belonging to the category of "partnership of local and foreign ownership" also expressed similar opinion:

"This hotel is owned by a couple from Italy, and his Cambodian friend [...] our relationship with traditional intermediaries is very good because we have been working with them for a long time and we understand each other well. We always support each other, and our relationship is strong." 
Interestingly, table 5.1 shows that there were two hotel attributes (hotel size and age) in which the perceived levels of satisfaction of hoteliers with TI were different from OI. Regarding the hotel size attribute, the ANOVA results illustrate that there was a significant difference in the mean scores of the overall level of satisfaction of hoteliers in Cambodia with TI $(p=0.027$, Table 5.1). As shown in table 5.1.a, Post Hoc comparisons using the Tukey HSD test indicates that the mean score for large hotels $(\mathrm{M}=4.58, \mathrm{SD}=0.515)$ was significantly different from small hotels $(\mathrm{M}=3.94$, $\mathrm{SD}=0.725, p=0.039)$. Similarly, the mean score for large hotels $(\mathrm{M}=4.58, \mathrm{SD}=0.515)$ trended towards significant difference with medium hotels $(\mathrm{M}=3.9, \mathrm{SD}=0.738, p=0.058)$. These results indicate that large hotels, on average, reported a slightly higher level of satisfaction with TI. Nevertheless, the mean score of medium hotels $(\mathrm{M}=3.9, \mathrm{SD}=0.738)$ was not significantly different from small hotels $(\mathrm{M}=3.94, \mathrm{SD}=0.725, p=0.985)$ regarding their level of satisfaction with $\mathrm{TI}$.

Respondent \#22 from large hotel expressed his opinion on his level of satisfaction with TI:

"We have about 300 rooms for one of our properties [...] I could say that our relationship with traditional intermediaries is very good. This is because traditional intermediaries help us a lot to fill our rooms and their business is consistent which is something we are looking for in the long term.

However, respondent \#18 from a small hotel had a different view:

"Our hotel is a small boutique hotel of 21 rooms [...], our experiences with traditional intermediaries are neither good nor bad. We have experienced many problems working with them such as complaints from them for no room allotment when they need it, and our rate is not competitive. However, we are a small hotel, and room allotment is always a problem."

Furthermore, the Pearson correlation test presented in table 5.1 shows there is a positive correlation between hotel size and their overall level of satisfaction with TI $[r=0.359, p=0.023]$. This result revealed that the larger the hotel size was, the higher the overall level of satisfaction with TI was. 
Table 5.1.a ANOVA Post Hoc Tukey HSD test result for overall Level of Satisfaction with TI

\begin{tabular}{|c|c|c|c|c|c|c|}
\hline \multirow{2}{*}{$\begin{array}{l}\text { (I) What is the } \\
\text { size of your } \\
\text { hotel? }\end{array}$} & \multirow{2}{*}{$\begin{array}{l}(\mathrm{J}) \text { What is the } \\
\text { size of your } \\
\text { hotel? }\end{array}$} & \multirow{2}{*}{$\begin{array}{c}\text { Mean Difference (I- } \\
\text { J) }\end{array}$} & \multirow[b]{2}{*}{ Std. Error } & \multirow[b]{2}{*}{$p$ value } & \multicolumn{2}{|c|}{ 95\% Confidence Interval } \\
\hline & & & & & Lower Bound & Upper Bound \\
\hline Small hotel (1-50 & Medium hotel & .044 & .265 & .985 & -.60 & .69 \\
\hline rooms) & Large hotel & $-.639^{*}$ & .251 & .039 & -1.25 & -.03 \\
\hline Medium hotel & Small hotel & -.044 & .265 & .985 & -.69 & .60 \\
\hline (51-120 rooms) & Large hotel & -.683 & .288 & .058 & -1.39 & .02 \\
\hline Large hotel & Small hotel & $.639^{*}$ & .251 & .039 & .03 & 1.25 \\
\hline $\begin{array}{l}\text { (Above } 120 \\
\text { rooms) }\end{array}$ & Medium hotel & .683 & .288 & .058 & -.02 & 1.39 \\
\hline
\end{tabular}

The findings also show that there was significant difference in overall level of satisfaction meanscores with TI among the three hotel ages : new, average and old hotels ( $p=0.024$, see Table 5.1). The Tukey HSD test presented in table 5.1.b also indicates that the mean score of average hotel $(\mathrm{M}=3.87, \mathrm{SD}=0.64)$ was significantly different from old hotels $(\mathrm{M}=4.58, \mathrm{SD}=0.515, p=0.028)$. This finding indicates that average hotels in Cambodia seem to have experienced a lower level of satisfaction with TI than old hotels (Mean difference $=-0.717$, see Table 5.1.b). However, the mean score of new hotels $(\mathrm{M}=4.0, \mathrm{SD}=0.816)$ was not significantly different from average and old hotels $(p>0.05$, Table 5.1.b).

Respondent \#30 from an average hotel explained his views:

"[...] we started our hotel six years ago. Our cooperation with traditional intermediaries was not very good in general. One of the problems that we usually face is the price that they usually ask is lower than we can offer. Some traditional intermediaries are still new to us, and they did not support us as much as we wanted them to, so we could not provide them with a special rate."

On the contrary, respondent \#4 from an old hotel described his positive relationship with TI as follows: 
"Our hotel was established in 2001, so we are in operation for almost 20 years now. In terms of our business relationship with traditional intermediaries, I would say it is extremely good. Because we were here a long time ago, we understand each other more, and they trust the level of service that we provide to their guests. With greater business volume, we also provide them with a special rate, but each traditional usually receive different rates based on their performance."

With regards to hotel age, Pearson correlation test for the overall level of satisfaction with TI reveals that there was a positive correlation between hotel age and the overall level of satisfaction with TI [ $r=0.316, p=0.047$ ]. Consequently, we could state that older hotels in Cambodia display a higher overall level of satisfaction with TI $(\mathrm{M}=4.58$, Old hotel) than new and average hotels.

Table 5.1.b ANOVA Post Hoc Tukey HSD test result for Level of satisfaction with TI of a hotel age

\begin{tabular}{|c|c|c|c|c|c|c|}
\hline \multirow{2}{*}{$\begin{array}{l}\text { (I) How old is } \\
\text { your hotel? }\end{array}$} & \multirow{2}{*}{$\begin{array}{l}(\mathrm{J}) \text { How old is } \\
\text { your hotel? }\end{array}$} & \multirow{2}{*}{$\begin{array}{c}\text { Mean Difference (I- } \\
\mathrm{J}) \\
\end{array}$} & \multirow[b]{2}{*}{ Std. Error } & \multirow[b]{2}{*}{$p$ value. } & \multicolumn{2}{|c|}{ 95\% Confidence Interval } \\
\hline & & & & & Lower Bound & Upper Bound \\
\hline \multirow[t]{4}{*}{ New } & Average (4-10 & .133 & .254 & .860 & -.49 & .75 \\
\hline & years) & & & & & \\
\hline & Old (above 10 & -.583 & .269 & .089 & -1.24 & .07 \\
\hline & years) & & & & & \\
\hline \multirow[t]{3}{*}{ Average } & New (1-3 years) & -.133 & .254 & .860 & -.75 & .49 \\
\hline & Old (above 10 & $-.717^{*}$ & .260 & .024 & -1.35 & -.08 \\
\hline & years) & & & & & \\
\hline \multirow[t]{3}{*}{ Old } & New (1-3 years) & .583 & .269 & .089 & -.07 & 1.24 \\
\hline & Average (4-10 & $.717^{*}$ & .260 & .024 & .08 & 1.35 \\
\hline & years) & & & & & \\
\hline
\end{tabular}

In contrast with TI, Table 5.1 illustrates that the perceived levels of satisfaction of hoteliers with OI were similar for the following two hotel attributes (hotel size and age). For example, in the case of hotel age attribute, the ANOVA results illustrate that there was no significant difference in the level of satisfaction mean scores with OI among the three categories of hotel ages ( $p=0.432$, Table 5.1). The mean score responses ranged from 3.88 to 4.23 showing that the overall level of 
satisfaction of hotels in Cambodia with OI was consistent in terms of their rating which is between "Neither good nor bad" and "Extremely good."

\subsection{The overall frequency of conflicts with intermediaries}

In this section, we discuss the overall frequency of conflicts between hotels and their intermediaries by taking into account the five hotel attributes (category, location, ownership, hotel size, and hotel age). As mentioned in chapter 4, our respondents were asked to assess the overall frequency of conflict with TI and OI by using a five-point Likert scale ranging from (1) Never, (2) Sometimes, (3) About half of the time, (4) Most of the time, (5) Always. ANOVA analysis has been performed to determine whether differences among hotels lay. Pearson correlation tests were also performed to obtain an overall impression of the linear relationship between the following hotel attributes (category, hotel size, and hotel age) and the overall frequency of conflicts between hoteliers and the two distinct channels of distributions (TI and OI).

Table 5.2 Hotel attributes and overall frequency of conflict with the two channels of distribution

\begin{tabular}{|c|c|c|c|c|c|c|}
\hline $\begin{array}{c}\text { Hotel } \\
\text { Attributes }\end{array}$ & & Category & Mean & Std. & ANOVA test results & $\begin{array}{c}\text { Pearson Correlation } \\
\text { test result }\end{array}$ \\
\hline \multirow{6}{*}{ Category } & \multirow{3}{*}{$\begin{array}{l}\text { Conflicts } \\
\text { with TI }\end{array}$} & 3* & 2.43 & 0.976 & \multirow{3}{*}{$F(2,37)=0.233, p=0.793$} & \multirow{3}{*}[r=-0.090,p=0.581]{} \\
\hline & & $4^{*}$ & 2.47 & 0.915 & & \\
\hline & & $5^{*}$ & 2.28 & 0.669 & & \\
\hline & \multirow{3}{*}{$\begin{array}{l}\text { Conflicts } \\
\text { with OI }\end{array}$} & $3 *$ & 2.43 & 1.397 & \multirow{3}{*}{$F(2,39)=0.087, p=0.917$} & \multirow{3}{*}[r=-0.050,p=0.753]{} \\
\hline & & $4^{*}$ & 2.47 & 0.943 & & \\
\hline & & $5^{*}$ & 2.33 & 0.84 & & \\
\hline \multirow{6}{*}{ Location } & \multirow{3}{*}{$\begin{array}{l}\text { Conflicts } \\
\text { with TI }\end{array}$} & Siem Reap & 2.38 & 0.805 & \multirow{3}{*}{$F(2,37)=1.495, p=0.238$} & \\
\hline & & Phnom Penh & 2.15 & 0.555 & & \\
\hline & & Sihanoukville & 2.83 & 1.169 & & \\
\hline & \multirow{3}{*}{$\begin{array}{l}\text { Conflicts } \\
\text { with OI }\end{array}$} & Siem Reap & 2.48 & 0.981 & \multirow{3}{*}{$F(2,39)=0.605, p=0.551$} & \\
\hline & & Phnom Penh & 2.2 & 0.775 & & \\
\hline & & Sihanoukville & 2.67 & 1.366 & & \\
\hline Ownership & & Local owner & 2.48 & 0.753 & $F(2,37)=0.923, p=0.406$ & \\
\hline
\end{tabular}




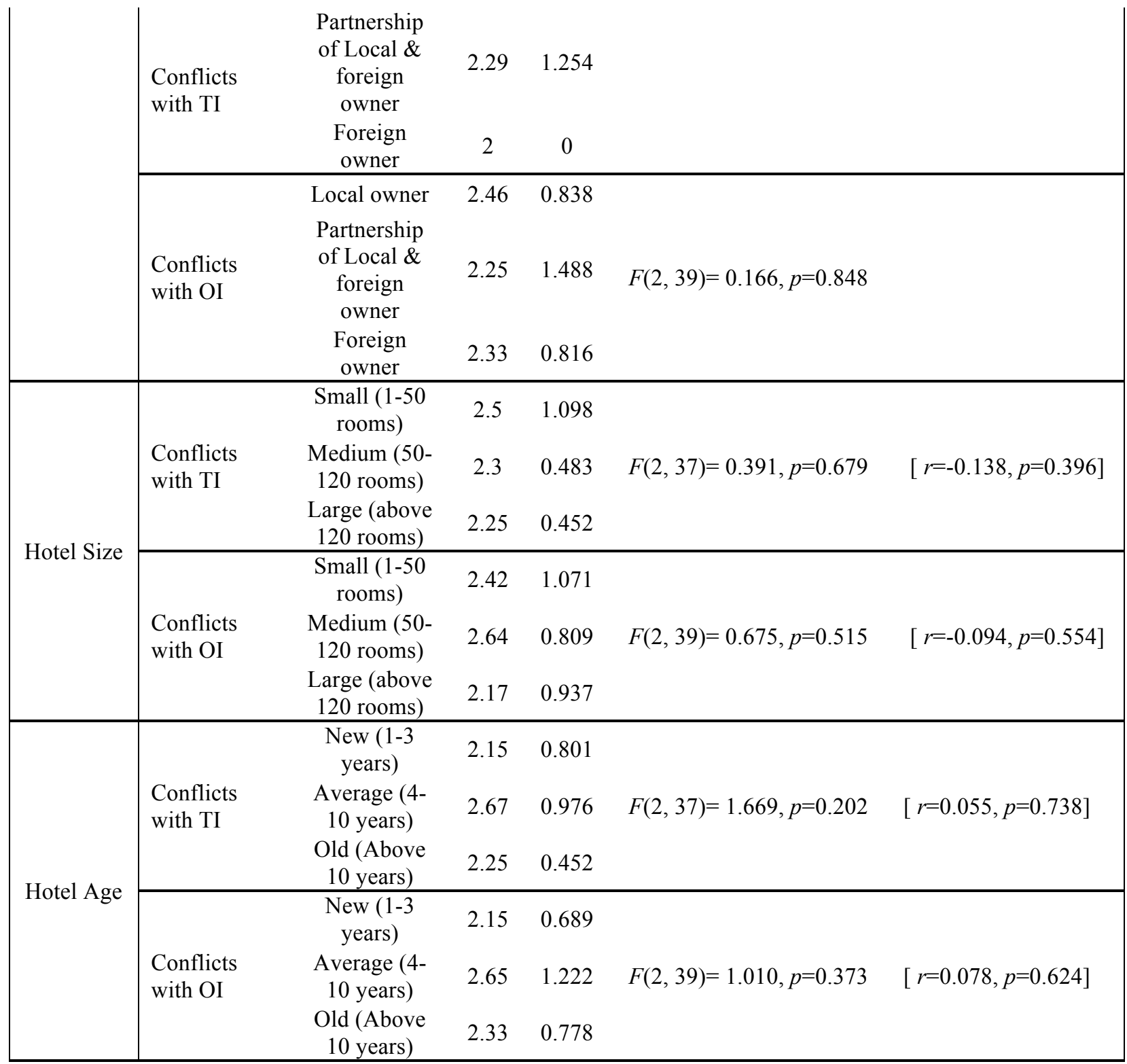

Note: A five-point Likert Scale of perceived frequency of conflict from 1: Never, 2: Sometimes, 3: About half of the time, 4: Most of the time, and 5: Always.

Among the five hotel attributes (category, location, ownership, hotel size, and hotel age), the rating of all responses could not be differentiated for both TI and OI (see Table 5.2). For instance, in the case of hotel categories (3,4, and 5-star hotels), the ANOVA test presented in Table 5.2 illustrates that there was no significant difference in terms of mean scores between the three categories of hotels with regards to the frequency of conflicts between hotels and OI. These mean scores ranged from 2.33 to 2.47 (from "sometimes" to "about half of the time") on the perceived frequency of 
conflicts Likert scale. Similarly, we found the same result when it comes to the overall frequency of conflicts of hotels in Cambodia with TI with mean scores ranging from 2.28 to 2.47. Hence, we could state that the rating of the overall frequency of conflicts among the three hotel categories was consistent.

Respondent \#12 from a four-star hotel described his opinion concerning the overall conflict with online intermediaries (OI):

"For online intermediaries, about half of the time we have conflict with them. It is usually about the promotion. For example, we have five online intermediaries, and we do the same promotion with them, but one or two online intermediaries might sell it at a price that is a few dollars different because of the tax calculation in their system. Sometimes we need to get them to fix the same rate."

Another respondent \#28 from a five-star hotel explained a similar view on this case:

"We have problems with online intermediaries sometimes as well and mainly due to rate parity and room allotment. We have often received reports from other online intermediaries that their competitors are selling lower rates than their rates and they need us to fix it. Other problems would be with room allotment that we did not give them enough."

Finally, the Pearson Correlation test presented in Table 5.2 indicates that there was no significant correlation between hotel star rating and the overall frequency of conflicts with both intermediaries OI [ $r=-0.050, p=0.753]$ and TI [ $r=-0.090, p=0.581]$. This finding suggests that the categories of hotels do not significantly influence the frequency of conflicts that hotels in Cambodia encounter with TI and OI.

Similarly, Table 5.2 indicates there was no significant difference in the mean scores between the three categories of hotel ownership (local ownership, partnership of local \& foreigner, and foreign ownership). The rating of mean scores for overall frequency of conflicts with TI varied from 2.0 
to 2.48 which is the equivalent of "sometimes" and "about half of the time" on the perceived frequency of conflicts Likert scale.

Respondent \#2 from the category of "partnership of local and foreign owners' hotel" raised his view regarding the frequency of conflicts encountered with TI:

"This hotel is a partnership investment between a foreigner and local people [...] we sometimes have conflicts with traditional intermediaries, but out of the scale of 5, I would rate them 2. This is not quite often because we cooperate well with them by regularly communicating. It helps a lot to avoid misunderstanding and strengthen our business relationship."

Similar respondent \#9 from a local owner provided similar opinion:

"[...] our hotel is owned by local people. We experience conflict about 50\% of the time with traditional intermediaries, especially when dealing with cancellation terms. They sometimes cancel our rooms at the last minute and try to avoid the charges by explaining the reasons that their guests provided to them. We cannot wave that all the time and that is when the problems occur."

Finally, the remaining findings regarding the following hotel attributes (hotel category, location, ownership, hotel size, and hotel age) also illustrate that there were no significant differences in terms of mean scores of the overall frequency of conflicts between hotels in Cambodia and their intermediaries (OI and TI). These results suggest that there was a consistency in terms of responses with regards to the above hotel attributes. The Pearson Correlation tests also indicated that there were no significant correlations between hotel size (hotel age) and the frequency of conflicts between hotels and both intermediaries TI/OI (see Table 5.2). These results reveal that both age and hotel size do not influence the overall frequency of conflicts with TI and OI. 


\subsection{Contract stage of conflicts: Comparative study of potential sources of conflict}

In addition to the overall frequency of conflicts between hotels and intermediaries discussed above, our respondents have also assessed the frequency of different sources of conflicts that could occur over the four following stages of conflicts (contract stage of conflicts, pre-stay stage of conflicts, stay stage of conflicts, and post-stay stage of conflicts). Likert scale was used to rate from (1) Never, (2) Sometimes, (3) About half of the time, (4) Most of the time, (5) Always

In Table 5.3, we only illustrated the significant results within each source of conflict at the contract stage that led to differences in terms of frequency of conflicts $(p<5 \%)$ as well as the results that trended towards significant level $(p<10 \%)$ by taking into account hotel attributes and respondents' background. The remaining empty boxes reveal that our findings did not show a significant difference in terms of frequency of a particular conflict between hoteliers and intermediaries.

Table 5.3 shows the results of all sources of potential conflicts between hotels in Cambodia and their traditional and online intermediaries at the contract stage in terms of hotel attributes (category, location, ownership, hotel size, and hotel age) and respondents' backgrounds (respondents' job titles, and respondents' nationalities). ANOVA analyses were conducted to determine whether differences among hotels and hoteliers lay with regards to the frequency of different sources of conflicts. Pearson correlation tests were also undertaken regarding the following hotel attributes: category of hotels, hotel size, and hotel age. Finally, independent sample t-tests were performed to assess the mean score differences between respondents' backgrounds (respondents' job titles and nationalities) and the different sources of potential conflicts at the contract stage that they might have encountered with TI and OI. The detailed results of all sources of potential conflicts in terms of hotel attributes and respondents' background were shown in Appendix 1-7. 
Table 5.3 Contract stage of conflicts: Main findings by hotel attributes and respondents' backgrounds

\begin{tabular}{|c|c|c|c|c|c|c|c|c|c|c|c|}
\hline \multirow{2}{*}{\multicolumn{2}{|c|}{$\begin{array}{l}\text { AT: ANOVA Test } \\
\text { PCT: Pearson Correlation } \\
\text { Test } \\
\text { IT: Independent Sample t- } \\
\text { test }\end{array}$}} & \multicolumn{8}{|c|}{ Hotel attributes } & \multicolumn{2}{|c|}{$\begin{array}{l}\text { Respondents' } \\
\text { backgrounds }\end{array}$} \\
\hline & & \multicolumn{2}{|c|}{ Category } & \multirow{2}{*}{$\begin{array}{l}\begin{array}{l}\text { Loca } \\
\text { tion }\end{array} \\
\text { AT }\end{array}$} & \multirow{2}{*}{$\begin{array}{l}\text { Owne } \\
\text { rship }\end{array}$} & \multicolumn{2}{|c|}{ Hotel Size } & \multicolumn{2}{|c|}{ Hotel Age } & \multirow{2}{*}{$\begin{array}{l}\text { Job } \\
\text { title } \\
\text { s } \\
\text { IT }\end{array}$} & \multirow{2}{*}{$\begin{array}{c}\text { Nationa } \\
\text { lities }\end{array}$} \\
\hline \multicolumn{2}{|c|}{ Conducted Tests $\longrightarrow$} & AT & PCT & & & AT & PCT & AT & $\mathrm{C}$ & & \\
\hline & $\begin{array}{l}\text { Sources of } \\
\text { potential } \\
\text { conflicts }\end{array}$ & & & & & & & & & & \\
\hline \multirow{10}{*}{$\begin{array}{l}\text { Contract } \\
\text { Stage }\end{array}$} & $\begin{array}{l}\text { Price Level } \\
\text { with TI }\end{array}$ & & $p=0.056$ & & & & & & & & \\
\hline & $\begin{array}{l}\text { Commission } \\
\text { with TI }\end{array}$ & & & & & & & & & & \\
\hline & $\begin{array}{l}\text { Price-Quality } \\
\text { Ratio } \\
\text { with TI } \\
\end{array}$ & & & & & & & $p=0.045$ & & & \\
\hline & Release Period & & & & & & & & & & \\
\hline & $\begin{array}{l}\text { Fulfillment of } \\
\text { contract } \\
\text { Conditions } \\
\text { with TI }\end{array}$ & & & & & & & & & & $p=0.042$ \\
\hline & $\begin{array}{l}\text { Price Level } \\
\text { with OI }\end{array}$ & & & & & & & & & & \\
\hline & $\begin{array}{l}\text { Commission } \\
\text { with OI }\end{array}$ & & & & & & & $p=0.067$ & & & $p=0.009$ \\
\hline & $\begin{array}{l}\text { Price-Quality } \\
\text { Ratio } \\
\text { with OI }\end{array}$ & & & & & & & & & & \\
\hline & $\begin{array}{l}\text { Release Period } \\
\text { with OI }\end{array}$ & & & & & & & & & & \\
\hline & $\begin{array}{l}\text { Fulfillment of } \\
\text { contract } \\
\text { Conditions } \\
\text { with OI }\end{array}$ & & & & & & & & & & \\
\hline
\end{tabular}

Note: A five-point Likert Scale of perceived conflict from 1: Never, 2: Sometimes, 3: About half of the time, 4: Most of the time, 5: Always. 
In the contract stage of conflicts, there were five important results of ANOVA test, Pearson correlation test, and independent samples t-test across hotel attributes and respondents' backgrounds for both TI and OI (see Table 5.3). For instance, our findings show that there was no significant difference in the mean-score price level related conflict with TI between the three hotel star rating levels ( $p=0.166$, see Appendix 1). In the meantime, The Pearson correlation test shows that there is a moderate positive correlation $(p=0.056)$ between hotel star rating and price level related conflict. This result reveals that higher star rating of hotels leads to an increase of the frequency of price level related source of conflict between hoteliers and TI.

One of the respondents from a 3-star hotel stated the following comment regarding its price level related conflict with $\mathrm{TI}$ :

"We are a local 3-star hotel, and for price level with TI, we do not usually have problems with them as we usually give them each year and always get along well with them. They may expect better rates, but it is also based on their previous year performance that they support us as well. So, I would say it is somewhat unlikely which is number 2." (Respondent\#7)

Another respondent from a 5-star hotel provided the following comment regarding the price level related source of conflict:

"[...] we are a five-star international hotel, and in the case of TI, it is normal that they always want a better rate than what they could support us for the room night numbers, so problems during negotiation are unavoidable related to the price level. So, I would say it is 4: Somewhat likely."

Regarding price level-related conflict with TI, there was no significant difference in the mean conflict with TI score between the three hotel star rating levels ( $p=0.166$, see Appendix 1). This result suggests that there were no differences in terms of mean score rating among the three hotel categories. 
With regards to the price-quality ratio related conflict with TI, the ANOVA test of the hotel age attribute illustrates that there was significant difference in the mean-scores of price-quality ratio related conflict with TI among the three categories of hotel age ( $p=0.045$, Table 5.3). From table 5.3.a, Post Hoc comparison Tukey HSD test indicates that the mean score for average hotel $(\mathrm{M}=2.67, \mathrm{SD}=1.496$, Appendix 1) trended towards significant difference from old hotels $(\mathrm{M}=1.67$, $\mathrm{SD}=0.492, p=0.067)$. These results suggest that average Cambodian hotels reported a slightly higher frequency of price-quality ratio related conflict with TI. However, the mean score of new hotels ( $\mathrm{M}=1.77, \mathrm{SD}=1.013$, Appendix 1) was not statistically different from average and old hotels $(p>0.05$, Table 5.3).

One respondent \#14 from an average hotel (4-10 years old) raised his views about price-quality ratio related conflict with TI:

"Our hotel was established six years ago and I would rate the price-quality ratio with traditional intermediaries as a number 3: About half of the time. We sometimes receive feedback from guests that our room cost is high compared to what we offer in our room facilities. This is when TI usually takes advantage of us by complaining that they have received a low rate."

Another respondent \#1 from an old hotel (above 10 year old) mentioned that he did not have many price-quality conflicts with TI. He stated :

"[...] we have been in operation for 12 years. We come up with our pricing year-by-year, and we decide to increase our pricing or decrease it based on the market. Our price tends to reflect the market well, and we do not have many issues based on this. I would rate it number 2 somewhat unlikely." 
Table 5.3.a ANOVA Post Hoc Tukey HSD test result for Price-Quality ratio with TA

\begin{tabular}{llrrrrr}
\hline \hline \multirow{2}{*}{$\begin{array}{l}\text { (I) How old is } \\
\text { your hotel? }\end{array}$} & $\begin{array}{l}\text { (J) How old is } \\
\text { your hotel? }\end{array}$ & $\begin{array}{c}\text { Mean Difference (I- } \\
\mathrm{J})\end{array}$ & & \multicolumn{4}{c}{ Std. Error } & $p$ value. & Lower Bound & Upper Bound \\
\hline \multirow{2}{*}{ New } & Average & -.897 & .424 & .100 & -1.93 & .14 \\
& Old & .103 & .448 & .972 & -.99 & 1.20 \\
\hline \multirow{2}{*}{ Average } & New & .897 & .424 & .100 & -.14 & 1.93 \\
& Old & 1.000 & .433 & .067 & -.06 & 2.06 \\
\hline \multirow{2}{*}{ Old } & New & -.103 & .448 & .972 & -1.20 & .99 \\
& Average & -1.000 & .433 & .067 & -2.06 & .06 \\
\hline \hline
\end{tabular}

Regarding the fulfillment of contract conditions related conflict between hotels and TI, our findings from Table 5.3 show that there was also a significant difference in the mean scores between Cambodians $(\mathrm{M}=1.91, \mathrm{SD}=1.027)$ and foreigners $(\mathrm{M}=1.13, \mathrm{SD}=0.354) ; t(38)=2.102, p$ $=0.042$ (see Appendix 7). This result reveals that the frequency of this type of conflict between hoteliers and TI is lower in hotels managed by foreigner than by Cambodians.

For instance, respondent \#8 (Cambodian) expressed his viewpoint on fulfillment of contract condition-related conflict:

"Traditional intermediaries do not fulfill contract conditions 100\%. Some local travel agencies, when they book two rooms, they occasionally give us a last-minute release notice. Sometimes they break because of the cancellation at the last minute, and then they send the requests about refunding the payment. Sometimes we agree, and sometimes we do not. Yes, we have some problems I would say number 4: most of the time."

However, foreign respondent \#4 expressed a different opinion when dealing with TI in terms of fulfillment of contract condition-related conflict:

"For Fulfillment of contract conditions with tour operators, they follow the contract very well, and we do not have any issues about that. Sometimes, we have some cancellations, and we also try to understand their situation. So, it is case by case. However, in reality, we 
prefer to avoid something that would ruin our business relationship. So, overall, we are good. I think the rating is number 1 for us: close to Never."

Cambodian respondents tended to perceive more battles resulted from this source of conflict than foreign managers. A few Cambodian managers mentioned that there are TI who do not always follow the terms of contracts. For instance, they try to avoid paying cancellation fees.

Another noticeable result at the contract stage is related to the frequency of the commission conflict between hotels of different ages and OI. Table 5.3 reveals that the finding was trended towards statistical significant threshold of 0.05 ( $p=0.067)$. Table 5.3.b of Post Hoc comparisons using the Tukey HSD test indicates that the mean score for average hotel was trended towards a significant difference with average hotels $(p=0.054)$. This finding reveals that average hotels ( $4-10$ years) seem to have faced more commission related conflicts with OI than new hotels (1-3 years) since average hotel score-mean was higher than the one for new hotels (see appendix 5). Our finding also shows that there is no significant difference in terms of frequency of this type of conflict between new $\&$ old hotels $(p=0.401)$ as well as average $\&$ old hotels $(p=0.603)$ since both $p$-values are greater than 0.05 .

There was another observable finding with regards to respondents' nationalities and the commission related conflict between hotels and OI. Table 5.3 illustrates that there was significant difference in the sore-means between Cambodians $(\mathrm{M}=1.39, \mathrm{SD}=0.659)$ and foreigners $(\mathrm{M}=2.22$, $\mathrm{SD}=1.202) ; t(40)=-2.762, p=0.009$ (see Appendix 7). Our finding suggests that when dealing with OI there were different perceptions of the frequency of commission related conflict between Cambodians and foreigners. On the basis of mean-scores, foreigners reported more repetition of this type of conflicts with OI than their counterpart Cambodians.

Foreign respondent\#13 from an average hotel commented on his experience when dealing with commission related conflict with OI:

"At an early stage of our hotel operation, we do not have many problems with online intermediaries. However, recently we faced some frequent problems such as low ranking 
on their pages, no show from guests and some online travel agencies did not take credit cards from guests making last minute bookings. So, we ended up with no payment sometimes."

On the other hand, Cambodian respondent $\# 27$ belonging to a new hotel expressed his positive perception in terms of commission related conflict with OI:

"[...] although we are new, commission is not a problem for us. We give them the commission rate that we agreed in the contract, and it is easy to deal with those online travel agencies such as booking.com, Agoda, Expedia, or Ctrip."

These two respondents experienced different frequency of the commission related conflict with OI. A new hotel managed by a Cambodian respondent above had a common perception of commission related conflict with OI. Nonetheless, average hotel with foreign respondent above had the opposite views with this regard. Communication and misunderstanding were among the factors that contributed to this.

Table 5.3.b ANOVA Post Hoc Tukey HSD test result for Commission with OI

\begin{tabular}{|c|c|c|c|c|c|c|}
\hline \multirow{2}{*}{$\begin{array}{l}\text { (I) How old is } \\
\text { your hotel? }\end{array}$} & \multirow{2}{*}{$\begin{array}{l}(\mathrm{J}) \text { How old is } \\
\text { your hotel? }\end{array}$} & \multirow{2}{*}{$\begin{array}{c}\text { Mean Difference (I- } \\
\text { J) }\end{array}$} & \multirow[b]{2}{*}{ Std. Error } & \multirow[b]{2}{*}{$p$ value } & \multicolumn{2}{|c|}{$95 \%$ Confidence Interval } \\
\hline & & & & & Lower Bound & Upper Bound \\
\hline \multirow[t]{2}{*}{ New } & Average & -.729 & .303 & .054 & -1.47 & .01 \\
\hline & Old & -.429 & .329 & .401 & -1.23 & .37 \\
\hline \multirow[t]{2}{*}{ Average } & New & .729 & .303 & .054 & -.01 & 1.47 \\
\hline & Old & .299 & .310 & .603 & -.46 & 1.05 \\
\hline \multirow[t]{2}{*}{ Old } & New & .429 & .329 & .401 & -.37 & 1.23 \\
\hline & Average & -.299 & .310 & .603 & -1.05 & .46 \\
\hline
\end{tabular}

All the remaining findings at the contract stage indicated that there were no statistical differences in terms of frequency of conflicts at $5 \%$ threshold with regards to hotel attributes and respondents' backgrounds. These results show common perceptions of the frequency of remaining conflicts at the contract stage. 


\subsection{Pre-stay stage of conflicts: Comparative study of potential sources of conflict}

In this section, we present the findings at the pre-stay stage of potential conflicts encountered by hotels with traditional intermediaries (TI) and online intermediaries (OI). The three prominent sources of conflicts in this stage are as follows: information provision, booking details, and cancellation terms compliance.

Table 5.4 Pre-stay stage of conflicts: Main findings by hotel attributes and respondents' backgrounds

\begin{tabular}{|c|c|c|c|c|c|c|c|c|c|c|c|}
\hline \multirow{2}{*}{\multicolumn{2}{|c|}{$\begin{array}{l}\text { AT: ANOVA Test } \\
\text { PCT: Pearson } \\
\text { Correlation Test } \\
\text { IT: Independent } \\
\text { Sample t-test }\end{array}$}} & \multicolumn{8}{|c|}{ Hotel attributes } & \multicolumn{2}{|c|}{$\begin{array}{l}\text { Respondents' } \\
\text { backgrounds }\end{array}$} \\
\hline & & \multicolumn{2}{|c|}{ Category } & \multirow{2}{*}{$\begin{array}{l}\text { Loca- } \\
\text { tion }\end{array}$} & \multirow{2}{*}{$\begin{array}{l}\begin{array}{l}\text { Owne- } \\
\text { rship }\end{array} \\
\text { AT } \\
\end{array}$} & \multicolumn{2}{|c|}{ Hotel Size } & \multicolumn{2}{|c|}{ Hotel Age } & \multirow{2}{*}{$\begin{array}{l}\text { Job } \\
\text { titles } \\
\text { IT } \\
\end{array}$} & \multirow{2}{*}{ 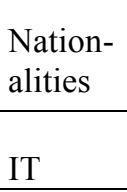 } \\
\hline Cond & cted Tests & AT & PCT & & & AT & PCT & AT & PCT & & \\
\hline & $\begin{array}{l}\text { Sources of } \\
\text { potential } \\
\text { conflicts } \\
\end{array}$ & & & & & & & & & & \\
\hline \multirow{6}{*}{$\begin{array}{l}\text { Pre- } \\
\text { stay } \\
\text { Stage }\end{array}$} & $\begin{array}{l}\text { Information } \\
\text { provision } \\
\text { with TI }\end{array}$ & $p=0.007$ & & & & & & & & & \\
\hline & $\begin{array}{l}\text { Booking } \\
\text { details TI }\end{array}$ & & & & & & & $p=0.02$ & & & \\
\hline & $\begin{array}{l}\text { Cancellation } \\
\text { Terms } \\
\text { Compliance } \\
\text { TI } \\
\end{array}$ & & & & & & & & & & \\
\hline & $\begin{array}{l}\text { Information } \\
\text { provision } \\
\text { with OI }\end{array}$ & & & & & & & & & & $p=0.004$ \\
\hline & $\begin{array}{l}\text { Booking } \\
\text { details OI }\end{array}$ & & & & & & & & & & \\
\hline & $\begin{array}{l}\text { Cancellation } \\
\text { Terms } \\
\text { Compliance } \\
\text { OI }\end{array}$ & & & & & $p=0.030$ & $p=0.008$ & & & & \\
\hline
\end{tabular}

Note: A five-point Likert Scale of perceived conflict from 1: Never, 2: Sometimes, 3: About half of the time, 4: Most of the time, 5: Always. 
In the case of information provision related conflict with TI, the finding of the ANOVA test presented in Table 5.4 shows that there was significant difference among the three hotel categories $(p=0.007)$. The Tukey HSD test presented in Table 5.4.a indicates that the mean score of the frequency of information provision conflict between 4-star hotels and TI was statistically different from 5-star hotels $(p=0.005)$. 4-star hotels seem to have more issues with TI for this type of conflict than 5-star hotels. However, the mean score of 3-star hotels $(p>0.05)$ was not statistically different from both 4 and 5-star hotels.

For example, respondent \#24 from a 4-star hotel commented on this issue:

"We somehow experienced this problem as well for provision of information. The main causes are probably from a lack of cooperation and follow up. Sometimes we do last minute promotion to fill up our room occupancy, but they occasionally complain that we do not update them. We usually update all our partners."

However, respondent \#11 from a 5-star hotel raised different opinions on this conflict:

"It is somewhat unlikely for information provision. It all depends on how the relationship is going. So, when we have updates, we update all the travel agents, and whether information is distributed correctly within these channels is the question. So, this is case by case."

Respondents from 4-star and 5-star hotels above expressed slightly opposite views with respect to provision of information related conflict that they encounter with TI.

Interestingly, the finding of Pearson correlation test shows that there is no significant correlation between hotel star rating and provision of information related conflict with TI [ $r=-0.240, p=0.135]$ (see appendix 1). This indicates that the star rating does not influence the frequency of the conflict with TI resulting from information provision. 
Table 5.4.a ANOVA Post Hoc Tukey HSD test result for Provision of information for TI

\begin{tabular}{llrrrrr}
\hline \hline \multirow{2}{*}{$\begin{array}{l}\text { (I) Star rating of } \\
\text { hotels }\end{array}$} & $\begin{array}{l}\text { (J) Star rating of } \\
\text { hotels }\end{array}$ & $\begin{array}{r}\text { Mean Difference (I- } \\
\mathrm{J})\end{array}$ & \multicolumn{3}{c}{$\begin{array}{c}\text { 9- } \\
\text { Std. Error }\end{array}$} & $\begin{array}{c}\text { value } \\
\text { Lowfidence Interval }\end{array}$ \\
\hline 3 & 4 & -.505 & .279 & .181 & -1.19 & .18 \\
& 5 & .206 & .272 & .730 & -.46 & .87 \\
\hline 4 & 3 & .505 & .279 & .181 & -.18 & 1.19 \\
& 5 & $.711^{*}$ & .213 & .005 & .19 & 1.23 \\
\hline 5 & 3 & -.206 & .272 & .730 & -.87 & .46 \\
& 4 & $-.711^{*}$ & .213 & .005 & -1.23 & -.19 \\
\hline \hline
\end{tabular}

Moreover, there was another significant finding in the case of hotel age from the table above with respect to booking details related conflict with TI ( $p=0.02)$. The Post Hoc comparisons Tukey HSD test in Table 5.4.b shows that the mean-score for new hotels was trended toward statistical significance from average hotels $(p=0.079)$. Also, the mean-score for average hotels was statistically different from old hotels $(p=0.025)$. These findings reveal that new and average hotels encountered different levels of conflicts' booking details with TI by comparison with old hotels.

For example, respondent\#35 from an average hotel described his experience with TI on the booking details related conflict as follows:

"For booking details, we have some issues as well. It mostly comes from the traditional intermediaries themselves. For example, when they book different room types and expect another one which sometimes happens. This happened because some of their staff have not learned about our property very well and some have not seen the room themselves."

However, respondent\#17 from an old hotel have an opposite view on this type of conflict:

"We have our system set up, and our staff have had extensive experience in managing bookings properly. This helps us a lot from making mistakes and makes our guests happy as well as our partners such as traditional intermediaries. So, with this problem, it is all good for us." 
The response from the above average hotel shows that this type of conflict could be related to the lack of product knowledge from the sale person working with traditional intermediaries, which could lead to wrong expectations from guests. The old hotel, on the other hand, did encounter this kind of conflict because of long-term operation and well-trained staffs.

Table 5.4.b ANOVA Post Hoc Tukey HSD test result for booking details with TI

\begin{tabular}{|c|c|c|c|c|c|c|}
\hline \multirow{2}{*}{$\begin{array}{l}\text { (I) How old is } \\
\text { your hotel? }\end{array}$} & \multirow{2}{*}{$\begin{array}{l}(\mathrm{J}) \text { How old is } \\
\text { your hotel? }\end{array}$} & \multirow{2}{*}{$\begin{array}{c}\text { Mean Difference (I- } \\
\mathrm{J}) \\
\end{array}$} & \multirow[b]{2}{*}{ Std. Error } & \multirow[b]{2}{*}{$p$ value } & \multicolumn{2}{|c|}{ 95\% Confidence Interval } \\
\hline & & & & & Lower Bound & Upper Bound \\
\hline New (1-3 years) & Average & -.559 & .250 & .079 & -1.17 & .05 \\
\hline & Old & .141 & .265 & .856 & -.51 & .79 \\
\hline Average (4-10 & New & .559 & .250 & .079 & -.05 & 1.17 \\
\hline years) & Old & $.700^{*}$ & .256 & .025 & .07 & 1.33 \\
\hline Old (above 10 & New & -.141 & .265 & .856 & -.79 & .51 \\
\hline years). & Average & $-.700^{*}$ & .256 & .025 & -1.33 & -.07 \\
\hline
\end{tabular}

Furthermore, regarding the provision of information related conflict with OI, our finding shows that the nationality of respondent matters. The independent sample t-test shows a significant difference in the score rating between Cambodians and foreigners $(p=0.004)$. Foreign managers in Cambodia encountered more often provision of information conflicts with TI than Cambodian managers (see Appendix 7).

For instance, a foreign manager\#24 described his views with OI for provision of information related conflict:

"We are not supposed to have this problem, but we experience it as well actually. For example, when we start our new channel for room selling such as on Expedia or Ctrip, we usually provide more detailed information about our hotel, our room types, facilities, and the surrounding environment. When our guests want to book the rooms at our hotels, they should have all information there, but some guests do not even read all the details, and 
when they arrive here, they complain to us. The problem happens but mostly from the guest's side."

In contrast, a Cambodian respondent\#17 expressed a different opinion on this issue:

"For provision of information, we do not have many conflicts based on this factor because we usually provide as many details as possible regarding our hotel. So, I would rate it number 1 -extremely unlikely."

Foreign respondent above noted that even his hotel had problem for provision of information related conflict, but it is mainly from the guests' sides and not from their part. The Cambodian respondent, however, perceived this conflict as rare and in broad agreement with most hoteliers who participated in this study.

Finally, concerning the cancellation compliance related conflict with OI, our results showed that there were two noticeable significant results for ANOVA and Pearson correlation tests with respect to hotel size. Table 5.4 showed that there was significant statistical difference in the mean-scores between the three hotel sizes ( $p=0.03)$. From table 5.4.c, Post Hoc comparisons using Tukey HSD test result for cancellation terms compliance related conflict with OI illustrates that small hotels faced different frequency of conflicts from large hotels ( $p=0.028$, see Appendix 4). However, medium hotels reflect common perception of the frequency of conflicts with small and large hotels ( $p>0.05$, see Appendix 4). Finally, Pearson Correlation test result indicates that there is a negative correlation $[r=-0.402, p=0.008]$ between hotel size and cancellation terms compliance related with OI (see the Appendix 4). Larger hotels encountered less cancellation terms compliance related conflicts with OI than small hotels.

For instance, hotelier\#19 from a small hotel faced the following experiences with cancellation terms compliance related conflict with OI. 
"We had some problems for cancellation terms when some online travel agencies such as Booking.com accepted bookings from guests without requesting their credit cards. This became a problem when the guest changed their mind at the last minute and they didn't turn up at our hotel."

In contrary to hotelier\#19, respondent\#31mentioned different experiences with this type of conflict:

\begin{abstract}
"We do not have many conflicts in this area. Usually, the cancellation terms of online intermediaries show the guests the period when cancellations are free; when there will be a 50\% charge; and then a 100\% charge. If they cancel at the last minute, they need to bear that cost, and usually, online intermediaries do not negotiate on this matter."
\end{abstract}

Even hotelier\#19 above expressed some problems that his hotel faced with cancellation terms compliance related conflict with OI, but hotelier\#31 along with most other hoteliers who participated in this study perceived this type of conflict with OI rather a rare problem. This is because most online intermediaries usually require credit cards before accepting bookings and they can charge when necessary.

Table 5.4.c ANOVA Post Hoc Tukey HSD test result for cancellation terms compliance with OI

\begin{tabular}{|c|c|c|c|c|c|c|}
\hline \multirow{2}{*}{$\begin{array}{l}\text { (I) What is the } \\
\text { size of your } \\
\text { hotel? }\end{array}$} & \multirow{2}{*}{$\begin{array}{l}(\mathrm{J}) \text { What is the } \\
\text { size of your } \\
\text { hotel? }\end{array}$} & \multirow{2}{*}{$\begin{array}{c}\text { Mean Difference (I- } \\
\mathrm{J})\end{array}$} & \multirow[b]{2}{*}{ Std. Error } & \multirow[b]{2}{*}{$p$ value } & \multicolumn{2}{|c|}{$95 \%$ Confidence Interval } \\
\hline & & & & & Lower Bound & Upper Bound \\
\hline Small hotel (1-50 & Medium hotel & .612 & .378 & .250 & -.31 & 1.53 \\
\hline rooms) & Large hotel & $.991^{*}$ & .368 & .028 & .09 & 1.89 \\
\hline Medium hotel & Small hotel & -.612 & .378 & .250 & -1.53 & .31 \\
\hline (51-120 rooms) & Large hotel & .379 & .417 & .638 & -.64 & 1.39 \\
\hline Large hotel & Small hotel & $-.991^{*}$ & .368 & .028 & -1.89 & -.09 \\
\hline $\begin{array}{l}\text { (Above } 120 \\
\text { rooms) }\end{array}$ & Medium hotel & -.379 & .417 & .638 & -1.39 & .64 \\
\hline
\end{tabular}


With regard to Table 5.4, the findings illustrate that there were no statistical significances in terms of the mean scores between the sources of conflict in the pre-stay stage of conflict and the remaining hotel attributes and respondents' backgrounds.

\subsection{Stay stage of conflicts: Comparative study of potential sources of conflict}

Table 5.6 summarizes the results of the source of conflicts in the stay stage of conflicts in terms of hotel attributes and respondents' backgrounds. Operation error related-conflict and overbooking related-conflict were the main two sources of conflicts in this stage.

Table 5.5 Stay stage of conflicts: Main findings by hotel attributes and respondents' backgrounds

\begin{tabular}{|c|c|c|c|c|c|c|c|c|c|c|c|}
\hline \multirow{2}{*}{\multicolumn{2}{|c|}{$\begin{array}{l}\text { AT: ANOVA Test } \\
\text { PCT: Pearson Correlation Test } \\
\text { IT: Independent Sample t-test }\end{array}$}} & \multicolumn{8}{|c|}{ Hotel attributes } & \multicolumn{2}{|c|}{$\begin{array}{l}\text { Respondents' } \\
\text { backgrounds }\end{array}$} \\
\hline & & \multicolumn{2}{|c|}{ Category } & \multirow{2}{*}{ 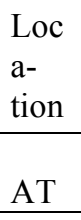 } & \multirow{2}{*}{$\begin{array}{l}\text { Own } \\
\text { e- } \\
\text { rship }\end{array}$} & \multicolumn{2}{|c|}{ Hotel Size } & \multicolumn{2}{|c|}{ Hotel Age } & \multirow{2}{*}{$\begin{array}{l}\begin{array}{l}\text { Job } \\
\text { titles }\end{array} \\
\text { IT } \\
\end{array}$} & \multirow{2}{*}{ 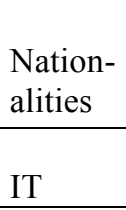 } \\
\hline \multicolumn{2}{|c|}{ Conducted Tests } & AT & PCT & & & AT & PCT & AT & PCT & & \\
\hline & $\begin{array}{l}\text { Sources of } \\
\text { potential conflicts }\end{array}$ & & & & & & & & & & \\
\hline \multirow{4}{*}{$\begin{array}{l}\text { Stay } \\
\text { Stage }\end{array}$} & $\begin{array}{l}\text { Operation error } \\
\text { with TI }\end{array}$ & & & & & & & & & & \\
\hline & $\begin{array}{l}\text { Overbooking } \\
\text { with TI }\end{array}$ & & $p=\mathbf{0 . 0 5 5}$ & & & $p=0.051$ & & & & & $p=0.062$ \\
\hline & $\begin{array}{l}\text { Operation error } \\
\text { with OI }\end{array}$ & & $p=0.096$ & & & & & & & & \\
\hline & $\begin{array}{l}\text { Overbooking } \\
\text { with OI }\end{array}$ & & & & & & & & & & \\
\hline
\end{tabular}

Note: A five-point Likert Scale of perceived conflict from 1: Never, 2: Sometimes, 3: About half of the time, 4: Most of the time, 5: Always

Referring to Table 5.5, the findings illustrate that all the highlighted results trended towards statistical significance for overbooking related conflict with TI in terms of hotel category, hotel size, and respondents' nationalities. For instance, there is a negative moderate correlation [ $r=-$ 
0.306, $p=0.055$, see Appendix 1] between hotel star rating and overbooking related conflict with TI. This finding indicated 5-star hotels reported a lower frequency of conflicts than 4 and 3-star hotels. Likewise, trended towards significant level (0.05) was observed between overbooking related conflict and TI with regards to the three hotel sizes $(p=0.051)$. In Table 5.5.a, Post Hoc comparisons using Tukey HSD test result for overbooking related conflict with TI illustrated that medium hotels perceived more of this type of conflict than large hotels $(p=0.048)$. However, small hotels encounter similar level of this conflict with medium and large hotels $(p>0.05)$. Similarly, in the case of respondent's nationalities, the finding trended towards statistical significance between the mean-scores of Cambodians and foreigners with respect to overbooking related conflicts with TI $(p=0.062)$. This result reveals that Cambodian managers faced more frequently this type of conflict than foreign managers.

Cambodian respondent \#1 from a medium 5-star hotel described his experiences of conflict with overbooking-related conflict with TI:

"Overbooking through traditional intermediaries is not really a big problem because we usually receive bookings from them a long period before the guest's arrival. So, from our side, we have a good amount of time to manage everything. Also, our booking system helps us a lot. Most of our guests are Free Independent Travelers (FIT), and it is easy as well."

Contrary to the above respondent, foreign respondent\#28 from large 3-star hotels expressed slightly more overbooking related conflicts with TI:

"We work closely with Asian tourists, and we receive many bookings especially from Chinese tourists. Since most of their bookings are group tours, we sometimes have overbooking problems as well. Their group tours are big, and if not managed properly we sometimes have that problem."

Respondent \#1 from the 5-star hotel above stated that he had no overbooking-related conflict with TI due to the fact that his hotel had a good booking system in operation as well long-term bookings. His hotel received mostly FIT guests, which lessened the chance of this type of conflict arising. In 
contrast, the respondent \#28 from the 3-star hotel above perceived more issues for this source of conflict because he received mostly Group Inclusive Tour (GIT) guests who are usually a big group of tourists.

Table 5.5.a ANOVA Post Hoc Tukey HSD test result for Overbooking-related conflict with TI

\begin{tabular}{|c|c|c|c|c|c|c|}
\hline \multirow{2}{*}{$\begin{array}{l}\text { (I) What is the } \\
\text { size of your } \\
\text { hotel? }\end{array}$} & \multirow{2}{*}{$\begin{array}{l}\text { (J) What is the } \\
\text { size of your } \\
\text { hotel? }\end{array}$} & \multirow{2}{*}{$\begin{array}{c}\text { Mean Difference (I- } \\
\text { J) }\end{array}$} & \multirow[b]{2}{*}{ Std. Error } & \multirow[b]{2}{*}{$p$ value } & \multicolumn{2}{|c|}{ 95\% Confidence Interval } \\
\hline & & & & & Lower Bound & Upper Bound \\
\hline Small hotel (1-50 & Medium hotel & -.411 & .206 & .128 & -.91 & .09 \\
\hline rooms) & Large hotel & .139 & .195 & .758 & -.34 & .61 \\
\hline Medium hotel & Small hotel & .411 & .206 & .128 & -.09 & .91 \\
\hline (51-120 rooms) & Large hotel & $.550^{*}$ & .224 & .048 & .00 & 1.10 \\
\hline Large hotel & Small hotel & -.139 & .195 & .758 & -.61 & .34 \\
\hline $\begin{array}{l}\text { (Above } 120 \\
\text { rooms) }\end{array}$ & Medium hotel & $-.550^{*}$ & .224 & .048 & -1.10 & .00 \\
\hline
\end{tabular}

Another result with regards to operation error related conflict with OI also trended towards statistical significance in the case of hotel category. Our findings show that there was a positive moderate correlation [ $r=0.260, p=0.096$; see Appendix 1] between hotel star rating and operation error related conflict with TI. This result shows that 5-star hotels had more issues with operation error related conflict than 4 and 3-star hotels.

For example, respondent \#35 from a 5-star hotel commented on this issue:

“With online intermediaries, we experienced more problems resulting from operation error because bookings with online intermediaries are usually arranged at short notice. The problems that we experience with operational errors have included missed pickups of guests from the airport, which we occasionally include as a free service, and assigning the wrong room type once in a while."

In contrast, 3-star hotel respondent\#23 had different perception regarding this type of conflict: 
"I would say it is rare for us to experience this as we are small hotel with few rooms. We have complete control over our guests' services and train our staff to have proper attention for detail on every aspect during their stay with us. So, I would rate this as somewhat unlikely.

The above respondent from 5-star hotel mentioned the types of operation error that his hotel faced, which were mostly related to late pick up for guests from the airport or providing wrong room type to guests. However, similar to many hoteliers who participated in this study, respondent\#23 from a 3-star hotel mentioned that he did not experience this type of conflict. Operation error with TI are the among lowest sources of conflicts mentioned in the previous chapter.

All the remaining situations in table 5.5 show that there were no significant differences with respect to the mean-scores between the sources of conflicts in stay stage and the remaining hotel attributes and respondents' backgrounds.

\subsection{Post-stay stage of conflicts: Comparative study of potential sources of conflicts}

The findings presented in this section illustrate the results of the sources of conflicts at the poststay stage in terms of hotel attributes and respondents' backgrounds. This last stage is made up of the following types of conflicts: payment and complaint handling related conflicts

The ANOVA results for complaint handling of hotels with TI reveal that there was no significant difference in the mean-scores of complaint handling between the three hotel star rating levels ( $p=0.095$, Table 5.6). However, the statistical findings show that the results trended towards significant level $(p=0.05)$. Furthermore, the independent sample t-test by respondents' nationalities for the same type of conflict between hotels and TI shows that there was significant difference in terms of mean scores between Cambodian managers and foreign managers. This result revealed that Cambodian respondents reported having more complaint handling conflicts with TI than foreign respondents. 
Table 5.6 Post-stay stage of conflicts: Main findings by hotel attributes and respondents' backgrounds

\begin{tabular}{|c|c|c|c|c|c|c|c|c|c|c|c|}
\hline \multirow{2}{*}{\multicolumn{2}{|c|}{$\begin{array}{l}\text { AT: ANOVA Test } \\
\text { PCT: Pearson Correlation } \\
\text { Test } \\
\text { IT: Independent Sample t- } \\
\text { test }\end{array}$}} & \multicolumn{8}{|c|}{ Hotel attributes } & \multicolumn{2}{|c|}{$\begin{array}{l}\text { Respondents' } \\
\text { backgrounds }\end{array}$} \\
\hline & & \multicolumn{2}{|c|}{ Category } & \multirow{2}{*}{\begin{tabular}{|l}
$\begin{array}{l}\text { Loca- } \\
\text { tion }\end{array}$ \\
AT \\
\end{tabular}} & \multirow{2}{*}{$\begin{array}{l}\begin{array}{l}\text { Owne- } \\
\text { rship }\end{array} \\
\text { AT }\end{array}$} & \multicolumn{2}{|c|}{ Hotel Size } & \multicolumn{2}{|c|}{ Hotel Age } & \multirow{2}{*}{$\begin{array}{l}\begin{array}{l}\text { Job } \\
\text { titles }\end{array} \\
\text { IT } \\
\end{array}$} & \multirow{2}{*}{$\begin{array}{l}\begin{array}{l}\text { Nation- } \\
\text { alities }\end{array} \\
\text { IT }\end{array}$} \\
\hline \multicolumn{2}{|c|}{ Conducted Tests } & AT & PCT & & & AT & PCT & AT & PCT & & \\
\hline & $\begin{array}{l}\text { Sources of } \\
\text { potential conflicts }\end{array}$ & & & & & & & & & & \\
\hline \multirow{4}{*}{$\begin{array}{l}\text { Post- } \\
\text { stay } \\
\text { Stage }\end{array}$} & Payment with TI & & & & & & & & & & \\
\hline & $\begin{array}{l}\text { Complaint handling } \\
\text { with TI }\end{array}$ & $p=0.095$ & & & & & & & & & $p=0.017$ \\
\hline & Payment with OI & & & & & & & & & & $p=0.002$ \\
\hline & $\begin{array}{l}\text { Complaint handling } \\
\text { with OI }\end{array}$ & & & & & & & & & & $p=0.052$ \\
\hline
\end{tabular}

Note: A five-point Likert Scale of perceived conflict from 1: Never, 2: Sometimes, 3: About half of the time, 4: Most of the time, 5: Always

For example, Cambodian respondent \#29 referred to complaint handling-related conflict with TI:

"We have some problems for complaint handling when dealing with traditional intermediaries. The problems happen because guests are not happy with our services but they did not tell us during their stay, but they report that to their travel agents who arranged everything for them. And usually it becomes complicated when they already left the country and leave us to deal with their travel agents."

On the contrary to the above respondent, foreign hotelier\#37 stated that his hotel faced less of this type of conflict with TI: 
"We do not have many problems in terms of this issue. We aim to maintain a good relationship with traditional intermediaries because they are our big supporter and complaint handling is one of our priorities. We do not receive many complaints from our partners such as travel agencies because we train our staff to regularly check our guests' satisfaction levels throughout their time with us. We believe this helps to reduce the amount of complaints that we receive."

The two respondents disagreed with regards to complaint handling related conflict with TI. However, from the overall rating, complaint handling related conflict with TI was among the top four sources of conflicts that hoteliers in Cambodia have faced

The results regarding the payment related conflict with OI showed that there was significant difference in terms of mean scores between Cambodians and foreigners $(p=0.002)$. Foreign managers seem to have encountered more of this conflict than Cambodian respondents.

For example, foreign manager\#17 explained why his hotel encountered payment related conflict with OI:

"I would say it is somewhat likely for payment with online intermediaries when the guests used bad or stolen credit cards to book their rooms. We could end up with no charge to them because of this. Another problem is with the OI themselves that they allow guests to book rooms without credit cards; that can cause many problems."

However, Cambodian respondent\#29 perceived this type of conflict as less problematic:

"Payment from online intermediaries is not a big deal for us. They pay us as normal, and we do not have any issues with that. Most of them are multi-national companies, and they charge guests when they make bookings, so they have that money to pay us right away. I think it is extremely unlikely for us." 
Finally, another interesting result was also found with regard to complaint handling related conflict with OI. In terms of respondents' nationalities, the finding trended towards significance level $(p=0.052)$. This outcome suggests that there was also different level of frequency of conflict between foreigners and Cambodians with respect to complaint handling. Foreigners tended to face more of this conflict than Cambodians (see Appendix 7).

For instance, foreign respondent\#1 raised his views on why he observed this different from the local respondent:

"We experienced some problems of complaint handling with OI as well. It mostly happens with high-end guests who expect more than we offer, and they always complain to get some extra services for free or even a refund. Dealing with these kinds of guests, even small mistakes would result in a complaint when they go back to their countries."

Opposed to the above respondent, Cambodian hotelier \#5 mentioned that complaint handlingrelated conflict was less conflicting:

"I would say that this problem is less of a conflict for us. We cannot avoid it, but it does not occur so often for us. Because we want to get a good rating on the online reviews, we take care of our guests very carefully, and it pays off. We receive many good reviews from guests who booked through OI."

The above foreign respondent\#1 justified the higher frequency of this complaint handling conflict with OI by the fact that he targets a luxury clientele with expectations that are sometime hard to satisfy. The Cambodian respondent above provided different opinions about this problem. He experienced less of this type of conflict because his main focus is to enhance his hotel's service quality.

All the remaining results indicate that there were no statistical differences with respect to the mean scores between the sources of conflicts in post-stay stage and the remaining hotel attributes and respondents' backgrounds. 


\subsection{Chapter summary}

The findings in this chapter illustrate that there are some significant differences between respondents due to hotel attributes and respondents' backgrounds. With regards to the overall level of satisfaction, different perceptions from respondents were found for the attributes of hotel size and hotel age. However, there were no perceived differences of conflicts found among the respondents resulted from hotel attributes and respondents' backgrounds. Moreover, regarding the comparative study of potential sources of conflict among the four stages of conflicts, the different perception of the conflicts is found mostly in respondents' nationalities, hotel category, hotel size,

and hotel age with both TI and OI. However, more differences were found for hotel category with TI, while more differences were found for respondents' nationalities with OI. It is interesting to note that no statistical differences were found in the case of hotel location, ownership, and respondents' job titles. This indicated that within these cases, respondents had common perceptions of the potential sources of conflict with intermediaries. With respect to the sources of conflicts, different views were mostly associated with overbooking-related conflict with TI, complaint handling-related conflict with TI, cancellation terms compliance-related conflict with OI, and commission-related conflict with OI.

Chapters 4 and 5 have provided understandings regarding the level of satisfaction and potential sources of conflicts with both traditional and online intermediaries. The next chapter focuses on discussions, implications, recommendations and a conclusion for this study. 


\section{Chapter 6 Discussions, implications, and conclusions}

\subsection{Introduction}

This chapter discusses the key findings in chapter 4 and 5 in relation to the previous literature in chapter 2 by taking the research aims as the guide. The key findings will be highlighted by comparing and contrasting them with the previous studies on the satisfaction of hotels with their intermediaries, the sources of conflicts between hotels and their intermediaries, and the differences with respects to the level of satisfaction and sources of conflicts.

The first section of this chapter presents the research aims of this study. The second part discusses the first aim of the research which is about the overall level of satisfaction of hoteliers and intermediaries in Cambodia. This part explains why the level of satisfaction from hoteliers in Cambodia is slightly different from the previous studies. The third section examines the sources

of conflicts that arise between hotels and intermediaries in Cambodia and explains why the respondents from this study perceive similar viewpoints as previous studies. The fourth section discusses the cross-analysis of the level of satisfaction and sources of conflicts that influence hotel attributes and respondents' backgrounds (section 6.5). A summary of the main findings is presented in section 6.6, and the implications and recommendations are given in section 6.7. The contribution of this research to academic literature is presented in section 6.8; and section 6.9 presents the research limitations; and section 6.10 presents avenues for future research.

\subsection{Reminder of research aims}

The main focus of this thesis is to examine hoteliers' perceptions of the level of satisfaction and sources of conflicts with both traditional and online intermediaries in Cambodia. This study has three following aims:

1. To unveil the overall level of satisfaction of hoteliers with intermediaries in Cambodia

2. To discuss the sources of conflicts that arise between hotels and intermediaries in Cambodia 
3. To assess whether there are differences in terms of levels of satisfaction as well as sources of conflicts between traditional and online intermediaries

The next section will discuss the first aim of this study by looking at previous studies in this field.

\subsection{Discussion aim 1: Overall level of satisfaction of hoteliers with intermediaries in Cambodia}

The findings of this study reveal that the overall level of satisfaction of hoteliers in Cambodia with both traditional and online intermediaries is very positive. As shown in Table 4.1 in chapter 4, the level of satisfaction of hoteliers with traditional intermediaries (TI) ranged from "Somewhat good" to "Extremely good" with an overall mean-score of 4.13 out of 5.00 . Similarly, the level of satisfaction of hoteliers with online intermediaries (OI) is slightly lower with a mean-score of 4.00 which is also between "Somewhat good" to "Extremely good." The findings of this study are partly consistent with previous studies that revealed that hotels often have good relationships with TI and OI. With regards to TI, our finding is different with previous research because hoteliers in Cambodia seem to have a very positive perception of their level of satisfaction with TI. However, the finding with regards to the level of satisfaction with OI is consistent with previous studies.

For instance, the study conducted by Bastakis et al. (2004) on the level of satisfaction of hoteliers with TI in Eastern Mediterranean provides different results from the case of Cambodia. The authors argue that accommodation owners/managers in Eastern Mediterranean had a low level of satisfaction with traditional intermediaries such as large tour operators in terms of their personal and professional relationship. The authors assert that their relationship is ruined due to the fact that these tour operators are unresponsive or disrespectful with hotels. Hoteliers in this region reported that these compagnies had a very limited knowledge of their destinations and treated them very poorly. Moreover, those managers seemed to have had tough financial targets to meet which reflects their own incentives. This situation pushed them to have harsh negotiation with accommodation providers, and their relationship is perceived as poor (Bastakis et al., 2004). Another research which is aligned to these findings was conducted by (Buhalis, 2000b). In his 
study, this author also found that hoteliers in Mediterranean region are disappointed with their intermediaries. The overall score-mean of their relationship with intermediaries was 2.18 (1-5: Much worse -Much better) which illustrates that the level of satisfaction with TI had even deteriorated over time. Similarly, another study conducted by Medina-Muñoz and García-Falcón (2000) also confirmed that traditional intermediaries such as travel agencies did not establish good business relationship with hoteliers in Britain and Germany. This poor relationship reflects a low level of satisfaction with TI.

To sum up, all the above studies provide different findings from our case study in Cambodia which illustrates that most of hoteliers in Cambodia have a very good level of satisfaction with TI. One of the reasons that could explain this positive level of satisfaction is probably due to the fact that most traditional intermediaries in Cambodia are relatively small and medium firms that do not possess excessive power to influence hoteliers too much during their negotiation process which is in contrast to the findings of the above studies conducted in Britain, Germany, and Mediterranean region. Another possible explanation is related to the fact that hoteliers in Cambodia rely nowadays on different distribution channels and not only traditional intermediaries. As discussed in chapter 4, hotels in Cambodia also rely on online intermediaries and corporate segments as well. This may somehow provide some bargaining power to face traditional intermediaries.

With respect to the level of satisfaction with OI, the finding of this study is consistent with previous studies that revealed a good level of satisfaction of the relationship between hoteliers and OI. For instance, Myung et al. (2009) show that hoteliers in the Southwest and Midwest regions of the US were satisfied with the performance and contribution of online intermediaries to their businesses despite the fact that they face from time to time some problems with these online intermediaries. Hoteliers perceived OI as the business partners that assist them in inventories distribution, expose their properties to the global markets, and provide them assistance when problems arise (Myung et al., 2009). Additionally, hoteliers also have a positive perception in terms of profit generation by OI since they help to increase their sales volumes (Myung et al., 2009). The study from these scholars has aligned with the findings of our case study which revealed that the overall level of satisfaction of hoteliers in Cambodia with OI is good. Hoteliers in Cambodia perceived that OI helps to push their businesses when they do not receive adequate bookings from other channels of distributions, especially from last minute bookings. They mentioned that they could only rely on 
OI if they need to sell their rooms in the last minute and this has helped them to maximize their revenues. Another aspect which makes them happy with OI is due to the fact that it is easy to conduct business with OI and hoteliers are in complete control of their sale strategies. For instance, one respondent commented that he prefers working with OI because it is all online and they could sell his hotel's room based on the real situation, and he could introduce promotion to his guests anytime.

\subsection{Discussion aim 2: Potential sources of conflicts with intermediaries in Cambodia}

With regards to the second research aim, the findings of this study suggest that there are some potential sources of conflicts with intermediaries that hoteliers in Cambodia encounter when they deal with TI and OI. The conflicts also vary in terms of frequency as discussed in chapter 4 (see Table 4.4). Our study reveals that the most conflictual sources of conflicts with TI include price level, payment and price-quality ratio related conflicts. These results are partly consistent with the previous literature. Similarly, this study found that the most dominant sources of conflicts for OI are price related conflicts, overbooking related conflict, and complaint handling related conflict (see Table 4.4). To some degree, these findings are similar to previous studies.

First, in terms of sources of conflicts with TI, Table 4.4 illustrates that the mean-scores of price level related conflict, payment related conflict, and price-quality ratio related conflict ranged from 2.08 to 2.53 which reflects as "Somewhat unlikely" to "Neither likely nor unlikely." These three sources of conflicts are perceived as more problematic than others. Similar to our study, Ivanov et al. (2014) argue that the most common conflicts between hoteliers and travel agencies in Bulgaria are related to delayed payments, disagreement regarding prices, and misinforming customers from travel agencies. On the five-point scale of Likert scale (1: very rarely -5: very often), these authors found that the mean scores of Bulgarian hoteliers regarding the above three common sources of conflicts with travel agents ranged from 2.34 to 3.00 which are quite similar the mean-scores of hoteliers in Cambodia. Thus, the findings of this study partly align with the early study conducted by Ivanov et al. (2014) regarding the sources of conflicts between accommodation establishments and travel agencies in the context of Bulgaria. We also found the following two common sources 
of conflicts: payment and price level related conflicts. While hotel managers in Cambodia found that price-quality ratio related conflict is the most common source of conflict with TI, the study related to Bulgarian hoteliers found that this is not the case. Information provision (misinforming customers) was the most common one with regards to their relationship with travel agents. Ivanov et al. (2014) assert that information provision is one of the most common sources of conflict between accommodation providers and travel agencies in Bulgaria. This is probably related to the fact that there are often issues that occur when travel agencies present wrong information about accommodation establishments on their website such as renovation plan, and promotion. In contrast, respondents from Cambodia revealed that provision of information between hoteliers and TI is among the least sources of conflicts. Partly different from what Ivanov et al. (2014) pointed out, Buhalis (2000b) argue that, in his study of conflicts between hoteliers and tour operators in the Mediterranean region, the most common sources of conflicts with TI from the perspective of hoteliers include price related conflict, contract \& agreement related conflict, and tour operators' bankruptcies. The author states that price related conflict was related to the price level negotiation and the bargaining power of tour operators to pay a low price to hoteliers in this region. Another prominent source of conflict is related to contract \& agreement between hoteliers and tour operators who are not always willing to comply with contract terms agreement. Tour operators' bankruptcy is also another major source of conflict that hoteliers in his study had experienced, leading to a huge amount of losses when tour operators are forced into liquidation (Buhalis, 2000b). These findings are moderately different from the results in Cambodia which also found that the price level related conflict is an important source of conflict with TI, similar to Buhalis's findings.

Fulfillment of contract conditions (or contract \& agreement in Buhalis's study) is less frequent issue in the context of Cambodia.

In terms of sources of conflicts with OI, the findings of this study found that price related conflict, overbooking related conflict, and complaint handling related conflict are the most common ones. The mean scores of these sources of conflicts were slightly lower than those with TI and ranged from 1.71 to 2.60 which is between "Extremely unlikely" to "Neither likely nor unlikely." These findings align with the previous literature to some extent. For instance, Myung et al. (2009) found 
in their study that price was the most problematic source of conflict with OI. The authors stated that online intermediaries such as large online travel agencies have the power to influence the room rate given the advantages that they have to allow guests comparing room rates across a large number of hotels within the same area. Consequently, hotels always need to update their room rates for OI in order to align with the rates offered by their competitors. Similar to this study, Christodoulidou, Brewer, Feinstein, and Bai (2007) also stated that price related conflict is one of the challenges that hotels face, especially with rate parity. Hotels find it difficult to manage rate parity across all OI channels of distribution and this could lead to some problems for them. Hoteliers from Cambodia also perceive price level related conflict as one of the most essential sources of conflicts with OI. They mentioned that price manipulation from OI channels lead to price parity and this occurs frequently. For example, even hoteliers are willing to keep rate parity across all channels for their hotels, and some OI manipulates prices by undercutting their commission and display a bit lower rate on their channels while hotels still get the same price that they put on sales. If hotels do not control accurately, it causes conflicts with other OI channels who found the price differences of hotels in their systems. Ling, Dong, Guo, and Liang (2015) argue that high commission to OI is one of the primary source of conflicts between hotels and OI. This commission rate could be as high as $15 \%-30 \%$. The authors state that hotels could effectively avoid this problem by introducing online booking system so that customers can book through their own hotel websites. This finding is in contrast with the situation in Cambodia which revealed that hotels in this country had faced less commission related conflict with OI. The respondents from this study commented that the commission rates that they pay ranged from $15 \%-22 \%$ which are slightly lower than the previous study, yet they perceive that is less conflictual once they already agree at the first time and this rate is not much of the negotiation.

\subsection{Discussion aim 3: differences of levels of satisfaction and sources of conflicts by hotel attributes and respondents' backgrounds}

With regards to the level of satisfaction with TI and hotel attributes, the most differences were found among hotel size (small vs. medium vs. large), and hotel age (new vs. average vs. old). In respect to sources of conflicts by hotel attributes and respondents' background, the main 
differences were found among the three categories of hotels, hotel size, hotel age, and respondents' nationalities. The findings with trending towards statistical significant level $(p>0.05)$ will not be discussed in this chapter.

The findings of this study reveal that the main differences are found in hotel size with regards to the overall level of satisfaction of hoteliers in Cambodia with TI. The results show that there are differences of perception of the level of satisfaction between small and large hotels. The respondents from small hotels in this study seem to be less satisfied than those belonging to large hotels. This could be due to the fact that small hotels have fewer rooms. Since traditional intermediaries require room allotments, small hotels might find it hard to commit. Bastakis et al. (2004) explain that small accommodation enterprises tend to experience tougher cooperation with tour operators than large accommodation enterprises because they tend to receive more pressures during negotiation than the large ones. The authors further assert that small accommodation enterprises are frequently run by family and lack of expertise and the resources to find other distribution channels. With regards to the influence of hotel age on the level of satisfaction with TI, Buhalis (2000b) argue that new hotels tend to be more satisfied with their relationship with tour operators and the possible underlying reason is that tour operators tend to change from old hotels to the new ones because they provide more modern facilities which is good for better competitiveness between hotels. This finding is different from the result in Cambodia which found that old hotels have a higher level of satisfaction with TI. One possible explanation is that old hotels in Cambodia may have built a long-term business relationship for many years and they understand each other more, which help to contribute to this good level of satisfaction between old hotels and TI.

In terms sources of conflicts, the findings of this study show that there are main differences in terms of hotel category for information provision related conflict with TI. Ivanov et al. (2014) revealed that there were no differences among hotel categories in Bulgaria with regards to the provision of information. The authors state that misinforming customers were among the primary sources of conflicts. These findings are different for our study which found that there were differences among 4-star and 5-star hotels for their perception on provision information related conflict. The 4-star hotel respondents from this study encountered more of this type conflict than 
those from 5-star hotels. Among the reasons that they mentioned, they cited the level of cooperation. 5-star hotels tend to have better cooperation, and they perceive this as less conflictual. With respect to hotel size, the findings of this study revealed differences among hotels for cancellation terms compliance with OI. Small hotels faced more of this type of conflict than large hotels, and one of the possible explanation is the booking without guests' credit cards. This is one of the reasons that small hotels used to explain the reason of this type of conflict because when guests cancel their room bookings, hotels could not charge for cancellation fees and that is when this type of conflict occurs between hoteliers and OI. No previous research mentioned this detail regarding information provision related conflict with OI. Thus, this is a new finding not mentioned in previous studies.

Ivanov et al. (2014) investigated cancellation terms compliance with TI, especially with travel agencies and tour operators, and found significant differences among hotel attributes. They found that large hotels in Bulgaria encounter more conflicts with cancellation terms compliance than small hotels do. Large hotels cooperate more often with TI because they have more room available to sell. As a result, this causes more frequent cancellation terms compliance related conflicts.

Regarding hotel age, the results of this research indicate that there are differences between average and old hotels in terms of price-quality ratio related conflict. Respondents from average hotels have encountered more price-quality ratio conflicts than old hotels. This could be due to the fact that old hotels have more experiences in the market and they are in a better position to evaluate the market price every year to reset their room rate based on their previous rates, facilities and quality of the rooms that they offer by comparison with other competitors in the market. Similarly, the findings of our case study found some differences in terms of booking details conflicts between hoteliers and TI in Cambodia. Average hotels rated higher level of booking details conflict than old hotels. To our knowledge, no previous studies have examined the relationship between pricequality ratio and booking details related conflicts and the age of hotels. Both Buhalis (2000b) and Ivanov et al. (2014) discussed the above sources of conflicts by taking into account only hotel size. Hence, these findings could not be compared or contrasted with the previous literature. 
Finally, with respect to respondents' nationalities, some differences were also found with regard to fulfillment of contract conditions and complaint handling related conflicts between hoteliers and TI. In both cases, Cambodian managers encountered more of these two types conflicts with TI than foreigners. Foreign managers reported that they tend to value business relationship over personal relationships with TI, and when conflicts occur, it is more "objective" rather than "subjective." Cambodian respondents value both types of relationships, but personal relationship tends to come first. There were previous studies by Medina-Muñoz et al. (2003), Buhalis (2000b), and Ivanov et al. (2014) regarding these same sources of conflicts, however; these authors did not assess the influence of the nationality of the respondent on the perceived level of conflict. The only previous study that looked at the nationality of respondents was conducted Bastakis et al. (2004). These authors focused on tour operators' nationalities rather hoteliers' nationalities.

Likewise with commission, information provision, and payment related conflicts with OI. Myung et al. (2009), Stangl et al. (2016), and Lee, Denizci Guillet, and Law (2012) did not assess the relationship between these sources of conflicts and respondents' nationalities. Therefore, we could easily state that our findings are quite innovative by comparison with previous studies on sources of conflicts between hoteliers and their intermediaries.

\subsection{Summary of the research findings}

This study examines the hoteliers' perceptions of the level of satisfaction and sources of conflicts with both traditional and online intermediaries in Cambodia. The main aims of this study were (1) to unveil the overall level of satisfaction of hoteliers with intermediaries in Cambodia, (2) to discuss the sources of conflicts that arise between hotels and intermediaries in Cambodia and (3) to assess whether there are differences in terms of levels of satisfaction as well as sources of conflicts between traditional and online intermediaries.

With regards to the first research aim, this study found that the overall level of satisfaction of hoteliers with intermediaries is very good. The overall level of satisfaction of hoteliers with traditional intermediaries (TI) such as travel agencies, tour operators are perceived as satisfied between "Somewhat good" and "Extremely good." Similarly, the overall level of satisfaction of 
hoteliers with online intermediaries (OI) such as Booking.com, Expedia, Agoda, and Ctrip is also perceived very good ranging from "Somewhat good" to "Extremely good."

In respect to the second research aim, the findings of this study reveal that common sources of conflicts between hoteliers in Cambodia and TI are price level; payment; and price-quality ratio related conflicts. The least common sources of conflicts with TI are booking details; commission,; and overbooking related conflicts. Likewise, the most frequent sources of conflicts between hoteliers in Cambodia and OI are price level; overbooking; and complaint handling related conflicts. The least frequent ones are as follows: commission; booking details; and fulfillment of contract conditions related conflicts.

Concerning the third research aim, some differences were found regarding the level of satisfaction and the frequency of conflicts in terms of hotel attributes and respondents' backgrounds. Regarding the level of satisfaction between hoteliers and TI, differences were found among hotel size and hotel age. Concerning the sources of conflicts, differences were also found in the case of respondents' nationalities, hotel category, hotel size, and hotel age with both TI and OI. However, more differences were found for hotel category with TI, while more differences were found for respondents' nationalities with OI. It is surprising to note that no statistical differences were found in the case of hotel location, ownership, and respondents' job titles.

\subsection{Research implications}

First, the findings of this study in figure 4.1 (page 54) illustrated that hoteliers in Cambodia rely on three channels of distributions including traditional intermediaries, online intermediaries, and corporate segments. However, out of the three regions, only Phnom Penh depends heavily on corporate segments while the other two regions focus mainly on traditional and online intermediaries. The possible explanation for this may be due to the location advantages since Phnom Penh is the capital city. Most of business, political, and diplomatic activities happen in Phnom Penh rather than in other tourist areas. Second, the overall level of satisfaction with online and traditional intermediaries are very high and received almost the same rating scores. The implication of this could be lying in the fact that both hoteliers and intermediaries in Cambodia are gaining benefits from each other with fair share and make their cooperation smooth and 
healthy. Another possible explanation may lie in the fact that many new hotels have opened every year in Cambodia, especially in these three regions, and many new intermediaries are entering this new market. This leads to new cooperation which are usually smooth and healthy. Furthermore, the findings also suggest that the most common sources of conflicts for traditional and online intermediaries are moderately different. In respect to traditional intermediaries, the most common sources of conflicts are price level related conflict, payment related conflict, and price-quality ratio related conflict. Similarly, the most frequent sources of conflict with online intermediaries are price level; overbooking; and complaint handling related conflicts. One possible explanation for this is due to the fact that both intermediaries are business oriented entities and they strive to maximize their profits in any way possible, and as a result they use their bargaining power to negotiate and force hoteliers to sell at lower prices. This eventually leads to conflicts. The nature of their own business could explain another possible implication that they have different sources of conflicts. Traditional intermediaries work with guests that book tailored-made tours or package tours, and their guests could be from local or oversea. They may have other wholesalers in other countries as well to provide them the guests. This nature of business relationship always resulted in late payment, and this eventually passes on to hoteliers which frequently receive late payment from traditional intermediaries. Online intermediaries, on the other hand, are considered to have a suitable payment method because it is usually on time. This is because their nature of the business is working directly with guests and every time they make a booking, means of payment is required

such as credit card. Because of this, hoteliers receive payment from them without any conflicts. Moreover, as findings revealed differences of sources of conflicts in this study, strategies should be applied accordingly. It is recommended that management from hotels may adopt suitable strategies to apply for their own hotels to achieve successful cooperation and growth for their businesses.

\subsection{Contribution of the study}

The findings of this study make both theoretical and practical contributions to knowledge body of tourism. In terms of theoretical contribution, this research makes a contribution to tourism distribution channels literature in the context of a developing country. To our knowledge, this is the first comparative study that looks at similarities and differences in terms of perceived sources 
of conflicts between hotels and two channels of distribution (traditional and online intermediaries). Furthermore, it is also the first exploratory study that deals with tourism distribution channels in the context of Cambodia. Hence, this study contributes to the knowledge body of tourism literature in Cambodia since Cambodia's tourism research is still at an early stage of development. With regards to practical contribution, these research findings are valuable to various tourism stakeholders including accommodation/hotel operators, traditional and online intermediaries, management of hotels and intermediaries, and tourism policy makers. For instance, accommodation/hotel operators could use the findings to pinpoint the main sources of conflicts and their level of satisfaction with intermediaries in order to strengthen their business relationship and gain business value. Similarly, management from intermediaries could understand the perception of their business partners (i.e., hoteliers) and they could gain benefits from enhancing their cooperation with hoteliers by focusing on the sensitive sources of conflicts.

\subsection{Research limitations}

Limitations need to be acknowledged for this study. First, respondents are selected from only three regions in Cambodia including Siem Reap, Phnom Penh, and Sihanoukville. This may not represent Cambodia as a whole since there are some other less touristic regions which may lead to different results. Second, this study is conducted from the perspective of hoteliers without considering intermediaries' perspectives. Both traditional and online intermediaries may perceive the level of satisfaction and sources of conflicts differently. Finally, respondents from this study belong to commercial accommodations from 3-star to 5-star hotels. Other types of accommodations may have different points of views regarding the topic discussed in this thesis.

\subsection{Avenues for future research}

As Cambodia tourism research is still at an early stage, future research should be expanded and developed. First, future research should include the perspective of traditional and online intermediaries into the research so that a complete understanding of this topic could be obtained. Second, a new area of research could focus on the hotel dependency on large intermediaries or on the bargaining power of large international intermediaries on hotels in Cambodia. Moreover, future research may also shed light on respondents' backgrounds by expanding to more aspects 
such as respondents' ages, level of education, and experiences. Finally, future research may be undertaken in other developing countries in order to obtain a generalization of conclusion about the level of satisfaction and sources of conflicts between hoteliers and intermediaries. 


\section{References}

Andriotisy, K. (2003). Dependency on Tour Operators. International Journal of Hospitality \& Tourism Administration, 4(3), 23-47. doi:10.1300/J149v04n03_02

Asia Development Bank. (2016). Here Comes Cambodia: Asia’s New Tiger Economy. Ayres, D. (2000). Sihanouk and the Sangkum

From Independence to Chaos. In D. M. Ayres (Ed.), Anatomy of a Crisis (pp. 31-66): University of Hawai'i Press.

Bastakis, C., Buhalis, D., \& Butler, R. (2004). The perception of small and medium sized tourism accommodation providers on the impacts of the tour operators' power in Eastern Mediterranean. Tourism Management, 25(2), 151-170. doi:https://doi.org/10.1016/S0261-5177(03)00098-0

Bertram, D. (2007). Likert scales. Retrieved November, 2, 2013.

Bill, C., \& Judy, S. (2003). The Evolution of Electronic Distribution: Effects on Hotels and Intermediaries. Cornell Hotel and Restaurant Administration Quarterly, 44(4), 38-50. doi:10.1177/0010880403444004

Blaikie, N. (2010). Designing social research. Cambridge, Polity Press. 2nd Ed.

Bonna Realty. (2016). Property market in Cambodia Retrieved from

Boone, N. H., \& Boone, D. A. (2012). Analyzing likert data. Journal of extension, 50(2), 1-5.

Buhalis, D. (2000a). Relationships in the Distribution Channel of Tourism. International Journal of Hospitality \& Tourism Administration, 1(1), 113-139. doi:10.1300/J149v01n01_07

Buhalis, D. (2000b). Relationships in the Distribution Channel of Tourism: Conflicts between Hoteliers and Tour Operators in the Mediterranean Region. International Journal of Hospitality \& Tourism Administration, 1 (1): 113-39.

Buhalis, D., \& Laws, E. (2001). Tourism distribution channels: Practices, issues and transformations. Cengage Learning EMEA.

Calveras, A., \& Vera-Hernández, M. (2005). Quality Externalities among Hotel Establishments: What is the Impact of Tour Operators? Tourism Economics, 11(4), 571-599. doi: $10.5367 / 000000005775108755$

Cambodia Ministry of Tourism. (2017). Tourism Statistic Reports. Retrieved from

Chang, Y.-W., Hsu, P.-Y., \& Lan, Y.-C. (2019). Cooperation and competition between online travel agencies and hotels. Tourism Management, 71, 187-196. doi:https://doi.org/10.1016/j.tourman.2018.08.026

Chens, C.-Y., Sok, P., \& Sok, K. (2008). Evaluating the Competitiveness of the Tourism Industry in Cambodia: Self-assessment from Professionals. Asia Pacific Journal of Tourism Research, 13(1), 41-66. doi:10.1080/10941660701883367

Chheang, V. (2008a). The Political Economy of Tourism in Cambodia. Asia Pacific Journal of Tourism Research, 13(3), 281-297. doi:10.1080/10941660802280414

Chheang, V. (2008b). Tourism and Local Community Development in Siem Reap. Ritsumeikan Asia Pacifi c University.

Christodoulidou, N., Brewer, P., Feinstein, A. H., \& Bai, B. (2007). Electronic Channels of Distribution: Challenges and Solutions for Hotel Operators. Hospitality Review, Vol. 25 : Iss. 2 , Article 8 . . 
Clerides, S., Nearchou, P., \& Pashardes, P. (2008). Intermediaries as quality assessors: Tour operators in the travel industry. International Journal of Industrial Organization, 26(1), 372-392. doi:https://doi.org/10.1016/j.ijindorg.2007.02.001

Coff, R. W. (1999). When Competitive Advantage Doesn't Lead to Performance: The ResourceBased View and Stakeholder Bargaining Power. Organization Science, 10(2), 119-133. doi:10.1287/orsc.10.2.119

Cooper, C., \& Lewis, J. (2001). Transformation and Trends in the Tourism Industry: implicaitons for distribution channels. Tourism Distribution channels - practices, issues, and transformations.

Creswell. (2007). Designing and conducting mixed methods research / John W. Creswell, Vicki L. Plano Clark. Thousand Oaks, Calif.: Thousand Oaks, Calif. : SAGE Publications.

Creswell. (2014). Research design: Qualitative, quantitative, and mixed methods approaches SAGE Publications, 4th ed.(Thousand Oaks).

Cross, W. E. (2013). Crafting a Design to Yield a Complete Story. In A. Galletta (Ed.), Mastering the Semi-Structured Interview and Beyond (pp. 9-44): NYU Press.

Douglas, G. P., \& Christian, S. (2005). Tourism Distribution Channels: The Visitors' Perspective. Journal of Travel Research, 44(1), 50-63. doi:10.1177/0047287505276591

Dwyer, L., \& Thomas, F. (2012). Tourism yield measures for Cambodia. Current Issues in Tourism, 15(4), 303-328. doi:10.1080/13683500.2011.604405

Erdener, K., \& Ali, K. (2012). Assessing tourism market potential in a dynamic emerging economy: Theoretical and empirical insights from Cambodia. Asia Pacific Journal of Marketing and Logistics, 24(2), 199-221. doi:10.1108/13555851211218020

Estisgreen, C., \& Lomanno, M. (2012). Distribution Channel Analysis: a Guide for Hotels. Retrieved from

Fallavier, P. (2005). The case of Phnom Penh Department of Urban Studies and Planning, Massachusetts Institute of Technology.

Fletcher, J., Fyall, A., Gilbert, D., \& Wanhill, S. (2013). Tourism : principles and practice.

Ford, R. C., Wang, Y., \& Vestal, A. (2012). Power asymmetries in tourism distribution networks. Annals of Tourism Research, 39(2), 755-779. doi:https://doi.org/10.1016/j.annals.2011.10.001

Fylan, F. (2005). Semi-structured interviewing. A handbook of research methods for clinical and health psychology. J. Miles, \& Gilbert, P. Oxford.

Garcia-Falcon, J. M., \& Medina-Muñoz, D. (1999). The Relationship Between Hotel Companies and Travel Agencies: An Empirical Assessment of the United States Market. The Service Industries Journal, 19(4), 102-122. doi:10.1080/02642069900000047

Gee, C., Markens, J., \& Choy, D. (1989). The Travel Industry. 2nd edition(Van Nostrand Reinhold, New York).

Guo, X., \& He, L. (2012). Tourism Supply-Chain Coordination: The Cooperation between Tourism Hotel and Tour Operator. Tourism Economics, 18(6), 1361-1376. doi:10.5367/te.2012.0179

Holloway, C. (1989). The Business of Tourism 3rd edition(Pitman, Plymouth).

Hughes. (2003). The political economy of Cambodia's transition, 1991-2001. (London: RoutledgeCurzon).

Ivanov, \& Hristov, S. (2006). Management of Overbookings in the Hotel Industry - Basic Concepts and Practical Challenges Tourism Today, Vol. 6, pp. 19-32. 
Ivanov, Stoilova, E., \& Illum, S. F. (2014). Conflicts between accommodation establishments and travel agencies. Tourism and Hospitality Research, 15(1), 54-70. doi: $10.1177 / 1467358414553870$

Jackie Ong, L. T., \& Smith, R. A. (2014). Perception and reality of managing sustainable coastal tourism in emerging destinations: the case of Sihanoukville, Cambodia. Journal of Sustainable Tourism, 22(2), 256-278. doi:10.1080/09669582.2013.809091

Jennings, G. R. (2005). Interviewing: a focus on Qualitative Techniques. In B.W. Richie, P. Burns, \& C. Palmer (Eds.), Tourism research methods. (pp. 99-107)(Wallingford, UK: CABI Publishing.).

John, T. (2017). Modern Cambodia Since 1863. Oxford Research Encyclopedia of Asian History: Interactive Factory.

Karamustafa, K. (2000). Marketing-channel Relationships: Turkeys Resort Purveyors' Interactions with International Tour Operators. Cornell Hotel and Restaurant Administration Quarterly, 41(4), 21-31. doi:10.1177/001088040004100411

Klemm, M., \& Parkinson, L. (2001). UK tour operator strategies: causes and consequences. International Journal of Tourism Research, 3(5), 367-375. doi:10.1002/jtr.351

Knowles, T., \& Grabowski, P. (1999). Strategic Marketing in the Tour Operator Sector. In F. Vellas \& L. Bécherel (Eds.), The International Marketing of Travel and Tourism: A Strategic Approach (pp. 247-262). London: Macmillan Education UK.

Laurette, D., \& Leo, M. R. (2000). Marketing Your Hotel to and through Intermediaries: An Overlooked Best Practice. Cornell Hotel and Restaurant Administration Quarterly, 41(1), 73-83. doi:10.1177/001088040004100125

Lee, H. A., Denizci Guillet, B., \& Law, R. (2012). An Examination of the Relationship between Online Travel Agents and Hotels: A Case Study of Choice Hotels International and Expedia.com. Cornell Hospitality Quarterly, 54(1), 95-107. doi:10.1177/1938965512454218

Lim, V. (2006). Cambodia's agricultural exports and standards: Trade facilitation or trade barriers? Economic Institute of Cambodia, 9-12.

Ling, L., Dong, Y., Guo, X., \& Liang, L. (2015). Availability management of hotel rooms under cooperation with online travel agencies. International Journal of Hospitality Management, 50, 145-152. doi:https://doi.org/10.1016/j.ijhm.2015.07.005

Matthews, B., \& Ross, L. (2010). Research methods: A practical guide for the social sciences New York, NY: Pearson Longman, 1st ed. .

McIntosh, M. J., \& Morse, J. M. (2015). Situating and Constructing Diversity in Semi-Structured Interviews. Global Qualitative Nursing Research, 2, 2333393615597674. doi:10.1177/2333393615597674

Medina-Muñoz, \& García-Falcón, J. M. (2000). Successful relationships between hotels and agencies. Annals of Tourism Research, 27(3), 737-762. doi:https://doi.org/10.1016/S0160-7383(99)00104-8

Medina-Muñoz, Medina-Muñoz, D. R., \& García-Falcón, J. M. (2003). Understanding European tour operators' control on accommodation companies: an empirical evidence. Tourism Management, 24(2), 135-147. doi:https://doi.org/10.1016/S0261-5177(02)00062-6

Mill, P., \& Morrison, A. (1985). The tourism system: an introductory text: Prentice Hall International Editions, New Jersey.

Ministry of Tourism. (2011). Annual report on tourism statistics 2010. Retrieved from Ministry of Tourism. (2016). Tourism statistics Report. 
Ministry of Tourism. (2018a). Phnom Penh City Retrieved from http://www.tourismcambodia.org/provincial guide/index.php?view=detail\&prv=15 comp

Ministry of Tourism. (2018b). Tourism Business Statistics 2018. Retrieved from

Morgan, D. L. (2014). Pragmatism as a Paradigm for Social Research. Qualitative Inquiry, 20(8), 1045-1053. doi:10.1177/1077800413513733

Myung, E., Li, L., \& Bai, B. (2009). Managing the Distribution Channel Relationship With EWholesalers: Hotel Operators' Perspective. Journal of Hospitality Marketing \& Management, 18(8), 811-828. doi:10.1080/19368620903235837

Nemoto, T., \& Beglar, D. (2014). Likert-scale questionnaires. In JALT 2013 Conference Proceedings (pp. 1-8).

Patton, M. Q. (2002). Qualitative research and evaluation methods. Thousand Oaks: Sage Publications, Inc.

Pearce, D. (2012). Frameworks for tourism research. Wallingford, Oxfordshire; Cambridge, MA: CABI.

Pearce, D., Tan, R., \& Schott, C. (2004). Tourism distribution channels in Wellington, New Zealand. International Journal of Tourism Research, 6(6), 397-410. doi:10.1002/jtr.503

Punch, K. (2014). Introduction to social research : quantitative \& qualitative approaches / Keith F. Punch (3rd ed.. ed.). Los Angeles, California: Los Angeles, California : SAGE.

Rich, B. M. (2002). E-Commerce (A Special Report): Selling Strategies --- Travel -- Book 'Em: The Internet introduced a middleman to the hotel industry; Now hotels want that business back. Wall Street Journal.

Rob, L., Rosanna, L., Ada, L., Daniel, L., \& Lawrence Hoc Nang, F. (2015). Distribution channel in hospitality and tourism: Revisiting disintermediation from the perspectives of hotels and travel agencies. International Journal of Contemporary Hospitality Management, 27(3), 431-452. doi:10.1108/IJCHM-11-2013-0498

Sarheim, L., \& Vadehra, B. (2016). IN FOCUS: SIEM REAP, CAMBODIA. Retrieved from

Stangl, B., Inversini, A., \& Schegg, R. (2016). Hotels' dependency on online intermediaries and their chosen distribution channel portfolios: Three country insights. International Journal of Hospitality Management, 52, 87-96. doi:https://doi.org/10.1016/j.ijhm.2015.09.015

Swati, D., \& Kamal, M. (2007). Managing reservations through online distribution channels: An insight into mid-segment hotels in India. International Journal of Contemporary Hospitality Management, 19(5), 388-396. doi:10.1108/09596110710757552

Thakran, K., \& Verma, R. (2013). The Emergence of Hybrid Online Distribution Channels in Travel, Tourism and Hospitality. Cornell Hospitality Quarterly, 54(3), 240-247. doi:10.1177/1938965513492107

Ujma, D. (2001). Distribution channels for tourism: Theory and practice. In D. Buhalis, \& E. Laws (Eds.), Tourism distribution channels: Practices, issues and transformations. London: Conti- nuum International Publishing Group.

Wanhill, S. (1993). Intermediaries. Tourism: Principles and Practice(Pitman, London).

World Travel \& Tourism Council. (2017). Economic Impact 2017 Cambodia Retrieved from 


\section{APPENDICES}

\section{Appendix 1: Result of ANOVA and Pearson Correlation tests on source of conflicts by hotel category}

\begin{tabular}{|c|c|c|c|c|c|c|}
\hline $\begin{array}{l}\text { Stage of } \\
\text { issues }\end{array}$ & Conflict factors & Category & Mean & Std & ANOVA test results & $\begin{array}{c}\text { Pearson Correlation test } \\
\text { result }\end{array}$ \\
\hline \multirow{30}{*}{$\begin{array}{l}\text { Contract } \\
\text { Stage }\end{array}$} & \multirow{3}{*}{$\begin{array}{l}\text { Conflicts with TI } \\
\text { from contract } \\
\text { issues? } \\
\text { Price Level }\end{array}$} & 3 & 1.86 & 1.574 & \multirow{3}{*}{$F(2,37)=1.888, p=0.166$} & \multirow{3}{*}[r=0.304,p=0.056]{} \\
\hline & & 4 & 2.4 & 1.056 & & \\
\hline & & 5 & 2.89 & 1.231 & & \\
\hline & \multirow{3}{*}{ Commission } & 3 & 1.57 & 1.512 & \multirow{3}{*}{$F(2,37)=1.150, p=0.328$} & \multirow{3}{*}[r=0.101,p=0.537]{} \\
\hline & & 4 & 1.13 & 0.352 & & \\
\hline & & 5 & 1.67 & 1.188 & & \\
\hline & \multirow{3}{*}{ Price Quality Ratio } & 3 & 2.43 & 1.813 & \multirow{3}{*}{$F(2,37)=1.078, p=0.351$} & \multirow{3}{*}[r=0.005,p=0.975]{} \\
\hline & & 4 & 1.73 & 0.884 & & \\
\hline & & 5 & 2.22 & 1.114 & & \\
\hline & \multirow{3}{*}{ Release Period } & 3 & 2 & 1.528 & \multirow{3}{*}{$F(2,37)=0.229, p=0.797$} & \multirow{3}{*}[r=-0.025,p=0.878]{} \\
\hline & & 4 & 1.67 & 0.976 & & \\
\hline & & 5 & 1.83 & 1.043 & & \\
\hline & \multirow{3}{*}{$\begin{array}{l}\text { Fulfilment of } \\
\text { contract Conditions }\end{array}$} & 3 & 2.14 & 1.952 & \multirow{3}{*}{$F(2,37)=0.669, p=0.518$} & \multirow{3}{*}[r=-0.148,p=0.362]{} \\
\hline & & 4 & 1.67 & 0.488 & & \\
\hline & & 5 & 1.67 & 0.767 & & \\
\hline & \multirow{3}{*}{$\begin{array}{l}\text { Conflicts with OI } \\
\text { from contract } \\
\text { issues? } \\
\text { Price Level }\end{array}$} & 3 & 2.14 & 0.9 & \multirow{3}{*}{$F(2,39)=0.536, p=0.589$} & \multirow{3}{*}[r=0.143,p=0.368]{} \\
\hline & & 4 & 2.65 & 1.367 & & \\
\hline & & 5 & 2.72 & 1.32 & & \\
\hline & \multirow{3}{*}{ Commission } & 3 & 1.57 & 0.787 & \multirow{3}{*}{$F(2,39)=0.219, p=0.804$} & \multirow{3}{*}[r=0.066,p=0.677]{} \\
\hline & & 4 & 1.47 & 1.007 & & \\
\hline & & 5 & 1.67 & 0.767 & & \\
\hline & \multirow{3}{*}{ Price Quality Ratio } & 3 & 2 & 1.414 & \multirow{3}{*}{$F(2,39)=0.332, p=0.719$} & \multirow{3}{*}[r=-0.127,p=0.421]{} \\
\hline & & 4 & 1.88 & 1.111 & & \\
\hline & & 5 & 1.67 & 0.767 & & \\
\hline & \multirow{3}{*}{ Release Period } & 3 & 1.71 & 0.756 & \multirow{3}{*}{$F(2,39)=0.174, p=0.841$} & \multirow{3}{*}[r=-0.006,p=0.972]{} \\
\hline & & 4 & 1.94 & 1.249 & & \\
\hline & & 5 & 1.78 & 0.808 & & \\
\hline & \multirow{3}{*}{$\begin{array}{l}\text { Fulfilment of } \\
\text { contract Conditions }\end{array}$} & 3 & 1.43 & 0.787 & \multirow{3}{*}{$F(2,39)=0.445, p=0.644$} & \\
\hline & & 4 & 1.35 & 0.996 & & {$[r=0.117, p=0.461]$} \\
\hline & & 5 & 1.67 & 1.085 & & \\
\hline
\end{tabular}




\begin{tabular}{|c|c|c|c|c|c|c|}
\hline \multirow{16}{*}{$\begin{array}{c}\text { Pre-stay } \\
\text { Stage }\end{array}$} & $\begin{array}{l}\text { Conflicts with TI } \\
\text { from Pre-stay } \\
\text { issues? Information } \\
\text { provision }\end{array}$ & 3 & $\begin{array}{l}1.43 \\
1.93 \\
1.22\end{array}$ & $\begin{array}{l}0.787 \\
0.704 \\
0.428\end{array}$ & $F(2,37)=5.669, p=0.007$ & {$[r=-0.240, p=0.135]$} \\
\hline & \multirow{3}{*}{ Booking details } & 3 & 1.57 & 1.134 & \multirow{3}{*}{$F(2,37)=1.305, p=0.283$} & \multirow{3}{*}[r=-0.202,p=0.212]{} \\
\hline & & 4 & 1.67 & 0.617 & & \\
\hline & & 5 & 1.28 & 0.575 & & \\
\hline & \multirow{3}{*}{$\begin{array}{l}\text { Cancellation Terms } \\
\text { Compliance }\end{array}$} & 3 & 1.86 & 1.069 & \multirow{3}{*}{$F(2,37)=1.265, p=0.294$} & \multirow{3}{*}[r=-0.148,p=0.362]{} \\
\hline & & 4 & 2.2 & 1.207 & & \\
\hline & & 5 & 1.61 & 0.916 & & \\
\hline & \multirow{3}{*}{$\begin{array}{l}\text { Conflicts with OI } \\
\text { from Pre-stay } \\
\text { issues? Information } \\
\text { provision }\end{array}$} & 3 & 1.71 & 0.756 & \multirow{3}{*}{$F(2,39)=0.010, p=0.99$} & \multirow{3}{*}[r=-0.021,p=0.893]{} \\
\hline & & 4 & 1.71 & 1.16 & & \\
\hline & & 5 & 1.67 & 0.767 & & \\
\hline & \multirow{3}{*}{ Booking details } & 3 & 1.57 & 1.134 & \multirow{3}{*}{$F(2,39)=1.583, p=0.563$} & \multirow{3}{*}[r=-0.117,p=0.462]{} \\
\hline & & 4 & 1.71 & 1.047 & & \\
\hline & & 5 & 1.39 & 0.502 & & \\
\hline & \multirow{3}{*}{$\begin{array}{l}\text { Cancellation Terms } \\
\text { Compliance }\end{array}$} & 3 & 2 & 1.732 & \multirow{3}{*}{$F(2,39)=0.694, p=0.506$} & \multirow{3}{*}[r=-0.182,p=0.247]{} \\
\hline & & 4 & 1.82 & 1.074 & & \\
\hline & & 5 & 1.5 & 0.707 & & \\
\hline \multirow{12}{*}{$\begin{array}{l}\text { Stay } \\
\text { Stage }\end{array}$} & \multirow{3}{*}{$\begin{array}{l}\text { Conflicts with TI } \\
\text { from Stay } \\
\text { issues? Operation } \\
\text { Errors }\end{array}$} & 3 & 1.86 & 0.69 & \multirow{3}{*}{$F(2,37)=0.681, p=0.512$} & \multirow{3}{*}[r=-0.186,p=0.251]{} \\
\hline & & 4 & 1.67 & 0.488 & & \\
\hline & & 5 & 1.56 & 0.616 & & \\
\hline & \multirow{3}{*}{ Overbookings } & 3 & 1.71 & 0.756 & \multirow{3}{*}{$F(2,37)=1.935, p=0.159$} & \multirow{3}{*}[r=-0.306,p=0.055]{} \\
\hline & & 4 & 1.53 & 0.516 & & \\
\hline & & 5 & 1.28 & 0.461 & & \\
\hline & \multirow{3}{*}{$\begin{array}{l}\text { Conflicts with OI } \\
\text { from Stay } \\
\text { issues? Operation } \\
\text { Errors }\end{array}$} & 3 & 1.57 & 0.787 & \multirow{3}{*}{$F(2,39)=1.428, p=0.252$} & \multirow{3}{*}[r=0.260,p=0.096]{} \\
\hline & & 4 & 1.82 & 0.728 & & \\
\hline & & 5 & 2.17 & 0.985 & & \\
\hline & & 3 & 2.71 & 1.38 & & \\
\hline & Overbookings & 4 & 2 & 1.061 & $F(2,39)=0.982, p=0.384$ & {$[r=-0.053, p=0.737]$} \\
\hline & & 5 & 2.33 & 1.188 & & \\
\hline & $\begin{array}{l}\text { Conflicts with TI } \\
\text { from Post-Stay } \\
\text { issues? }\end{array}$ & 3 & 1.71 & 0.951 & $F(2,37)=1277 n=0.291$ & $r=0.092 p=0.573]$ \\
\hline Post- & Payment & 4 & 2.47 & 0.99 & & \\
\hline Stay & & 5 & 2.17 & 1.098 & & \\
\hline Stage & & 3 & 1.86 & 0.69 & & \\
\hline & $\begin{array}{l}\text { Complaint } \\
\text { handling }\end{array}$ & 4 & 2.2 & 0.775 & $F(2,37)=2.512, p=0.095$ & {$[r=-0.188, p=0.246]$} \\
\hline & & 5 & 1.67 & 0.594 & & \\
\hline
\end{tabular}




\begin{tabular}{|llllll|}
$\begin{array}{l}\text { Conflicts with OI } \\
\text { from Post-Stay }\end{array}$ & 3 & 2.14 & 1.215 & & \\
issues? & 4 & 1.47 & 0.874 & $F(2,39)=1.275, p=0.291$ & [ $r=-0.064, p=0.689]$ \\
Payment & 5 & 1.78 & 0.943 & & \\
& 3 & 2.14 & 0.9 & & \\
\cline { 2 - 6 } & 4 & 2.24 & 0.97 & $F(2,39)=0.041, p=0.960$ & {$[r=-0.004, p=0.981]$} \\
\hline Complaint & 5 & 2.17 & 0.707 & & \\
handling & & & & \\
\end{tabular}




\section{Appendix 2: Result of ANOVA tests on sources of conflict by hotel location}

\begin{tabular}{|c|c|c|c|c|c|}
\hline $\begin{array}{l}\text { Stage of } \\
\text { issues }\end{array}$ & Conflict factors & Location & Mean & Std & ANOVA test results \\
\hline \multirow{30}{*}{$\begin{array}{l}\text { Contract } \\
\text { Stage }\end{array}$} & \multirow{3}{*}{$\begin{array}{l}\text { Conflicts with TI } \\
\text { from contract } \\
\text { issues? } \\
\text { Price Level }\end{array}$} & Siem Reap & 2.62 & 1.396 & \multirow{3}{*}{$F(2,37)=0.134, p=0.875$} \\
\hline & & Phnom Penh & 2.38 & 1.193 & \\
\hline & & Sihanoukville & 2.5 & 1.049 & \\
\hline & \multirow{3}{*}{ Commission } & Siem Reap & 1.71 & 1.347 & \multirow{3}{*}{$F(2,37)=1.472, p=0.243$} \\
\hline & & Phnom Penh & 1.15 & 0.376 & \\
\hline & & Sihanoukville & 1.17 & 0.408 & \\
\hline & \multirow{3}{*}{ Price Quality Ratio } & Siem Reap & 2.38 & 1.359 & \multirow{3}{*}{$F(2,37)=1.755, p=0.187$} \\
\hline & & Phnom Penh & 1.62 & 0.768 & \\
\hline & & Sihanoukville & 2 & 1.095 & \\
\hline & \multirow{3}{*}{ Release Period } & Siem Reap & 1.9 & 1.221 & \multirow{3}{*}{$F(2,37)=0.275, p=0.761$} \\
\hline & & Phnom Penh & 1.62 & 0.87 & \\
\hline & & Sihanoukville & 1.83 & 1.169 & \\
\hline & \multirow{3}{*}{$\begin{array}{l}\text { Fulfilment of } \\
\text { contract Conditions }\end{array}$} & Siem Reap & 2 & 1.225 & \multirow{3}{*}{$F(2,37)=1.958, p=0.155$} \\
\hline & & Phnom Penh & 1.62 & 0.506 & \\
\hline & & Sihanoukville & 1.17 & 0.408 & \\
\hline & \multirow{3}{*}{$\begin{array}{l}\text { Conflicts with OI } \\
\text { from contract } \\
\text { issues? } \\
\text { Price Level }\end{array}$} & Siem Reap & 2.95 & 1.203 & \multirow{3}{*}{$F(2,39)=1.746, p=0.188$} \\
\hline & & Phnom Penh & 2.2 & 1.207 & \\
\hline & & Sihanoukville & 2.33 & 1.506 & \\
\hline & \multirow{3}{*}{ Commission } & Siem Reap & 1.62 & 0.74 & \multirow{3}{*}{$F(2,39)=0.597, p=0.555$} \\
\hline & & Phnom Penh & 1.4 & 0.632 & \\
\hline & & Sihanoukville & 1.83 & 1.602 & \\
\hline & \multirow{3}{*}{ Price Quality Ratio } & Siem Reap & 1.86 & 1.014 & \multirow{3}{*}{$F(2,39)=0.266, p=0.768$} \\
\hline & & Phnom Penh & 1.67 & 0.816 & \\
\hline & & Sihanoukville & 2 & 1.549 & \\
\hline & \multirow{3}{*}{ Release Period } & Siem Reap & 1.71 & 0.956 & \multirow{3}{*}{$F(2,39)=0.931, p=0.403$} \\
\hline & & Phnom Penh & 1.8 & 0.775 & \\
\hline & & Sihanoukville & 2.33 & 1.506 & \\
\hline & \multirow{3}{*}{$\begin{array}{l}\text { Fulfilment of } \\
\text { contract Conditions }\end{array}$} & Siem Reap & 1.57 & 1.076 & \multirow{3}{*}{$F(2,39)=0.797, p=0.458$} \\
\hline & & Phnom Penh & 1.27 & 0.458 & \\
\hline & & Sihanoukville & 1.83 & 1.602 & \\
\hline \multirow{2}{*}{$\begin{array}{l}\text { Pre-stay } \\
\text { Stage }\end{array}$} & \multirow{2}{*}{$\begin{array}{l}\text { Conflicts with TI } \\
\text { from Pre-stay }\end{array}$} & Siem Reap & 1.43 & 0.676 & \multirow{2}{*}{$F(2,37)=0.445, p=0.644$} \\
\hline & & Phnom Penh & 1.62 & 0.65 & \\
\hline
\end{tabular}




\begin{tabular}{|c|c|c|c|c|c|}
\hline & $\begin{array}{l}\text { issues? Information } \\
\text { provision }\end{array}$ & Sihanoukville & 1.67 & 0.816 & \\
\hline & \multirow{3}{*}{ Booking details } & Siem Reap & 1.33 & 0.73 & \multirow{3}{*}{$F(2,37)=1.015, p=0.372$} \\
\hline & & Phnom Penh & 1.69 & 0.63 & \\
\hline & & Sihanoukville & 1.5 & 0.837 & \\
\hline & \multirow{3}{*}{$\begin{array}{l}\text { Cancellation Terms } \\
\text { Compliance }\end{array}$} & Siem Reap & 1.71 & 1.007 & \multirow{3}{*}{$F(2,37)=0.797, p=0.458$} \\
\hline & & Phnom Penh & 1.92 & 0.862 & \\
\hline & & Sihanoukville & 2.33 & 1.633 & \\
\hline & \multirow{3}{*}{$\begin{array}{l}\text { Conflicts with OI } \\
\text { from Pre-stay } \\
\text { issues? Information } \\
\text { provision }\end{array}$} & Siem Reap & 1.81 & 0.981 & \multirow{3}{*}{$F(2,39)=0.676, p=0.515$} \\
\hline & & Phnom Penh & 1.47 & 0.64 & \\
\hline & & Sihanoukville & 1.83 & 1.329 & \\
\hline & \multirow{3}{*}{ Booking details } & Siem Reap & 1.76 & 0.944 & \multirow{3}{*}{$F(2,39)=1.493, p=0.237$} \\
\hline & & Phnom Penh & 1.27 & 0.458 & \\
\hline & & Sihanoukville & 1.5 & 1.225 & \\
\hline & \multirow{3}{*}{$\begin{array}{l}\text { Cancellation Terms } \\
\text { Compliance }\end{array}$} & Siem Reap & 1.81 & 1.123 & \multirow{3}{*}{$F(2,39)=1.295, p=0.285$} \\
\hline & & Phnom Penh & 1.4 & 0.632 & \\
\hline & & Sihanoukville & 2.17 & 1.602 & \\
\hline \multirow{12}{*}{$\begin{array}{l}\text { Stay } \\
\text { Stage }\end{array}$} & Conflicts with TI & Siem Reap & 1.62 & 0.59 & \multirow{3}{*}{$F(2,37)=0.341, p=0.713$} \\
\hline & $\begin{array}{l}\text { Irom stay } \\
\text { issues? Operation }\end{array}$ & Phnom Penh & 1.62 & 0.506 & \\
\hline & Errors & Sihanoukville & 1.83 & 0.753 & \\
\hline & & Siem Reap & 1.38 & 0.498 & \\
\hline & Overbookings & Phnom Penh & 1.62 & 0.506 & $F(2,37)=0.875, p=0.425$ \\
\hline & & Sihanoukville & 1.33 & 0.816 & \\
\hline & Conflicts with OI & Siem Reap & 1.95 & 0.921 & \\
\hline & $\begin{array}{l}\text { lrom Stay } \\
\text { issues? Operation }\end{array}$ & Phnom Penh & 1.67 & 0.617 & $F(2,39)=2.105, p=0.135$ \\
\hline & Errors & Sihanoukville & 2.5 & 1.049 & \\
\hline & & Siem Reap & 2.33 & 1.354 & \\
\hline & Overbookings & Phnom Penh & 2.13 & 0.915 & $F(2,39)=0.135, p=0.874$ \\
\hline & & Sihanoukville & 2.33 & 1.211 & \\
\hline & $\begin{array}{l}\text { Conflicts with TI } \\
\text { from Post-Stay } \\
\text { issues? }\end{array}$ & Siem Reap & 2.1 & & $F(2,37)=0.348, p=0.708$ \\
\hline & Payment & Phnom Penh & 2.23 & 1.092 & \\
\hline Stage & & Sihanoukville & 2.5 & 1.225 & \\
\hline & & Siem Reap & 1.71 & 0.561 & \\
\hline & $\begin{array}{l}\text { Complaint } \\
\text { handling }\end{array}$ & Phnom Penh & 2.23 & 0.832 & $F(2,37)=2.307, p=0.114$ \\
\hline & & Sihanoukville & 1.83 & 0.753 & \\
\hline
\end{tabular}


Conflicts with OI

from Post-Stay

issues?

Siem Reap $\quad 1.62 \quad 0.921$

Payment

Phnom Penh $\quad 1.53 \quad 0.834$

$F(2,39)=2.502, p=0.095$

Sihanoukville $\quad 2.5 \quad 1.225$

Complaint

handling

Siem Reap $\quad 2.1 \quad 0.831$

Phnom Penh $\quad 2.2 \quad 0.775$

$F(2,39)=0.540, p=0.587$

Sihanoukville

$2.5 \quad 1.049$ 


\section{Appendix 3: Result of ANOVA tests on sources of conflict by hotel ownership}

\begin{tabular}{|c|c|c|c|c|c|}
\hline $\begin{array}{c}\text { Stage of } \\
\text { issues }\end{array}$ & Conflict factors & Ownership & Mean & Std & ANOVA test results \\
\hline \multirow{28}{*}{$\begin{array}{l}\text { Contract } \\
\text { Stage }\end{array}$} & \multirow{3}{*}{$\begin{array}{l}\text { Conflicts with TI from } \\
\text { contract issues? } \\
\text { Price Level }\end{array}$} & Local owner & 2.74 & 1.375 & \multirow{3}{*}{$F(2,37)=1.458, p=0.246$} \\
\hline & & $\begin{array}{l}\text { Local \& } \\
\text { foreign owner }\end{array}$ & 2.29 & 1.113 & \\
\hline & & Foreign owner & 1.83 & 0.408 & \\
\hline & \multirow{3}{*}{ Commission } & Local owner & 1.59 & 1.217 & \multirow{3}{*}{$F(2,37)=0.904, p=0.414$} \\
\hline & & $\begin{array}{c}\text { Local \& } \\
\text { foreign owner }\end{array}$ & 1.29 & 0.488 & \\
\hline & & Foreign owner & 1 & 0 & \\
\hline & \multirow{3}{*}{ Price Quality Ratio } & Local owner & 2.37 & 1.214 & \multirow{3}{*}{$F(2,37)=2.904, p=0.067$} \\
\hline & & $\begin{array}{c}\text { Local \& } \\
\text { foreign owner }\end{array}$ & 1.57 & 1.134 & \\
\hline & & Foreign owner & 1.33 & 0.516 & \\
\hline & \multirow{3}{*}{ Release Period } & Local owner & 1.93 & 1.141 & \multirow{3}{*}{$F(2,37)=0.741, p=0.484$} \\
\hline & & $\begin{array}{c}\text { Local \& } \\
\text { foreign owner }\end{array}$ & 1.71 & 1.254 & \\
\hline & & Foreign owner & 1.33 & 0.516 & \\
\hline & \multirow{3}{*}{$\begin{array}{l}\text { Fulfilment of contract } \\
\text { Conditions }\end{array}$} & Local owner & 1.89 & 1.121 & \multirow{3}{*}{$F(2,37)=0.835, p=0.442$} \\
\hline & & $\begin{array}{c}\text { Local \& } \\
\text { foreign owner }\end{array}$ & 1.43 & 0.535 & \\
\hline & & Foreign owner & 1.5 & 0.548 & \\
\hline & $\begin{array}{l}\text { Conflicts with OI from } \\
\text { contract issues? }\end{array}$ & Local owner & 2.71 & 1.213 & \multirow{3}{*}{$F(2,39)=0.475, p=0.626$} \\
\hline & \multirow[t]{2}{*}{ Price Level } & $\begin{array}{c}\text { Local \& } \\
\text { foreign owner }\end{array}$ & 2.5 & 1.414 & \\
\hline & & Foreign owner & 2.17 & 1.472 & \\
\hline & \multirow{3}{*}{ Commission } & Local owner & 1.43 & 0.634 & \multirow{3}{*}{$F(2,39)=5.561, p=0.008$} \\
\hline & & $\begin{array}{c}\text { Local \& } \\
\text { foreign owner }\end{array}$ & 2.38 & 1.302 & \\
\hline & & Foreign owner & 1.17 & 0.408 & \\
\hline & \multirow{3}{*}{ Price Quality Ratio } & Local owner & 1.89 & 0.956 & \multirow{3}{*}{$F(2,39)=0.274, p=0.762$} \\
\hline & & $\begin{array}{c}\text { Local \& } \\
\text { foreign owner }\end{array}$ & 1.63 & 1.408 & \\
\hline & & Foreign owner & 1.67 & 0.816 & \\
\hline & \multirow{3}{*}{ Release Period } & Local owner & 1.82 & 0.863 & \multirow{3}{*}{$F(2,39)=1.527, p=0.230$} \\
\hline & & $\begin{array}{c}\text { Local \& } \\
\text { foreign owner }\end{array}$ & 2.25 & 1.389 & \\
\hline & & Foreign owner & 1.33 & 0.816 & \\
\hline & & Local owner & 1.5 & 0.923 & $F(2,39)=0.141, p=0.869$ \\
\hline
\end{tabular}




\begin{tabular}{|c|c|c|c|c|c|}
\hline & $\begin{array}{l}\text { Fulfilment of contract } \\
\text { Conditions }\end{array}$ & $\begin{array}{l}\text { Local \& } \\
\text { foreign owner } \\
\text { Foreign owner }\end{array}$ & 1.63 & 1.408 & \\
\hline \multirow{18}{*}{$\begin{array}{l}\text { Pre-stay } \\
\text { Stage }\end{array}$} & \multirow{3}{*}{$\begin{array}{l}\text { Conflicts with TI from } \\
\text { Pre-stay } \\
\text { issues? Information } \\
\text { provision }\end{array}$} & Local owner & 1.48 & 0.753 & \multirow{3}{*}{$F(2,37)=0.194, p=0.824$} \\
\hline & & $\begin{array}{c}\text { Local \& } \\
\text { foreign owner }\end{array}$ & 1.57 & 0.535 & \\
\hline & & Foreign owner & 1.67 & 0.516 & \\
\hline & \multirow{3}{*}{ Booking details } & Local owner & 1.41 & 0.797 & \multirow{3}{*}{$F(2,37)=1.252, p=0.298$} \\
\hline & & $\begin{array}{c}\text { Local \& } \\
\text { foreign owner }\end{array}$ & 1.86 & 0.378 & \\
\hline & & Foreign owner & 1.33 & 0.516 & \\
\hline & \multirow{3}{*}{$\begin{array}{l}\text { Cancellation Terms } \\
\text { Compliance }\end{array}$} & Local owner & 1.81 & 1.001 & \multirow{3}{*}{$F(2,37)=0.665, p=0.52$} \\
\hline & & $\begin{array}{c}\text { Local \& } \\
\text { foreign owner }\end{array}$ & 2.29 & 1.254 & \\
\hline & & Foreign owner & 1.67 & 1.211 & \\
\hline & \multirow{3}{*}{$\begin{array}{l}\text { Conflicts with OI from } \\
\text { Pre-stay } \\
\text { issues? Information } \\
\text { provision }\end{array}$} & Local owner & 1.57 & 0.879 & \multirow{3}{*}{$F(2,39)=0.719, p=0.494$} \\
\hline & & $\begin{array}{l}\text { Local \& } \\
\text { foreign owner }\end{array}$ & 1.88 & 0.991 & \\
\hline & & Foreign owner & 2 & 1.095 & \\
\hline & \multirow{3}{*}{ Booking details } & Local owner & 1.43 & 0.742 & \multirow{3}{*}{$F(2,39)=0.811, p=0.452$} \\
\hline & & $\begin{array}{c}\text { Local \& } \\
\text { foreign owner }\end{array}$ & 1.75 & 1.035 & \\
\hline & & Foreign owner & 1.83 & 1.169 & \\
\hline & \multirow{3}{*}{$\begin{array}{l}\text { Cancellation Terms } \\
\text { Compliance }\end{array}$} & Local owner & 1.71 & 1.049 & \multirow{3}{*}{$F(2,39)=0.063, p=0.939$} \\
\hline & & $\begin{array}{c}\text { Local \& } \\
\text { foreign owner }\end{array}$ & 1.63 & 1.408 & \\
\hline & & Foreign owner & 1.83 & 0.753 & \\
\hline \multirow{11}{*}{$\begin{array}{l}\text { Stay } \\
\text { Stage }\end{array}$} & \multirow{3}{*}{$\begin{array}{l}\text { Conflicts with TI from } \\
\text { Stay issues? Operation } \\
\text { Errors }\end{array}$} & Local owner & 1.59 & 0.572 & \multirow{3}{*}{$F(2,37)=0.463, p=0.633$} \\
\hline & & $\begin{array}{c}\text { Local \& } \\
\text { foreign owner }\end{array}$ & 1.71 & 0.488 & \\
\hline & & Foreign owner & 1.83 & 0.753 & \\
\hline & \multirow{3}{*}{ Overbookings } & Local owner & 1.44 & 0.577 & \multirow{3}{*}{$F(2,37)=2.756, p=0.077$} \\
\hline & & $\begin{array}{c}\text { Local \& } \\
\text { foreign owner }\end{array}$ & 1.14 & 0.378 & \\
\hline & & Foreign owner & 1.83 & 0.408 & \\
\hline & \multirow{3}{*}{$\begin{array}{l}\text { Conflicts with OI from } \\
\text { Stay issues? Operation } \\
\text { Errors }\end{array}$} & Local owner & 2 & 0.861 & \multirow{3}{*}{$F(2,39)=0.594, p=0.557$} \\
\hline & & $\begin{array}{c}\text { Local \& } \\
\text { foreign owner }\end{array}$ & 1.63 & 1.061 & \\
\hline & & Foreign owner & 2 & 0.632 & \\
\hline & \multirow[b]{2}{*}{ Overbookings } & Local owner & 2.32 & 1.219 & \multirow[b]{2}{*}{$F(2,39)=0.239, p=0.789$} \\
\hline & & $\begin{array}{l}\text { Local \& } \\
\text { foreign owner }\end{array}$ & 2 & 1.309 & \\
\hline
\end{tabular}




\begin{tabular}{|c|c|c|c|c|c|}
\hline & & Foreign owner & 2.33 & 0.816 & \\
\hline \multirow{12}{*}{$\begin{array}{l}\text { Post-stay } \\
\text { Stage }\end{array}$} & $\begin{array}{l}\text { Conflicts with TI from } \\
\text { Post-Stay issues? }\end{array}$ & Local owner & 2.07 & 0.958 & \multirow{3}{*}{$F(2,37)=1.054, p=0.359$} \\
\hline & \multirow[t]{2}{*}{ Payment } & $\begin{array}{l}\text { Local \& } \\
\text { foreign owner }\end{array}$ & 2.71 & 1.38 & \\
\hline & & Foreign owner & 2.17 & 0.983 & \\
\hline & \multirow{3}{*}{ Complaint handling } & Local owner & 1.81 & 0.786 & \multirow{3}{*}{$F(2,37)=0.654, p=0.526$} \\
\hline & & $\begin{array}{c}\text { Local \& } \\
\text { foreign owner }\end{array}$ & 2.14 & 0.378 & \\
\hline & & Foreign owner & 2 & 0.632 & \\
\hline & $\begin{array}{l}\text { Conflicts with OI from } \\
\text { Post-Stay issues? }\end{array}$ & Local owner & 1.82 & 0.983 & \multirow{3}{*}{$F(2,39)=0.656, p=0.524$} \\
\hline & \multirow[t]{2}{*}{ Payment } & $\begin{array}{c}\text { Local \& } \\
\text { foreign owner }\end{array}$ & 1.63 & 1.188 & \\
\hline & & Foreign owner & 1.33 & 0.516 & \\
\hline & \multirow{3}{*}{ Complaint handling } & Local owner & 2.14 & 0.803 & \multirow{3}{*}{$F(2,39)=0.745, p=0.481$} \\
\hline & & $\begin{array}{c}\text { Local \& } \\
\text { foreign owner }\end{array}$ & 2.5 & 0.756 & \\
\hline & & Foreign owner & 2 & 1.095 & \\
\hline
\end{tabular}




\section{Appendix 4: Result of ANOVA and Pearson Correlation tests on sources of conflict by hotel size}

\begin{tabular}{|c|c|c|c|c|c|c|}
\hline $\begin{array}{l}\text { Stage of } \\
\text { issues }\end{array}$ & Conflict factors & $\begin{array}{l}\text { Hotel } \\
\text { Size }\end{array}$ & Mean & Std & ANOVA test results & $\begin{array}{c}\text { Pearson Correlation } \\
\text { test result }\end{array}$ \\
\hline \multirow{10}{*}{$\begin{array}{l}\text { Contract } \\
\text { Stage }\end{array}$} & $\begin{array}{l}\text { Conflicts with TI } \\
\text { from contract issues? } \\
\text { Price Level }\end{array}$ & $\begin{array}{l}\text { Small } \\
\text { Medium } \\
\text { Large }\end{array}$ & $\begin{array}{c}2.44 \\
3 \\
2.25\end{array}$ & $\begin{array}{l}1.617 \\
1.054 \\
0.622\end{array}$ & $F(2,37)=1.034, p=0.366$ & {$[r=-0.044, p=0.790]$} \\
\hline & Commission & $\begin{array}{l}\text { Small } \\
\text { Medium } \\
\text { Large }\end{array}$ & $\begin{array}{l}1.56 \\
1.6 \\
1.17\end{array}$ & $\begin{array}{l}1.294 \\
1.075 \\
0.389\end{array}$ & $F(2,37)=0.634, p=0.536$ & {$[r=-0.152, p=0.350]$} \\
\hline & Price Quality Ratio & $\begin{array}{l}\text { Small } \\
\text { Medium } \\
\text { Large }\end{array}$ & $\begin{array}{l}2.28 \\
2.2 \\
1.67\end{array}$ & $\begin{array}{l}1.602 \\
0.789 \\
0.492\end{array}$ & $F(2,37)=1.033, p=0.366$ & {$[r=-0.214, p=0.185]$} \\
\hline & Release Period & $\begin{array}{l}\text { Small } \\
\text { Medium } \\
\text { Large }\end{array}$ & $\begin{array}{c}2 \\
1.7 \\
1.58\end{array}$ & $\begin{array}{l}1.414 \\
0.675 \\
0.793\end{array}$ & $F(2,37)=0.568, p=0.571$ & {$[r=-0.169, p=0.298]$} \\
\hline & $\begin{array}{l}\text { Fulfillment of } \\
\text { contract Conditions }\end{array}$ & $\begin{array}{l}\text { Small } \\
\text { Medium } \\
\text { Large }\end{array}$ & $\begin{array}{l}1.89 \\
1.6 \\
1.67\end{array}$ & $\begin{array}{l}0.516 \\
0.651\end{array}$ & $F(2,37)=0.329, p=0.722$ & {$[r=-0.106, p=0.515]$} \\
\hline & $\begin{array}{l}\text { Conflicts with OI } \\
\text { from contract } \\
\text { issues? } \\
\text { Price Level }\end{array}$ & $\begin{array}{l}\text { Medium } \\
\text { Large }\end{array}$ & $\begin{array}{l}2.74 \\
2.82 \\
2.17\end{array}$ & $\begin{array}{l}1.284 \\
1.601 \\
0.835\end{array}$ & $F(2,39)=0.970, p=0.388$ & {$[r=-0.176, p=0.264]$} \\
\hline & Commission & $\begin{array}{l}\text { Small } \\
\text { Medium } \\
\text { Large }\end{array}$ & $\begin{array}{l}1.53 \\
1.45 \\
1.75\end{array}$ & $\begin{array}{c}1.02 \\
0.688 \\
0.754\end{array}$ & $F(2,39)=0.375, p=0.690$ & {$[r=0.100, p=0.529]$} \\
\hline & Price Quality Ratio & $\begin{array}{c}\text { Small } \\
\text { Medium } \\
\text { Large }\end{array}$ & $\begin{array}{c}1.84 \\
2 \\
1.58\end{array}$ & $\begin{array}{c}1.214 \\
1 \\
0.669\end{array}$ & $F(2,39)=0.486, p=0.619$ & {$[r=0.094, p=0.555]$} \\
\hline & Release Period & $\begin{array}{c}\text { Small } \\
\text { Medium } \\
\text { Large }\end{array}$ & $\begin{array}{c}1.89 \\
1.55 \\
2\end{array}$ & $\begin{array}{l}1.197 \\
0.688 \\
0.853\end{array}$ & $F(2,39)=0.667, p=0.519$ & {$[r=0.024, p=0.879]$} \\
\hline & $\begin{array}{l}\text { Fulfilment of } \\
\text { contract Conditions }\end{array}$ & $\begin{array}{c}\text { Small } \\
\text { Medium } \\
\text { Large }\end{array}$ & $\begin{array}{c}1.68 \\
1.18 \\
1.5\end{array}$ & $\begin{array}{l}1.336 \\
0.405 \\
0.674\end{array}$ & $F(2,39)=0.885, p=0.421$ & {$[r=-0.101, p=0.526]$} \\
\hline $\begin{array}{l}\text { Pre-stay } \\
\text { Stage }\end{array}$ & $\begin{array}{l}\text { Conflicts with TI } \\
\text { from Pre-stay }\end{array}$ & $\begin{array}{c}\text { Small } \\
\text { Medium }\end{array}$ & $\begin{array}{c}1.67 \\
1.3\end{array}$ & $\begin{array}{l}0.767 \\
0.483\end{array}$ & $F(2,37)=0.947, p=0.397$ & {$[r=-0.125, p=0.444]$} \\
\hline
\end{tabular}




\begin{tabular}{|c|c|c|c|c|c|c|}
\hline & $\begin{array}{l}\text { issues? Information } \\
\text { provision }\end{array}$ & Large & 1.5 & 0.674 & & \\
\hline & \multirow{3}{*}{ Booking details } & Small & 1.5 & 0.857 & \multirow{3}{*}{$F(2,37)=0.070, p=0.933$} & \multirow{3}{*}[r=-0.006,p=0.970]{} \\
\hline & & Medium & 1.4 & 0.699 & & \\
\hline & & Large & 1.5 & 0.522 & & \\
\hline & \multirow{3}{*}{$\begin{array}{l}\text { Cancellation Terms } \\
\text { Compliance }\end{array}$} & Small & 1.94 & 1.211 & \multirow{3}{*}{$F(2,37)=0.440, p=0.647$} & \multirow{3}{*}[r=-0.007,p=0.966]{} \\
\hline & & Medium & 1.6 & 0.699 & & \\
\hline & & Large & 2 & 1.128 & & \\
\hline & \multirow{3}{*}{$\begin{array}{l}\text { Conflicts with OI } \\
\text { from Pre-stay } \\
\text { issues? Information } \\
\text { provision }\end{array}$} & Small & 1.84 & 1.119 & \multirow{3}{*}{$F(2,39)=0.968, p=0.389$} & \multirow{3}{*}[r=-0.067,p=0.673]{} \\
\hline & & Medium & 1.36 & 0.505 & & \\
\hline & & Large & 1.75 & 0.866 & & \\
\hline & \multirow{3}{*}{ Booking details } & Small & 1.79 & 1.134 & \multirow{3}{*}{$F(2,39)=1.483, p=0.240$} & \multirow{3}{*}[r=-0.205,p=0.193]{} \\
\hline & & Medium & 1.27 & 0.467 & & \\
\hline & & Large & 1.42 & 0.515 & & \\
\hline & \multirow{3}{*}{$\begin{array}{l}\text { Cancellation Terms } \\
\text { Compliance }\end{array}$} & Small & 2.16 & 1.385 & \multirow{3}{*}{$F(2,39)=3.833, p=0.030$} & \multirow{3}{*}[r=-0.402,p=0.008]{} \\
\hline & & Medium & 1.55 & 0.522 & & \\
\hline & & Large & 1.17 & 0.389 & & \\
\hline \multirow{12}{*}{$\begin{array}{l}\text { Stay } \\
\text { Stage }\end{array}$} & \multirow{3}{*}{$\begin{array}{l}\text { Conflicts with TI } \\
\text { from Stay } \\
\text { issues? Operation } \\
\text { Errors }\end{array}$} & Small & 1.61 & 0.502 & \multirow{3}{*}{$F(2,37)=1.401, p=0.259$} & \multirow{3}{*}[r=-0.056,p=0.730]{} \\
\hline & & Medium & 1.9 & 0.738 & & \\
\hline & & Large & 1.5 & 0.522 & & \\
\hline & \multirow{3}{*}{ Overbookings } & Small & 1.39 & 0.502 & \multirow{3}{*}{$F(2,37)=3.237, p=0.051$} & \multirow{3}{*}[r=-0.070,p=0.668]{} \\
\hline & & Medium & 1.8 & 0.632 & & \\
\hline & & Large & 1.25 & 0.452 & & \\
\hline & \multirow{3}{*}{$\begin{array}{l}\text { Conflicts with OI } \\
\text { from Stay } \\
\text { issues? Operation } \\
\text { Errors }\end{array}$} & Small & 2 & 1 & \multirow{3}{*}{$F(2,39)=0.245, p=0.710$} & \multirow{3}{*}[r=-0.115,p=0.466]{} \\
\hline & & Medium & 2 & 0.632 & & \\
\hline & & Large & 1.75 & 0.866 & & \\
\hline & \multirow{3}{*}{ Overbookings } & Small & 2.42 & 1.465 & \multirow{3}{*}{$F(2,39)=0.322, p=0.727$} & \multirow{3}{*}[r=-0.102,p=0.521]{} \\
\hline & & Medium & 2.09 & 0.831 & & \\
\hline & & Large & 2.17 & 0.937 & & \\
\hline & $\begin{array}{l}\text { Conflicts with TI } \\
\text { from Post-Stay } \\
\text { issues? }\end{array}$ & Small & 2.17 & 0.985 & $F(2,37)=0.022 \quad n=0.978$ & $r=0.034, p=0.834]$ \\
\hline & Payment & Medium & 2.2 & 0.919 & & \\
\hline stay & & Large & 2.25 & 1.288 & & \\
\hline & & Small & 1.72 & 0.575 & & \\
\hline & Complaint handling & Medium & 2.3 & 0.823 & $F(2,37)=2.366, p=0.108$ & {$[r=0.100, p=0.537]$} \\
\hline & & Large & 1.83 & 0.718 & & \\
\hline
\end{tabular}




\begin{tabular}{|l|lccccc|}
$\begin{array}{l}\text { Conflicts with OI } \\
\text { from Post-Stay }\end{array}$ & Small & 1.74 & 1.046 & & \\
issues? & & & & $F(2,39)=0.020, p=0.981 \quad$ [ $r=-0.029, p=0.853]$ \\
Payment & Medium & 1.73 & 0.905 & & \\
& Large & 1.67 & 0.985 & & \\
\cline { 2 - 7 } & Small & 2.05 & 0.97 & & \\
& Complaint handling & Medium & 2.27 & 0.786 & $F(2,39)=0.477, p=0.624 \quad[r=0.149, p=0.347]$ \\
& Large & 2.33 & 0.651 & & \\
& & & &
\end{tabular}




\section{Appendix 5: Result of ANOVA and Pearson Correlation tests on sources of conflict by hotel age}

\begin{tabular}{|c|c|c|c|c|c|c|}
\hline $\begin{array}{l}\text { Stage of } \\
\text { issues }\end{array}$ & Conflict factors & Hotel Age & Mean & Std. & ANOVA test results & $\begin{array}{l}\text { Pearson Correlation test } \\
\text { result }\end{array}$ \\
\hline \multirow{30}{*}{$\begin{array}{l}\text { Contract } \\
\text { Stage }\end{array}$} & \multirow{3}{*}{$\begin{array}{l}\text { Conflicts with TI from } \\
\text { contract issues? } \\
\text { Price Level }\end{array}$} & New & 2.46 & 1.45 & \multirow{3}{*}{$F(2,37)=1.586, p=0.218$} & \multirow{3}{*}[r=-0.114,p=0.485]{} \\
\hline & & Average & 2.93 & 1.438 & & \\
\hline & & Old & 2.08 & 0.515 & & \\
\hline & \multirow{3}{*}{ Commission } & New & 1.38 & 0.87 & \multirow{3}{*}{$F(2,37)=1.69, p=0.199$} & \multirow{3}{*}[r=-0.110,p=0.500]{} \\
\hline & & Average & 1.8 & 1.424 & & \\
\hline & & Old & 1.08 & 0.289 & & \\
\hline & \multirow{3}{*}{ Price Quality Ratio } & New & 1.77 & 1.013 & \multirow{3}{*}{$F(2,37)=3.383, p=0.045$} & \multirow{3}{*}[r=-0.025,p=0.878]{} \\
\hline & & Average & 2.67 & 1.496 & & \\
\hline & & Old & 1.67 & 0.492 & & \\
\hline & \multirow{3}{*}{ Release Period } & New & 1.77 & 0.927 & \multirow{3}{*}{$F(2,37)=1.482, p=0.24$} & \multirow{3}{*}[r=-0.123,p=0.448]{} \\
\hline & & Average & 2.13 & 1.457 & & \\
\hline & & Old & 1.42 & 0.515 & & \\
\hline & \multirow{3}{*}{$\begin{array}{l}\text { Fulfilment of contract } \\
\text { Conditions }\end{array}$} & New & 1.46 & 0.66 & \multirow{3}{*}{$F(2,37)=1.418, p=0.255$} & \multirow{3}{*}[r=0.090,p=0.581]{} \\
\hline & & Average & 2.07 & 1.335 & & \\
\hline & & Old & 1.67 & 0.651 & & \\
\hline & $\begin{array}{l}\text { Conflicts with OI from } \\
\text { contract issues? }\end{array}$ & New & 3.08 & 1.188 & \multirow{3}{*}{$F(2,39)=1.697, p=0.196$} & \\
\hline & \multirow[t]{2}{*}{ Price Level } & Average & 2.53 & 1.419 & & {$[r=-0.281, p=0.072]$} \\
\hline & & Old & 2.17 & 1.03 & & \\
\hline & \multirow{3}{*}{ Commission } & New & 1.15 & 0.376 & \multirow{3}{*}{$F(2,39)=2.892, p=0.067$} & \\
\hline & & Average & 1.88 & 1.111 & & {$[r=0.203, p=0.198]$} \\
\hline & & Old & 1.58 & 0.669 & & \\
\hline & \multirow{3}{*}{ Price Quality Ratio } & New & 1.62 & 0.87 & \multirow{3}{*}{$F(2,39)=0.859, p=0.432$} & \multirow{3}{*}[r=0.025,p=0.876]{} \\
\hline & & Average & 2.06 & 1.298 & & \\
\hline & & Old & 1.67 & 0.651 & & \\
\hline & \multirow{3}{*}{ Release Period } & New & 1.62 & 0.768 & \multirow{3}{*}{$F(2,39)=0.548, p=0.582$} & \multirow{3}{*}[r=0.090,p=0.572]{} \\
\hline & & Average & 2 & 1.118 & & \\
\hline & & Old & 1.83 & 1.03 & & \\
\hline & \multirow{3}{*}{$\begin{array}{l}\text { Fulfilment of contract } \\
\text { Conditions }\end{array}$} & New & 1.46 & 0.776 & \multirow{3}{*}{$F(2,39)=0.114, p=0.893$} & \multirow{3}{*}[r=-0.016,p=0.921]{} \\
\hline & & Average & 1.59 & 1.326 & & \\
\hline & & Old & 1.42 & 0.669 & & \\
\hline Pre-stay & Conflicts with TI from & New & 1.46 & 0.66 & $F(2,37)=0.150, n=0.862$ & {$[r=0.025, n=0.879]$} \\
\hline & Pre-stay & Average & 1.6 & 0.737 & & \\
\hline
\end{tabular}




\begin{tabular}{|c|c|c|c|c|c|}
\hline & $\begin{array}{l}\text { issues? Information } \\
\text { provision }\end{array}$ & Old & 1.5 & 0.674 & \\
\hline & & New & 1.31 & 0.48 & \\
\hline & Booking details & Average & 1.87 & 0.915 & $\boldsymbol{F}(\mathbf{2}, \mathbf{3 7})=\mathbf{4 . 3 5 4}, \boldsymbol{p}=\mathbf{0 . 0 2} \quad[r=-0.068, p=0.675]$ \\
\hline & & Old & 1.17 & 0.389 & \\
\hline & & New & 2 & 0.913 & \\
\hline & $\begin{array}{l}\text { Cancellation Terms } \\
\text { Compliance }\end{array}$ & Average & 1.93 & 1.28 & $F(2,37)=0.329, p=0.722 \quad[r=-0.124, p=0.446]$ \\
\hline & & Old & 1.67 & 0.985 & \\
\hline & Conflicts with OI from & New & 1.38 & 0.65 & \\
\hline & $\begin{array}{l}\text { Pre-stay } \\
\text { issues? Information }\end{array}$ & Average & 1.65 & 0.996 & $F(2,39)=1.897, p=0.164 \quad[r=0.294, p=0.059]$ \\
\hline & provision & Old & 2.08 & 0.996 & \\
\hline & & New & 1.23 & 0.439 & \\
\hline & Booking details & Average & 1.82 & 1.131 & $F(2,39)=1.844, p=0.172 \quad[r=0.129, p=0.416]$ \\
\hline & & Old & 1.5 & 0.674 & \\
\hline & & New & 1.69 & 1.032 & \\
\hline & $\begin{array}{l}\text { Cancellation Terms } \\
\text { Comnliance }\end{array}$ & Average & 2.06 & 1.298 & $F(2,39)=2.143, p=0.131 \quad[r=-0.155, p=0.327]$ \\
\hline & & Old & 1.25 & 0.452 & \\
\hline & Conflicts with TI from & New & 1.62 & 0.506 & \\
\hline & Stay issues? Operation & Average & 1.67 & 0.617 & $F(2,37)=0.033, p=0.968 \quad[r=0.036, p=0.826]$ \\
\hline & Errors & Old & 1.67 & 0.651 & \\
\hline & & New & 1.31 & 0.48 & \\
\hline & Overbookings & Average & 1.67 & 0.617 & $F(2,37)=1.943, p=0.158 \quad[r=0.026, p=0.873]$ \\
\hline Stay & & Old & 1.33 & 0.492 & \\
\hline Stage & Conflicts with OI from & New & 1.69 & 0.855 & \\
\hline & Stay issues? Operation & Average & 1.94 & 0.966 & $F(2,39)=0.935, p=0.401 \quad[r=0.214, p=0.174]$ \\
\hline & Errors & Old & 2.17 & 0.718 & \\
\hline & & New & 2.15 & 1.214 & \\
\hline & Overbookings & Average & 2.53 & 1.375 & $F(2,39)=0.792, p=0.46 \quad[r=-0.046, p=0.770]$ \\
\hline & & Old & 2 & 0.739 & \\
\hline & $\begin{array}{l}\text { Conflicts with TI from } \\
\text { Post-Stay issues? }\end{array}$ & New & 2.08 & 0.76 & \\
\hline & Payment & Average & 2.4 & 1.121 & $F(2,37)=0.429, p=0.655 \quad[r=0.006, p=0.970]$ \\
\hline & & Old & 2.08 & 1.24 & \\
\hline $\begin{array}{l}\text { Post-stay } \\
\text { Stage }\end{array}$ & & New & 2 & 0.577 & \\
\hline & Complaint handling & Average & 2.07 & 0.884 & $F(2,37)=1.814, p=0.177 \quad[r=-0.231, p=0.152]$ \\
\hline & & Old & 1.58 & 0.515 & \\
\hline & $\begin{array}{l}\text { Conflicts with OI from } \\
\text { Post-Stay issues? }\end{array}$ & New & 1.46 & 0.967 & $F(2,39)=0.694, p=0.506 \quad[r=0.120, p=0.450]$ \\
\hline
\end{tabular}




\begin{tabular}{|lcccc|}
\hline & Average & 1.88 & 1.054 \\
& Old & 1.75 & 0.866 & \\
\cline { 2 - 6 } & New & 2 & 0.707 & \\
\multirow{3}{*}{ Complaint handling } & Average & 2.29 & 1.047 & $F(2,39)=0.489, p=0.617 \quad[r=0.120, p=0.450]$ \\
& Old & 2.25 & 0.622 & \\
\hline
\end{tabular}




\section{Appendix 6: Result of Independent Sample t-tests on sources of conflict by respondents' job titles}

\begin{tabular}{|c|c|c|c|c|c|}
\hline $\begin{array}{l}\text { Stage of } \\
\text { issues }\end{array}$ & Conflict & Job Title & $\begin{array}{l}\text { Mean } \\
(\mathrm{SD})\end{array}$ & Std & $\begin{array}{l}\text { Independent Sample t-test } \\
\text { results }\end{array}$ \\
\hline \multirow{20}{*}{$\begin{array}{l}\text { Contract } \\
\text { Stage }\end{array}$} & \multirow{2}{*}{ Price Level (TI) } & General Manager & 2.44 & 1.464 & \multirow{2}{*}{$t(38)=-0.361, p=0.720$} \\
\hline & & Sales Manager & 2.59 & 1.098 & \\
\hline & \multirow{2}{*}{ Commission (TI) } & General Manager & 1.56 & 1.294 & \multirow{2}{*}{$t(38)=0.578, p=0.567$} \\
\hline & & Sales Manager & 1.36 & 0.79 & \\
\hline & \multirow{2}{*}{$\begin{array}{l}\text { Price Quality ratio } \\
(\mathrm{TI})\end{array}$} & General Manager & 2.28 & 1.487 & \multirow{2}{*}{$t(38)=0.978, p=0.334$} \\
\hline & & Sales Manager & 1.91 & 0.868 & \\
\hline & \multirow{2}{*}{ Release period (TI) } & General Manager & 1.94 & 1.392 & \multirow{2}{*}{$t(38)=0.753, p=0.456$} \\
\hline & & Sales Manager & 1.68 & 0.78 & \\
\hline & \multirow{2}{*}{$\begin{array}{l}\text { Fulfilment of contract } \\
\text { conditions (TI) }\end{array}$} & General Manager & 1.83 & 1.295 & \multirow{2}{*}{$t(38)=0.481, p=0.633$} \\
\hline & & Sales Manager & 1.68 & 0.646 & \\
\hline & \multirow{2}{*}{ Price Level (OI) } & General Manager & 2.6 & 1.314 & \multirow{2}{*}{$t(40)=0.023, p=0.982$} \\
\hline & & Sales Manager & 2.59 & 1.26 & \\
\hline & \multirow{2}{*}{ Commission (OI) } & General Manager & 1.55 & 0.999 & \multirow{2}{*}{$t(40)=-0.152, p=0.880$} \\
\hline & & Sales Manager & 1.59 & 0.734 & \\
\hline & \multirow{2}{*}{$\begin{array}{l}\text { Price Quality ratio } \\
\text { (OI) }\end{array}$} & General Manager & 1.85 & 1.226 & \multirow{2}{*}{$t(40)=0.243, p=0.809$} \\
\hline & & Sales Manager & 1.77 & 0.813 & \\
\hline & \multirow{2}{*}{ Release period (OI) } & General Manager & 1.95 & 1.146 & \multirow{2}{*}{$t(40)=0.727, p=0.471$} \\
\hline & & Sales Manager & 1.73 & 0.827 & \\
\hline & \multirow{2}{*}{$\begin{array}{l}\text { Fulfilment of contract } \\
\text { conditions (OI) }\end{array}$} & General Manager & 1.55 & 1.276 & \multirow{2}{*}{$t(40)=0.307, p=0.760$} \\
\hline & & Sales Manager & 1.45 & 0.671 & \\
\hline \multirow{12}{*}{$\begin{array}{l}\text { Pre-stay } \\
\text { stage }\end{array}$} & \multirow{2}{*}{$\begin{array}{l}\text { Information provision } \\
\text { (TI) }\end{array}$} & General Manager & 1.61 & 0.778 & \multirow{2}{*}{$t(38)=0.721, p=0.475$} \\
\hline & & Sales Manager & 1.45 & 0.596 & \\
\hline & \multirow{2}{*}{ Booking details (TI) } & General Manager & 1.5 & 0.857 & \multirow{2}{*}{$t(38)=0.197, p=0.845$} \\
\hline & & Sales Manager & 1.45 & 0.596 & \\
\hline & \multirow{2}{*}{$\begin{array}{l}\text { Cancellation terms } \\
\text { compliance (TI) }\end{array}$} & General Manager & 1.94 & 1.162 & \multirow{2}{*}{$t(38)=0.368, p=0.715$} \\
\hline & & Sales Manager & 1.82 & 1.006 & \\
\hline & \multirow{2}{*}{$\begin{array}{l}\text { Information provision } \\
(\mathrm{OI})\end{array}$} & General Manager & 1.55 & 0.999 & \multirow{2}{*}{$t(40)=-0.938, p=0.354$} \\
\hline & & Sales Manager & 1.82 & 0.853 & \\
\hline & Booking details (OD) & General Manager & 1.6 & 0.995 & $t(40)=0372 n=0712$ \\
\hline & & Sales Manager & 1.5 & 0.74 & (1) \\
\hline & Cancellation terms & General Manager & 2 & 1.376 & $t(40)=1694 \quad n=0098$ \\
\hline & compliance (OI) & Sales Manager & 1.45 & 0.596 & \\
\hline
\end{tabular}




\begin{tabular}{|c|c|c|c|c|c|}
\hline \multirow{4}{*}{$\begin{array}{l}\text { Stay- } \\
\text { stage }\end{array}$} & Operation Errors (TI) & $\begin{array}{l}\text { General Manager } \\
\text { Sales Manager }\end{array}$ & $\begin{array}{l}1.67 \\
1.64\end{array}$ & $\begin{array}{l}0.594 \\
0.581\end{array}$ & $t(38)=0.162, p=0.872$ \\
\hline & Overbookings (TI) & $\begin{array}{l}\text { General Manager } \\
\text { Sales Manager }\end{array}$ & $\begin{array}{l}1.44 \\
1.45\end{array}$ & $\begin{array}{c}0.616 \\
0.51\end{array}$ & $t(38)=-0.057, p=0.955$ \\
\hline & Operation Errors (OI) & $\begin{array}{l}\text { General Manager } \\
\text { Sales Manager }\end{array}$ & $\begin{array}{c}1.85 \\
2\end{array}$ & $\begin{array}{l}0.933 \\
0.816\end{array}$ & $t(40)=-0.556, p=0.582$ \\
\hline & Overbookings (OI) & $\begin{array}{l}\text { General Manager } \\
\text { Sales Manager }\end{array}$ & $\begin{array}{l}2.15 \\
2.36\end{array}$ & $\begin{array}{l}1.268 \\
1.093\end{array}$ & $t(40)=-0.586, p=0.561$ \\
\hline \multirow{4}{*}{$\begin{array}{l}\text { Post- } \\
\text { stay } \\
\text { stage }\end{array}$} & Payment (TI) & $\begin{array}{l}\text { General Manager } \\
\text { Sales Manager }\end{array}$ & $\begin{array}{l}2.17 \\
2.23\end{array}$ & $\begin{array}{l}1.043 \\
1.066\end{array}$ & $t(38)=-0.181, p=0.858$ \\
\hline & $\begin{array}{l}\text { Complaint handling } \\
\text { (TI) }\end{array}$ & $\begin{array}{l}\text { General Manager } \\
\text { Sales Manager }\end{array}$ & $\begin{array}{l}1.89 \\
1.91\end{array}$ & $\begin{array}{l}0.758 \\
0.684\end{array}$ & $t(38)=-0.089, p=0.930$ \\
\hline & Payment (OI) & $\begin{array}{l}\text { General Manager } \\
\text { Sales Manager }\end{array}$ & $\begin{array}{l}1.75 \\
1.68\end{array}$ & $\begin{array}{r}1.07 \\
0.894\end{array}$ & $t(40)=0.225, p=0.823$ \\
\hline & $\begin{array}{l}\text { Complaint handling } \\
\text { (OI) }\end{array}$ & $\begin{array}{l}\text { General Manager } \\
\text { Sales Manager }\end{array}$ & $\begin{array}{l}2.05 \\
2.32\end{array}$ & $\begin{array}{l}0.826 \\
0.839\end{array}$ & $t(40)=-1.043, p=0.303$ \\
\hline
\end{tabular}




\section{Appendix 7: Result of Independent Sample t-tests on sources of conflict by respondents' nationalities}

\begin{tabular}{|c|c|c|c|c|c|}
\hline $\begin{array}{l}\text { Stage of } \\
\text { issues }\end{array}$ & Conflict & $\begin{array}{l}\text { Respondents' } \\
\text { Nationalities }\end{array}$ & $\begin{array}{l}\text { Mean } \\
(\mathrm{SD})\end{array}$ & Std. & $\begin{array}{l}\text { Independent Sample t- } \\
\text { test results }\end{array}$ \\
\hline \multirow{20}{*}{$\begin{array}{l}\text { Contract } \\
\text { Stage }\end{array}$} & \multirow{2}{*}{ Price Level (TI) } & Cambodian & 2.63 & 1.314 & \multirow{2}{*}{$t(38)=1.004, p=0.322$} \\
\hline & & Foreigner & 2.13 & 0.991 & \\
\hline & \multirow{2}{*}{ Commission (TI) } & Cambodian & 1.5 & 1.107 & \multirow{2}{*}{$t(38)=0.605, p=0.549$} \\
\hline & & Foreigner & 1.25 & 0.707 & \\
\hline & \multirow{2}{*}{ Price Quality ratio (TI) } & Cambodian & 2.06 & 1.243 & \multirow{2}{*}{$t(38)=-0.132, p=0.896$} \\
\hline & & Foreigner & 2.13 & 0.991 & \\
\hline & \multirow{2}{*}{ Release period (TI) } & Cambodian & 1.75 & 1.136 & \multirow{2}{*}{$t(38)=-0.575, p=0.569$} \\
\hline & & Foreigner & 2 & 0.926 & \\
\hline & \multirow{2}{*}{ Fulfillment of contract conditions (TI) } & Cambodian & 1.91 & 1.027 & \multirow{2}{*}{$t(38)=2.102, p=0.042$} \\
\hline & & Foreigner & 1.13 & 0.354 & \\
\hline & \multirow{2}{*}{ Price Level (OI) } & Cambodian & 2.61 & 1.298 & \multirow{2}{*}{$t(40)=0.104, p=0.917$} \\
\hline & & Foreigner & 2.56 & 1.236 & \\
\hline & \multirow{2}{*}{ Commission (OI) } & Cambodian & 1.39 & 0.659 & \multirow{2}{*}{$t(40)=-2.762, p=0.009$} \\
\hline & & Foreigner & 2.22 & 1.202 & \\
\hline & \multirow{2}{*}{ Price Quality ratio (OI) } & Cambodian & 1.73 & 0.944 & \multirow{2}{*}{$t(40)=-1.003, p=0.322$} \\
\hline & & Foreigner & 2.11 & 1.269 & \\
\hline & \multirow{2}{*}{ Release period (OI) } & Cambodian & 1.7 & 0.81 & \multirow{2}{*}{$t(40)=-0.176, p=0.086$} \\
\hline & & Foreigner & 2.33 & 1.414 & \\
\hline & \multirow{2}{*}{ Fulfillment of contract conditions (OI) } & Cambodian & 1.39 & 0.899 & \multirow{2}{*}{$t(40)=-1.337, p=0.189$} \\
\hline & & Foreigner & 1.89 & 1.269 & \\
\hline \multirow{11}{*}{$\begin{array}{l}\text { Pre- } \\
\text { Stage }\end{array}$} & \multirow{2}{*}{ Information provision (TI) } & Cambodian & 1.56 & 0.669 & \multirow{2}{*}{$t(38)=0.694, p=0.492$} \\
\hline & & Foreigner & 1.38 & 0.744 & \\
\hline & \multirow{2}{*}{ Booking details (TI) } & Cambodian & 1.53 & 0.761 & \multirow{2}{*}{$t(38)=0.994, p=0.326$} \\
\hline & & Foreigner & 1.25 & 0.463 & \\
\hline & \multirow{2}{*}{ Cancellation terms compliance (TI) } & Cambodian & 1.94 & 0.982 & \multirow{2}{*}{$t(38)=0.737, p=0.466$} \\
\hline & & Foreigner & 1.63 & 1.408 & \\
\hline & \multirow{2}{*}{ Information provision $(\mathrm{OI})$} & Cambodian & 1.48 & 0.712 & \multirow{2}{*}{$t(40)=-3.025, p=0.004$} \\
\hline & & Foreigner & 2.44 & 1.236 & \\
\hline & Bolking details $(\Omega \mathrm{I})$ & Cambodian & 1.48 & 0.795 & $t(40)=0003 n=0.372$ \\
\hline & Dooknilg detanis (UI) & Foreigner & 1.78 & 1.093 & $(40)--0.905, p-0.5 / 2$ \\
\hline & Cancellation terms compliance (OI) & Cambodian & 1.7 & 1.015 & $t(40)=-0.199, p=0.843$ \\
\hline
\end{tabular}




\begin{tabular}{|c|c|c|c|c|c|}
\hline & & Foreigner & 1.78 & 1.302 & \\
\hline \multirow{8}{*}{$\begin{array}{l}\text { Stay } \\
\text { Stage }\end{array}$} & \multirow{2}{*}{ Operation Errors (TI) } & Cambodian & 1.69 & 0.592 & \multirow{2}{*}{$t(38)=0.815, p=0.42$} \\
\hline & & Foreigner & 1.5 & 0.535 & \\
\hline & \multirow{2}{*}{ Overbookings (TI) } & Cambodian & 1.53 & 0.567 & \multirow{2}{*}{$t(38)=-1.924, p=0.062$} \\
\hline & & Foreigner & 1.13 & 0.354 & \\
\hline & \multirow{2}{*}{ Operation Errors (OI) } & Cambodian & 1.82 & 0.808 & \multirow{2}{*}{$t(40)=-1.611, p=0.115$} \\
\hline & & Foreigner & 2.33 & 1 & \\
\hline & \multirow{2}{*}{ Overbookings (OI) } & Cambodian & 2.3 & 1.185 & \multirow{2}{*}{$t(40)=0.432, p=0.668$} \\
\hline & & Foreigner & 2.11 & 1.167 & \\
\hline \multirow{8}{*}{$\begin{array}{l}\text { Post- } \\
\text { stay } \\
\text { Stage }\end{array}$} & \multirow{2}{*}{ Payment (TI) } & Cambodian & 2.19 & 0.998 & \multirow{2}{*}{$t(38)=-0.15, p=0.882$} \\
\hline & & Foreigner & 2.25 & 1.282 & \\
\hline & \multirow{2}{*}{ Complaint handling (TI) } & Cambodian & 2.03 & 0.695 & \multirow{2}{*}{$t(38)=2.494, p=0.017$} \\
\hline & & Foreigner & 1.38 & 0.518 & \\
\hline & \multirow{2}{*}{ Payment (OI) } & Cambodian & 1.48 & 0.834 & \multirow{2}{*}{$t(40)=-3.263, p=0.002$} \\
\hline & & Foreigner & 2.56 & 1.014 & \\
\hline & \multirow{2}{*}{ Complaint handling (OI) } & Cambodian & 2.06 & 0.788 & \multirow{2}{*}{$t(40)=-2.004, p=0.052$} \\
\hline & & Foreigner & 2.67 & 0.866 & \\
\hline
\end{tabular}




\section{Appendix 8: Information Sheet for participants}

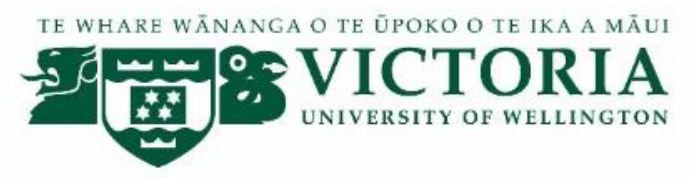

\section{Distribution channels of hotels in Cambodia: The perception of hoteliers of their relationship with intermediaries}

\section{INFORMATION SHEET FOR PARTICIPANTS}

You are invited to take part in this research. Please read this information before deciding whether or not to take part. If you decide to participate, thank you. If you decide not to participate, thank you for considering this request.

\section{Who am I?}

My name is Sarik Eng and I am a Master's student in Tourism Management at Victoria University of Wellington. This research project is undertaken as part of my thesis.

\section{What is the aim of the project?}

This project aims to examine distribution channels of hotels in Cambodia and to assess the perception of hoteliers of their relationships with traditional and online intermediaries. This research has been approved by the Victoria University of Wellington Human Ethics Committee with application reference number 0000026343.

\section{How can you help?}

You have been invited to participate because your role is assumed to deal with business relationships with intermediaries. If you agree to take part, I will interview you at your hotel. I will ask you questions about the hotel's relationship with intermediaries. The interview will take about 30 minutes. I will audio record the interview with your permission and write it up later. You can choose to not answer any question or stop the interview at any time, without giving a reason. You can withdraw from the study by contacting me at any time before 30 October, 2018. If you withdraw, the information you provided will be destroyed or returned to you.

\section{What will happen to the information you give?}

This research is confidential. This means that the researcher named below will be aware of your identity, but the research data will be combined, and your identity will not be revealed in any reports, presentations, or public documentation. 
Only my supervisor Associate Professor Mondher Sahli and I will read the notes or transcript of the interview. The interview transcripts, summaries and any recordings will be kept securely and destroyed on 30 March, 2021.

\section{What will the project produce?}

The information from my research will be used in my Master's thesis. Hence, a copy will be deposited in the Victoria University of Wellington Library. Findings may be presented at conferences or published in journals at a later date.

\section{If you accept this invitation, what are your rights as a research participant?}

You do not have to accept this invitation if you don't want to. If you do decide to participate, you have the right to:

- $\quad$ choose not to answer any question;

- $\quad$ ask for the recorder to be turned off at any time during the interview;

- $\quad$ withdraw from the study before 30 October, 2018;

- $\quad$ ask any questions about the study at any time;

- $\quad$ receive a copy of your interview recording; and

- be able to read any reports of this research by emailing the researcher to request a copy.

\section{If you have any questions or problems, who can you contact?}

If you have any questions, either now or in the future, please feel free to contact either:

\section{Student:}

Name: Sarik Eng

University email address:

engsari@myvuw.ac.nz

\section{Human Ethics Committee information}

Supervisor:

Name: Mondher Sahli

Role: BTM Programme Director

School: School of Management

Phone: 044635718

modher.sahli@vuw.ac.nz

If you have any concerns about the ethical conduct of the research, you may contact the Victoria University HEC Convenor: Dr Judith Loveridge. Email hec@vuw.ac.nz or telephone +64-4-463 6028. 


\section{Appendix 9: Consent to Interview}

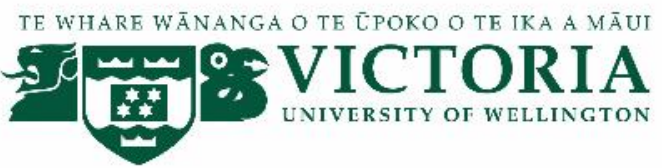

\section{Distribution channels of hotels in Cambodia: \\ The perception of hoteliers of their relationship with intermediaries \\ CONSENT TO INTERVIEW}

This consent form will be held for 3 years.

Researcher: Sarik Eng, School of Management, Victoria University of Wellington.

- I have read the Information Sheet and the project has been explained to me. My questions have been answered to my satisfaction. I understand that I can ask further questions at any time.

- I agree to take part in an audio recorded interview.

I understand that:

- I may withdraw from this study at any point before 30 October, 2018, and any information that I have provided will be returned to me or destroyed.

- $\quad$ The de-identified information I have provided will be destroyed on 30 March, 2021.

- Any information I provide will be kept confidential to the researcher and the supervisor.

- I understand that the results will be used for a Master's thesis. Hence, a copy will be deposited in the Victoria University of Wellington Library. Findings may be presented at conferences or published in journals at a later date.

- $\quad$ My name will not be used in reports, nor will any information that would identify me.

- I consent to information or opinions which I have given being attributed to my organisation in any reports on this research $\quad$ Yes No

I would like a copy of the recording of my interview:

Yes No

I would like a summary of my interview:

Yes No 
I would like to receive a copy of the final report and have added my Yes email address below.

Signature of participant:

Name of participant:

Date:

Contact details: 


\title{
Appendix 10: Interview guidelines
}

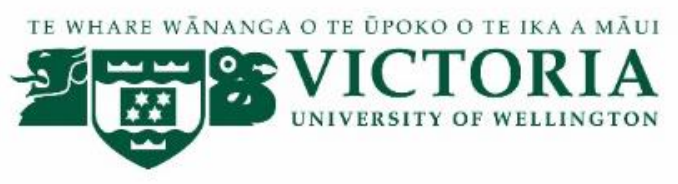

\author{
Interview Guidelines
}

\section{A Checklist of Questions for Hotel Representatives}

This project aims to examine distribution channels in mid-range to upscale hotels in Cambodia and to assess hoteliers' perceptions of their relationships with traditional and online intermediaries. This research has been approved by the Victoria University of Wellington Human Ethics Committee with application reference number 0000026343 . This interview will take about 30 minutes.

\section{Section A: Hotel Background}

1. Could you please provide me with some background information of your hotel?

- Hotel name

- Date of establishment

- Star rating

- Number of rooms

- Number of employees (\% of Full time and part-time)

- Average annual room occupancy

2. Could you please provide some detailed information of your hotel as below?

- Target Leisure or business guests? 
- $\%$ of business and leisure guests?

- $\%$ of international or domestic guests?

- Main markets (by nationality and percentage)

- FIT (Free Independent Traveler) \& GIT (Group Inclusive Tour)?

3. Could you please describe the ownership of your hotel?

- Who owns the hotel?

- Is it a $100 \%$ or partial ownership?

- Home country of the owner(s)?

4. Is your hotel affiliated with a hotel chain?

Yes No

5. If yes, what type of association is it?

- Fully owned

- Partially owned (Joint Venture)

- Management Service Contract

- Franchising agreement

- Leasing agreement 


\section{Section B: Distribution Channels}

6. What is the booking proportion your hotel receives from direct and indirect channels?

- $\%$ direct (through hotel website, walk-in or telephone booking)

- \% indirect (through intermediaries such as travel agencies, Agoda, booking.com, Expedia)

7. Which intermediaries does your hotel work with?

- Traditional intermediaries (TA: Travel Agencies)

For example: Foreign tour operators Local travel agencies

Wholesalers Inbound operators

Others $(\ldots \ldots \ldots \ldots \ldots \ldots \ldots)$

- Online intermediaries (OTAs: Online Travel Agencies)

For example: Agoda Expedia

Booking.com Hotels.com

Others $(\ldots \ldots \ldots \ldots \ldots \ldots \ldots)$

8. Could you please describe your distribution strategy to reach your targeted markets? 
9. What are the main advantages of working through intermediaries?

10. What are the main disadvantages of working through intermediaries?

\section{Section C: Nature of the Relationship with intermediaries}

11. How would you describe your relationship with traditional intermediaries such as a travel agency?

Extremely bad (1)

Somewhat bad (2)

Neither good nor bad (3)

Somewhat good (4)

Extremely good (5)

12. What factors have contributed to this level of satisfaction in your relationship with traditional intermediaries? 
13. Do you use different pricing and/or commission policies/practices for traditional intermediaries? Could you please elaborate?

14. How would you describe your relationship with online intermediaries such as Agoda, booking.com, Expedia, or Hotels.com?

Extremely bad (1)

Somewhat bad (2)

Neither good nor bad (3)

Somewhat good (4)

Extremely good (5)

15. What factors have contributed to this level of satisfaction of your relationship with online intermediaries?

16. Do you use different pricing and/or commission policies/practices for online intermediaries? Could you please elaborate? 
17. Overall, do you use different pricing and/or commission policies/practices between online and traditional intermediaries? Could you please elaborate?

\section{Section D: Potential conflicts with intermediaries}

18a. Have you experienced any conflicts with traditional intermediaries?

Never (1)

Sometimes (2)

About half the time (3)

Most of the time (4)

Always (5)

18b. If you have, could you please describe the nature of the conflicts that you had to deal with?

19a. Have you experienced any conflicts with online intermediaries?

Never (1)

Sometimes (2)

About half the time (3)

Most of the time (4)

Always (5) 
19b. If you have, could you please describe the nature of the conflicts that you had to deal with?

20a. How would you rate the conflicts with traditional intermediaries resulting from contract issues?

\begin{tabular}{|l|l|l|l|l|l|}
\hline Factors & $\begin{array}{l}\text { Extremely } \\
\text { Unlikely } \\
(1)\end{array}$ & $\begin{array}{l}\text { Somewhat } \\
\text { Unlikely (2) }\end{array}$ & $\begin{array}{l}\text { Neither likely } \\
\text { nor Unlikely } \\
(3)\end{array}$ & $\begin{array}{l}\text { Somewhat } \\
\text { Likely (4) }\end{array}$ & $\begin{array}{l}\text { Extremely } \\
\text { Likely (5) }\end{array}$ \\
\hline Price Level & & & & & \\
\hline Commission & & & & & \\
\hline Price/Quality ratio & & & & & \\
\hline Release Periods & & & & & \\
\hline $\begin{array}{l}\text { Fulfilment of } \\
\text { Contract conditions }\end{array}$ & & & & & \\
\hline
\end{tabular}

20b. How would you rate the conflicts with online intermediaries resulting from contract issues?

\begin{tabular}{|l|l|l|l|l|l|}
\hline Factors & $\begin{array}{l}\text { Extremely } \\
\text { Unlikely } \\
(1)\end{array}$ & $\begin{array}{l}\text { Somewhat } \\
\text { Unlikely (2) }\end{array}$ & $\begin{array}{l}\text { Neither likely } \\
\text { nor Unlikely } \\
(3)\end{array}$ & $\begin{array}{l}\text { Somewhat } \\
\text { Likely (4) }\end{array}$ & $\begin{array}{l}\text { Extremely } \\
\text { Likely (5) }\end{array}$ \\
\hline Price Level & & & & & \\
\hline Commission & & & & & \\
\hline Price/Quality ratio & & & & & \\
\hline Release Periods & & & & & \\
\hline $\begin{array}{l}\text { Fulfilment of } \\
\text { Contract conditions }\end{array}$ & & & & & \\
\hline
\end{tabular}


21a. How would you rate the conflicts with traditional intermediaries resulteing from Pre-stay issues?

\begin{tabular}{|l|l|l|l|l|l|}
\hline Factors & $\begin{array}{l}\text { Extremely } \\
\text { Unlikely } \\
(1)\end{array}$ & $\begin{array}{l}\text { Somewhat } \\
\text { Unlikely (2) }\end{array}$ & $\begin{array}{l}\text { Neither likely } \\
\text { nor Unlikely } \\
(3)\end{array}$ & $\begin{array}{l}\text { Somewhat } \\
\text { Likely (4) }\end{array}$ & $\begin{array}{l}\text { Extremely } \\
\text { Likely (5) }\end{array}$ \\
\hline $\begin{array}{l}\text { Provision of } \\
\text { information }\end{array}$ & & & & & \\
\hline Booking details & & & & & \\
\hline $\begin{array}{l}\text { Compliance with } \\
\text { cancellation terms }\end{array}$ & & & & & \\
\hline
\end{tabular}

21b. How would you rate the conflicts with online intermediaries resulting from Pre-stay issues?

\begin{tabular}{|l|l|l|l|l|l|}
\hline Factors & $\begin{array}{l}\text { Extremely } \\
\text { Unlikely } \\
(1)\end{array}$ & $\begin{array}{l}\text { Somewhat } \\
\text { Unlikely (2) }\end{array}$ & $\begin{array}{l}\text { Neither likely } \\
\text { nor Unlikely } \\
(3)\end{array}$ & $\begin{array}{l}\text { Somewhat } \\
\text { Likely (4) }\end{array}$ & $\begin{array}{l}\text { Extremely } \\
\text { Likely (5) }\end{array}$ \\
\hline $\begin{array}{l}\text { Provision of } \\
\text { information }\end{array}$ & & & & & \\
\hline Booking details & & & & & \\
\hline $\begin{array}{l}\text { Compliance with } \\
\text { cancellation terms }\end{array}$ & & & & & \\
\hline
\end{tabular}

22a. How would you rate the conflicts with traditional intermediaries resulting from Stay issues?

\begin{tabular}{|l|l|l|l|l|l|}
\hline Factors & $\begin{array}{l}\text { Extremely } \\
\text { Unlikely } \\
(1)\end{array}$ & $\begin{array}{l}\text { Somewhat } \\
\text { Unlikely (2) }\end{array}$ & $\begin{array}{l}\text { Neither likely } \\
\text { nor Unlikely } \\
(3)\end{array}$ & $\begin{array}{l}\text { Somewhat } \\
\text { Likely (4) }\end{array}$ & $\begin{array}{l}\text { Extremely } \\
\text { Likely (5) }\end{array}$ \\
\hline Operation errors & & & & & \\
\hline Overbooking & & & & & \\
\hline
\end{tabular}

22b. How would you rate the conflicts with online intermediaries resulting from Stay issues?

\begin{tabular}{|l|l|l|l|l|l|}
\hline Factors & $\begin{array}{l}\text { Extremely } \\
\text { Unlikely } \\
(1)\end{array}$ & $\begin{array}{l}\text { Somewhat } \\
\text { Unlikely (2) }\end{array}$ & $\begin{array}{l}\text { Neither likely } \\
\text { nor Unlikely } \\
(3)\end{array}$ & $\begin{array}{l}\text { Somewhat } \\
\text { Likely (4) }\end{array}$ & $\begin{array}{l}\text { Extremely } \\
\text { Likely (5) }\end{array}$ \\
\hline Operation errors & & & & & \\
\hline Overbooking & & & & & \\
\hline
\end{tabular}

23a. How would you rate the conflicts with traditional intermediaries resulting from Post-stay issues?

\begin{tabular}{|l|l|l|l|l|l|}
\hline Factors & $\begin{array}{l}\text { Extremely } \\
\text { Unlikely } \\
(1)\end{array}$ & $\begin{array}{l}\text { Somewhat } \\
\text { Unlikely (2) }\end{array}$ & $\begin{array}{l}\text { Neither likely } \\
\text { nor Unlikely } \\
(3)\end{array}$ & $\begin{array}{l}\text { Somewhat } \\
\text { Likely (4) }\end{array}$ & $\begin{array}{l}\text { Extremely } \\
\text { Likely (5) }\end{array}$ \\
\hline
\end{tabular}




\begin{tabular}{|l|l|l|l|l|l|}
\hline Payments & & & & \\
\hline Complaint handling & & & & & \\
\hline
\end{tabular}

23b. How would you rate the conflicts with online intermediaries resulting from Post-stay issues?

\begin{tabular}{|l|l|l|l|l|l|}
\hline Factors & $\begin{array}{l}\text { Extremely } \\
\text { Unlikely } \\
(1)\end{array}$ & $\begin{array}{l}\text { Somewhat } \\
\text { Unlikely (2) }\end{array}$ & $\begin{array}{l}\text { Neither likely } \\
\text { nor Unlikely } \\
(3)\end{array}$ & $\begin{array}{l}\text { Somewhat } \\
\text { Likely (4) }\end{array}$ & $\begin{array}{l}\text { Extremely } \\
\text { Likely (5) }\end{array}$ \\
\hline Payments & & & & & \\
\hline Complaint handling & & & & & \\
\hline
\end{tabular}

24a. Among the four stages below, which stage tended to cause more conflict for your hotel from traditional intermediaries?

\begin{tabular}{|l|l|l|l|l|l|}
\hline Factors & $\begin{array}{l}\text { Extremely } \\
\text { Unlikely } \\
(1)\end{array}$ & $\begin{array}{l}\text { Somewhat } \\
\text { Unlikely (2) }\end{array}$ & $\begin{array}{l}\text { Neither likely } \\
\text { nor Unlikely } \\
(3)\end{array}$ & $\begin{array}{l}\text { Somewhat } \\
\text { Likely (4) }\end{array}$ & $\begin{array}{l}\text { Extremely } \\
\text { Likely (5) }\end{array}$ \\
\hline Contract stage & & & & & \\
\hline Pre-stage & & & & & \\
\hline Stay stage & & & & & \\
\hline Post-stay stage & & & & & \\
\hline
\end{tabular}

24b. Among the four stages below, which stage tend to cause more conflicts for your hotel from online intermediaries?

\begin{tabular}{|l|l|l|l|l|l|}
\hline Factors & $\begin{array}{l}\text { Extremely } \\
\text { Unlikely } \\
(1)\end{array}$ & $\begin{array}{l}\text { Somewhat } \\
\text { Unlikely (2) }\end{array}$ & $\begin{array}{l}\text { Neither likely } \\
\text { nor Unlikely } \\
(3)\end{array}$ & $\begin{array}{l}\text { Somewhat } \\
\text { Likely (4) }\end{array}$ & $\begin{array}{l}\text { Extremely } \\
\text { Likely (5) }\end{array}$ \\
\hline Contract stage & & & & & \\
\hline Pre-stage & & & & & \\
\hline Stay stage & & & & & \\
\hline Post-stay stage & & & & & \\
\hline
\end{tabular}

25. What types of strategies have you adopted to solve and avoid those conflicts?

a. Traditional intermediaries 
b. Online intermediaries

26. Are there any other observations or comments you would like to make in terms of distribution channel issues in Cambodia?

a. Traditional intermediaries

b. Online intermediaries 